\title{
Avaliação de Desempenho de Algoritmos de Estimação do Olhar para Interação com Computadores Vestiveis
}

\author{
Fernando Omar Aluani
}

\author{
Dissertação apresentada \\ ao \\ Instituto de Matemática e Estatística \\ da \\ Universidade de São Paulo \\ para \\ obtenção do título \\ de \\ Mestre em Ciência da Computação
}

Programa:

Mestrado em Ciência da Computação

Orientador:

Prof. Dr. Carlos Hitoshi Morimoto

Durante o desenvolvimento deste trabalho o autor recebeu auxílio financeiro da CAPES e FDTE 



\section{Avaliação de Desempenho de Algoritmos de Estimação do Olhar para Interação com Computadores Vestiveis}

Esta versão da dissertação contém as correções e alterações sugeridas pela Comissão Julgadora durante a defesa da versão original do trabalho, realizada em 08/12/2017. Uma cópia da versão original está disponível no Instituto de Matemática e Estatística da Universidade de São Paulo.

Comissão Julgadora:

- Prof. Dr. Carlos Hitoshi Morimoto - IME-USP

- Prof. Dr. Carlos Eduardo Thomaz - FEI

- Prof. Dr. Flávio Luiz Coutinho - EACH-USP 



\title{
Resumo
}

\author{
Aluani, F. O. Avaliação de Desempenho de Algoritmos de Estimação do Olhar para Intera- \\ ção com Computadores Vestíveis. Dissertação (Mestrado) - Instituto de Matemática e Estatística, \\ Universidade de São Paulo, São Paulo, 2017.
}

Cada vez mais o rastreamento do olhar tem sido usado para interação humano-computador em diversos cenários, como forma de interação (usualmente substituindo o mouse, principalmente para pessoas com deficiências físicas) ou estudo dos padrões de atenção de uma pessoa (em situações como fazendo compras no mercado, olhando uma página na internet ou dirigindo um carro).

Ao mesmo tempo, dispositivos vestíveis tais quais pequenas telas montadas na cabeça e sensores para medir dados relativos à saúde e exercício físico realizado por um usuário, também têm avançado muito nos últimos anos, finalmente chegando a se tornarem acessíveis aos consumidores. Essa forma de tecnologia se caracteriza por dispositivos que o usuário usa junto de seu corpo, como uma peça de roupa ou acessório. O dispositivo e o usuário estão em constante interação e tais sistemas são feitos para melhorar a execução de uma ação pelo usuário (por exemplo dando informações sobre a ação em questão) ou facilitar a execução de várias tarefas concorrentemente. O uso de rastreadores de olhar em computação vestível permite uma nova forma de interação para tais dispositivos, possibilitando que o usuário interaja com eles enquanto usa as mãos para realizar outra ação.

Em dispositivos vestíveis, o consumo de energia é um fator importante do sistema que afeta sua utilidade e deve ser considerado em seu design. Infelizmente, rastreadores oculares atuais ignoram seu consumo e focam-se principalmente em precisão e acurácia, seguindo a ideia de que trabalhar com imagens de alta resolução e frequência maior implica em melhor desempenho. Porém tratar mais quadros por segundo ou imagens com resolução maior demandam mais poder de processamento do computador, consequentemente aumentando o gasto energético. Um dispositivo que seja mais econômico tem vários benefícios, por exemplo menor geração de calor e maior vida útil de seus componentes eletrônicos. Contudo, o maior impacto é o aumento da duração da bateria para dispositivos vestíveis. Pode-se economizar energia diminuindo resolução e frequência da câmera usada, mas os efeitos desses parâmetros na precisão e acurácia da estimação do olhar não foram investigados até o presente.

Neste trabalho propomos criar uma plataforma de testes, que permita a integração de alguns algoritmos de rastreamento de olhar disponíveis, tais como Starburst, ITU Gaze Tracker e Pupil, para estudar e comparar o impacto da variação de resolução e frequência na acurácia e precisão dos algoritmos. Por meio de um experimento com usuários analisamos o desempenho e consumo desses algoritmos sob diversos valores de resolução e frequência. Nossos resultados indicam que apenas a diminuição da resolução de 480 para 240 linhas (mantendo a proporção da imagem) já acarreta em ao menos $66 \%$ de economia de energia em alguns rastreadores sem perda significativa de acurácia.

Palavras-chave: rastreamento do olhar, computação vestível, consumo de energia. 


\section{Sumário}

Lista de Figuras $\quad$ v

$\begin{array}{ll}\text { Lista de Tabelas } & \text { vii }\end{array}$

1 Introdução $1 \ldots$

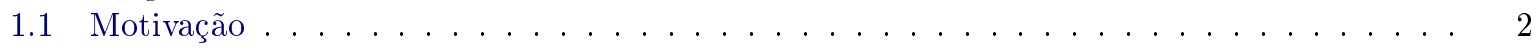

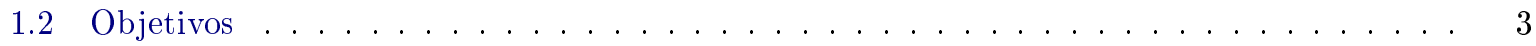

1.3 Contribuições . . . . . . . . . . . . . . . . . . . 3

1.4 Estrutura da Monografia . . . . . . . . . . . . . . . . . . 3

2 Fundamentos $\quad \mathbf{5}$

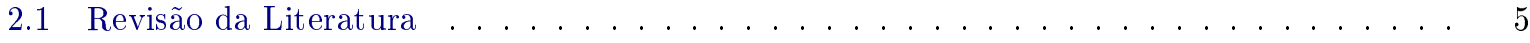

2.2 Rastreadores de Olhar . . . . . . . . . . . . . . . . . . . . . . 6

2.3 Algoritmos Detectores e Algoritmos Rastreadores . . . . . . . . . . . . . . . . . . 13

3 Metodologia $\quad \mathbf{1 5}$

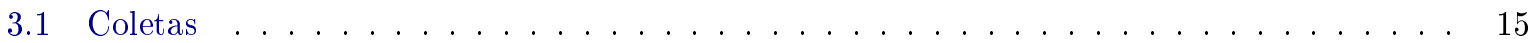

3.2 Algoritmos de Rastreamento . . . . . . . . . . . . . . . . . . . . . . . . 16

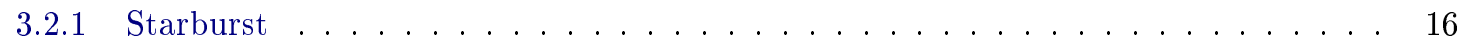

3.2 .2 ITU Gaze Tracker . . . . . . . . . . . . . . . . . . . . . 21

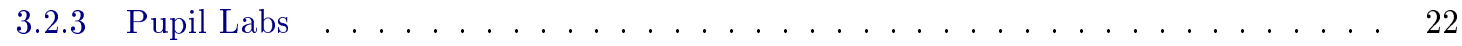

3.3 Processamento dos Dados . . . . . . . . . . . . . . . . . . . . . . . 24

3.4 Análise de Dados . . . . . . . . . . . . . . . . . . . . . . . . . . . . . . 24

3.4.1 Consumo de Tempo da CPU ou Consumo de Energia? . . . . . . . . . . . . . . . 24

4 Experimento $\quad \mathbf{2 7}$

4.1 Coletas com Usuários . . . . . . . . . . . . . . . . . . . . . . . . . . . 27

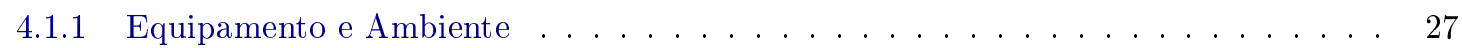

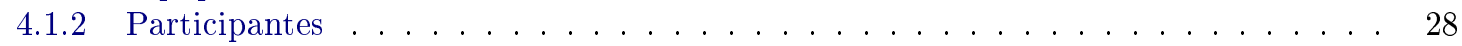

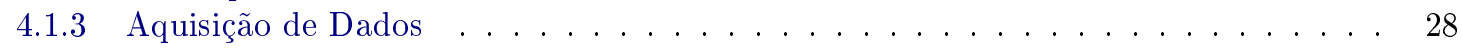

4.2 Processamento de Dados . . . . . . . . . . . . . . . . . . . . . . . 32

4.2.1 Calibração da Estimação do Olhar . . . . . . . . . . . . . . . . . . . . . . . . 34

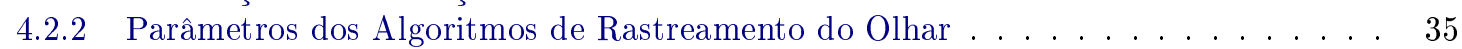

4.3 Tecnologias Usadas . . . . . . . . . . . . . . . . . . . . . . . . . . . . . . . . . . . . . . . . . .

4.3.1 Linguagens de Programação . . . . . . . . . . . . . . . . . . . . . . 36

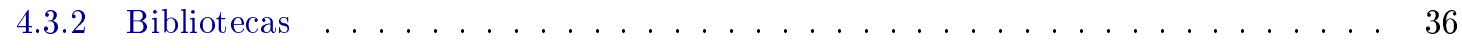

5 Resultados $\quad 39$

5.1 Análise de Variância . . . . . . . . . . . . . . . . . . . . . . . . 58

5.1 Erro de estimação do Starburst: . . . . . . . . . . . . . . . . . . 58

5.1 .2 Erro de estimação do ITU: . . . . . . . . . . . . . . . . . . . . . . . . . . . . . . . . . . . . .

5.1 .3 Erro de estimação do Pupil: . . . . . . . . . . . . . . . . . . . . . . 59

5.1 .4 Discussão Geral . . . . . . . . . . . . . . . . . . . 60

6 Conclusões $\quad \mathbf{6 1}$

6.1 Sugestões para Pesquisas Futuras . . . . . . . . . . . . . . . . . . . . 61 


\section{Lista de Figuras}

1.1 Rastreador vestível SMI Eye Tracking Natural Gaze. Fonte: SMI. . . . . . . . . . . . . 1

2.1 Exemplo de imagem do olho coletada por uma câmera perto do olho, com forte angulação e efeito de pupila escura pela iluminação PIV. Fonte: Swirski et al. [SBD12] . . . . . . . .

2.2 Diagrama da diferença entre uma câmera remota e uma montada próxima ao olho. Fonte: Swirski et al. [SBD12] . . . . . . . . . . . . . . . . . . .

2.3 Exemplos do processo de planificação. No topo as imagens originais do olho, abaixo as imagens planificadas. Note que nas imagens planificadas a íris tem um formato circular, enquanto as pálpebras seguem aproximadamente uma linha horizontal e os cílios seguem linhas verticais. Fonte: Pires et al. [PDTK13] . . . . . . . . . . . . .

2.4 Na esquerda, o dispositivo WearCam de Noris et al., usado por uma criança de 14 meses. Na direita, o dispositivo sozinho, mostrando as 2 câmeras e o espelho rotacionável. Fonte: Noris et al. [NKB11] . . . . . . . . . . . . . . . . . . . .

2.5 Ilustração conceito do dispositivo do Knopp. A câmera é posicionada abaixo de um olho. Fonte: Simon Knopp $\left[K B W^{+} 12\right] \ldots \ldots \ldots \ldots \ldots$. . . . . . . . . . .

2.6 Diferentes visões do protótipo do iShadow. O dispositivo contém uma câmera para o olho, e outra no centro da armação para a cena, e a placa eletrônica ficam ao lado. Baterias ficam localizadas atrás da orelha, mas não são visíveis nessa imagem. Fonte: Mayberry et al. $\left[M H M^{+} 14\right] \ldots \ldots \ldots \ldots \ldots \ldots \ldots \ldots . \ldots \ldots$

2.7 Visão geral do CIDER. (1) Um fotorreceptor PIV para detectar estado atual e atualizá-lo. (2) Estágio de busca usando rede neural para calcular uma estimação inicial da pupila. (3) Estágio de refinamento para determinar precisamente a pupila em altas frequências até não achar a pupila em algum quadro. Fonte: Mayberry et al. $\left[M T H^{+} 15\right]$. . . . . . . .

3.1 Detecção de características do Starburst. (a) O ponto inicial original (em amarelo) solta raios (traços azuis) para gerar pontos candidatos (cruzes verdes). (b,c) Pontos candidatos atiram raios de volta ao ponto inicial para detectar mais pontos. (d) Todos os pontos candidatos detectados na primeira iteração. O ponto central é mostrado como um círculo vermelho, que será o ponto inicial da próxima iteração. (e) Resultados da segunda iteração. (f) Posições iniciais de várias iterações mostram uma convergência rápida. Fonte: Winfield et al. [WPL05] . . . . . . . . . . . . . . . . . . . . .

3.2 Funcionamento do algoritmo Pupil. (1) Imagem da câmera do olho convertida para escala de cinza. (2) Detector de bordas Canny (linhas verdes). (3) Define região escura como um intervalo fixo do menor pico do histograma da imagem do olho. (4) Filtra bordas para ignorar reflexões especulares (região amarela) e bordas fora de regiões escuras (área azul). (5) Bordas sobrando são transformadas em contornos usando componentes conexos e divididas em sub-contornos baseados na continuidade da curvatura (linhas coloridas). (6) Elipses (azuis) candidatas à pupila. (7) Elipse final (vermelha) detectada pela busca combinatória, pixels de suporte da borda em branco. Fonte: Kassner et al. [KPB14] . . .

4.1 Rastreador de Olhar Monocular Pupil-Labs usado no experimento. . . . . . . . . . . . .

4.2 Diagrama das posições onde coletas foram realizadas em relação ao monitor. Não está em

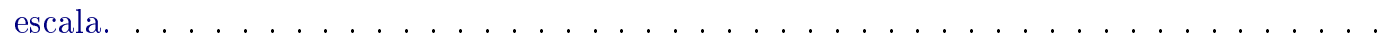

4.3 Participante realizando o experimento na posição central. . . . . . . . . . . . . . .

4.4 Diagrama do fluxo da aquisição de dados do experimento; e o diagrama do processo de uma coleta específica. 
4.5 Alvos no monitor para a aquisição de dados. Alvos com borda verde foram usados para a calibração da estimação do olhar. As setas indicam a sequência de alvos como foram mostrados ao usuário. Tanto as bordas verdes como as setas e os textos foram adicionados na imagem aqui para facilitar a visualização e não eram mostradas ao usuário durante o

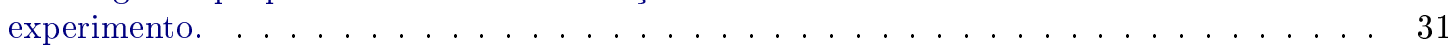

4.6 Progresso dos estados de um alvo durante uma coleta. . . . . . . . . . . . . . . . . . . . . . . . . . . . . .

4.7 Diagrama do fluxo de processamento dos dados das coletas. . . . . . . . . . . . . . . 33

5.1 Análise de erro médio do Pupil para cada configuração de frequência $\times$ resolução na posição

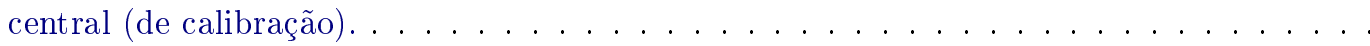

5.2 Análise de erro médio do ITU para cada configuração de frequência $\times$ resolução na posição central (de calibração) . . . . . . . . . . . . . . . . . . . . . .

5.3 Análise de erro médio do Starburst para cada configuração de frequência $\times$ resolução na posição central (de calibração). . . . . . . . . . . . . . . . . . . . . . 42

5.4 Análise de erro médio do Pupil para cada configuração de frequência $\times$ resolução na posição

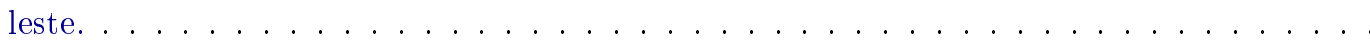

5.5 Análise de erro médio do ITU para cada configuração de frequência $\times$ resolução na posição

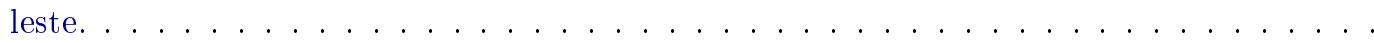

5.6 Análise de erro médio do Starburst para cada configuração de frequência $\times$ resolução na posição leste. . . . . . . . . . . . . . . . . . . . . . . . .

5.7 Análise de erro médio do Pupil para cada configuração de frequência $\times$ resolução na posição oeste. . . . . . . . . . . . . . . . . . . . . .

5.8 Análise de erro médio do ITU para cada configuração de frequência $\times$ resolução na posição oeste. . . . . . . . . . . . . . . . . . . . . .

5.9 Análise de erro médio do Starburst para cada configuração de frequência $\times$ resolução na

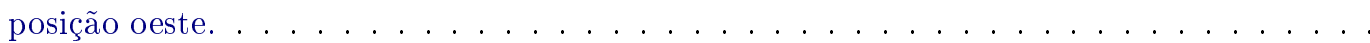

5.10 Análise de erro médio do Pupil para cada configuração de frequência $\times$ resolução na posição

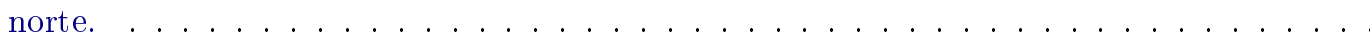

5.11 Análise de erro médio do ITU para cada configuração de frequência $\times$ resolução na posição

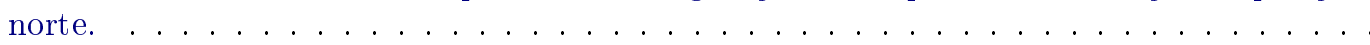

5.12 Análise de erro médio do Starburst para cada configuração de frequência $\times$ resolução na

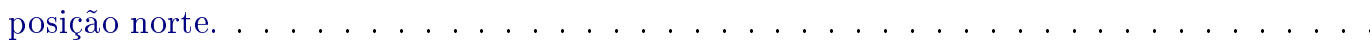

5.13 Análise de erro médio do Pupil para cada configuração de frequência $\times$ resolução na posição

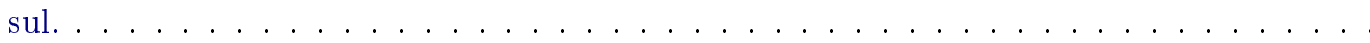

5.14 Análise de erro médio do ITU para cada configuração de frequência $\times$ resolução na posição

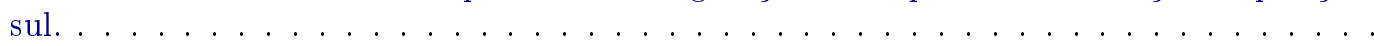

5.15 Análise de erro médio do Starburst para cada configuração de frequência $\times$ resolução na

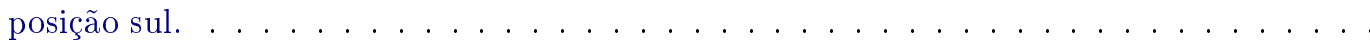

5.16 Análise de consumo médio da CPU (em segundos) em um caso de teste do Pupil para cada configuração de frequência $\times$ resolução. . . . . . . . . . . . . . . . . .

5.17 Análise de consumo médio da CPU (em segundos) em um caso de teste do ITU para cada configuração de frequência $\times$ resolução. . . . . . . . . . . . . . . . . .

5.18 Análise de consumo médio da CPU (em segundos) em um caso de teste do Starburst para cada configuração de frequência $\times$ resolução. . . . . . . . . . . . . . . 


\section{Lista de Tabelas}

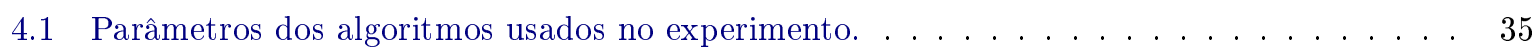




\section{Capítulo 1}

\section{Introdução}

Este trabalho de mestrado está inserido no contexto de visão computacional, particularmente no tema de rastreadores do olhar móveis e vestíveis. Existem algumas tecnologias diferentes para o rastreamento de olhar, como por exemplo eletro-oculografia, lentes de contato especiais e vídeo-oculografia (também conhecido como rastreadores baseados em vídeo) [MM05]. Ao longo desse trabalho, quando nos referimos a rastreador de olhar estamos nos referindo a rastreadores de olhar baseados em vídeo pois é a principal tecnologia usada atualmente devido ao seu baixo custo de aquisição e ao fato que não incomodam o usuário com equipamentos desconfortáveis em sua cabeça ou olho. Além disso, os rastreadores que estudaremos neste trabalho são todos baseados em vídeo.

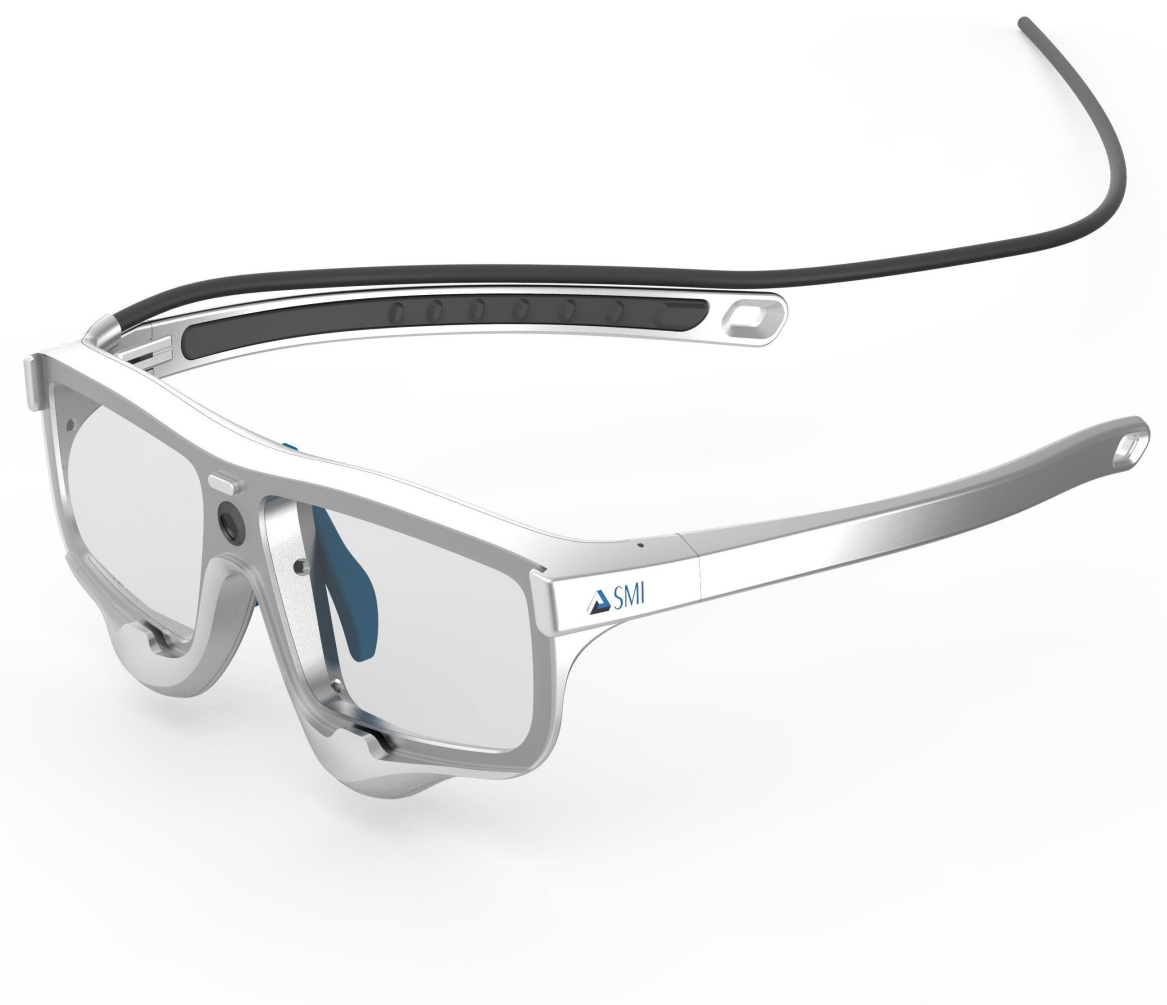

Figura 1.1: Rastreador vestível SMI Eye Tracking Natural Gaze. Fonte: SMI.

Enquanto rastreadores vestíveis também podem ser considerados um tanto quanto intrusivos, em geral são somente um tipo especial de óculos com o equipamento do rastreador (câmeras e luzes infravermelhas) embutido (exemplo vide Figura 1.1, e não diferem muito da sensação de usar um óculos, algo que pode 
ser considerado comum para boa parte dos humanos. Para aqueles que já usam óculos, dependendo do dispositivo e do algoritmo, é possível usarem seu óculos ou lente corretiva ao mesmo tempo que um rastreador de olhar vestível.

Rastreadores de olhar detectam os movimentos do olho do usuário e estimam para onde o usuário está olhando ([HJ10] e [MM05]). Essa informação é processada por aplicações para que o usuário interaja com o computador pelo olhar. Rastreadores vestíveis são rastreadores que o usuário pode usar em qualquer ambiente. Para esses tipos de rastreadores, um ponto importante é o consumo de energia, onde um valor menor aumenta a duração de baterias, que é uma característica vantajosa para qualquer dispositivo vestível.

Porém, rastreadores do olhar atuais ignoram o consumo de energia e focam-se na melhoria da precisão e acurácia do rastreador. Foi sugerido que câmeras de maior resolução e maior frequência (ou quadros por segundo, do inglês frames per second) são importantes para manter precisão e acurácia altas [HNA+11]. No entanto, ter que processar imagens de resolução maior mais vezes por segundo aumenta o consumo de energia. Pode-se economizar energia usando câmeras com menor resolução e frequência, diminuindo o custo computacional. O efeito desses parâmetros na precisão e acurácia da estimação do olhar não foi investigado a fundo até o presente.

Dispositivos vestíveis, como pequenas telas montadas na cabeça e sensores para medir dados relativos à saúde e exercício físico realizado por um usuário, também têm avançado muito nos últimos anos, finalmente chegando a se tornarem acessíveis aos consumidores. Essa forma de tecnologia se caracteriza por dispositivos que o usuário usa junto ao seu corpo, como uma peça de roupa ou acessório. A diferença de computação vestível para computação móvel é a constante interação presente entre um usuário e seu dispositivo vestível. O uso de rastreadores de olhar em computação vestível permite uma nova forma de interação para tais dispositivos, possibilitando que o usuário interaja com eles enquanto usa as mãos para realizar outra ação.

\section{$1.1 \quad$ Motivação}

Rastreadores de olhar vestíveis podem ser utilizados de diversas maneiras:

- Pesquisas científicas;

- Estudos com usuários em diversas áreas (como estudos de mercado, psicologia, aprendizado cognitivo);

- Acessabilidade de pessoas com deficiências motoras à computadores;

- Outra forma de interação para jogos digitais, e mais ainda para dispositivos e aplicações de realidade aumentada ou realidade virtual;

Com tantas aplicações, é de se esperar que o uso de dispositivos vestíveis tem crescido nos últimos anos, como notado por [BG10]. No entanto, dispositivos vestíveis com interação pelo olhar ainda não são comuns, em parte por alguns problemas que essa tecnologia ainda apresenta. Porém a tendência é eles se tornarem mais acessíveis ao público e assim contribuir fortemente para computação ubíqua no futuro.

Um grande problema de rastreadores vestíveis, como já mencionado, é o consumo de energia. Fabricantes de rastreadores de olhar e pesquisadores não apresentam dados sobre consumo de energia ou duração de bateria de seus dispositivos[BG10]. Estudando como rastreadores gastam energia e desenvolvendo meios para diminuir o consumo será uma significativa contribuição para o campo, permitindo que dispositivos vestíveis sejam usados por mais tempo. Investigar o efeito da resolução e frequência da 
câmera de um rastreador de olhar baseado em vídeo na sua precisão e acurácia é uma forma simples e efetiva de atingir esse objetivo.

Mesmo que a importância de tais parâmetros no custo computacional varie com o algoritmo em si, de uma forma ou outra o custo de todos algoritmos de rastreamento do olhar (baseados em vídeo) são relacionados com a sua resolução e frequência. Além do mais, esses parâmetros são comuns a todos rastreadores de olhar, portanto esses efeitos são genéricos, e aplicáveis a todos rastreadores baseados em vídeo.

Dessa forma, a motivação por trás desse trabalho é economia de energia para melhorar a utilidade de rastreadores vestíveis e diminuir custos de equipamentos. Esperamos mostrar que mesmo com uma ação simples como diminuir a resolução e frequência da câmera, um rastreador de olhar possa economizar uma quantidade significativa de energia, sem perda correspondente de precisão e acurácia.

\subsection{Objetivos}

O presente trabalho de mestrado tem como objetivo entender como resolução e frequência da câmera de um rastreador de olhar afetam a precisão, acurácia e consumo de energia do mesmo. Para tal iremos criar uma plataforma de testes que permita a integração de alguns algoritmos open-source de rastreamento de olhar disponíveis, tais como Starburst, ITU Gaze Tracker e Pupil, e utilizá-la para avaliar o efeito de diferentes parâmetros da câmera no desempenho dos rastreadores.

\subsection{Contribuições}

Como contribuições deste trabalho esperamos avançar o entendimento sobre a relação entre desempenho, consumo de energia e parâmetros comuns de uma câmera digital em rastreadores vestíveis, a fim de atacar o problema de consumo de energia. Nossas avaliações indicam que apenas a diminuição da resolução de 480 para 240 linhas (mantendo a proporção da imagem) já acarreta em ao menos 65\% de economia de energia em alguns rastreadores, sem afetar precisão e acurácia.

De forma secundária, a plataforma de testes desenvolvida para a realização do experimento que nos mostrou a relação entre desempenho, energia, e os parâmetros da câmera, foi feita de forma genérica para poder ser usada para realizar outros experimentos além do qual executamos. Esperamos que isso ajude outros pesquisadores a realizarem seus experimentos com rastreadores de olhar.

\subsection{Estrutura da Monografia}

Esta monografia está organizada da seguinte maneira:

1. No capítulo 2, uma breve revisão da literatura é apresentada. Foco será dado a avanços recentes de rastreadores móveis e seu consumo de energia, assim como desafios existentes neste quesito.

2. No capítulo 3 será apresentada a metodologia empregada no trabalho.

3. O capítulo 4 irá detalhar o experimento com usuários que foi realizado.

4. No capítulo 5 iremos apresentar os resultados do experimento.

5. Finalmente, no capítulo 6 iremos discutir sobre os resultados e apresentar nossas conclusões. 


\section{Capítulo 2}

\section{Fundamentos}

Neste capítulo iremos apresentar uma revisão bibliográfica dos principais trabalhos sobre algoritmos de rastreamento do olhar. Iremos focar em métodos para rastreadores vestíveis que usam iluminação pertodo-infravermelho (PIV), já que são os mais pesquisados e usados comercialmente. Durante a revisão também apresentaremos alguns dos conceitos fundamentais usados neste trabalho.

\subsection{Revisão da Literatura}

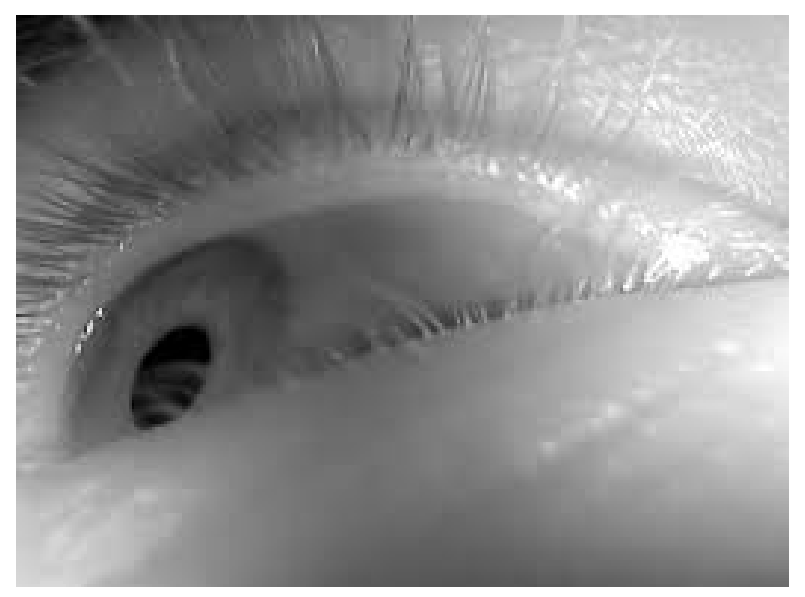

Figura 2.1: Exemplo de imagem do olho coletada por uma câmera perto do olho, com forte angulação e efeito de pupila escura pela iluminação PIV. Fonte: Swirski et al. [SBD12]

Rastreadores do olhar podem ser divididos em dois tipos de acordo com a iluminação usada:

- Iluminação Ativa: usam fontes de luz perto-do-infravermelho, usualmente com comprimento de onda em torno de $780-880 \mathrm{~nm}$, que são visíveis a muitas câmeras digitais no mercado, mas imperceptíveis ao olho humano e portanto não distraem o usuário [HJ10].

- Iluminação Passiva: não usam nenhuma fonte de luz própria do rastreador. Simplesmente capturam imagens com a iluminação natural do ambiente.

O uso de iluminação ativa traz vantagens como maior contraste entre estruturas do olho e reflexos na córnea que podem ser usados por um rastreador. Se a fonte de luz PIV está localizada longe do eixo ótico da câmera (chamado de luz off-axis), a imagem capturada mostra o chamado efeito de pupila escura (vide 2.1), onde a pupila é escura e tem um grande contraste em relação as estruturas do olho 
vizinhas. Muitos rastreadores de iluminação ativa (e todos apresentados neste trabalho) usam esse método. Mas o uso de iluminação ativa também tem suas desvantagens, as principais sendo consumo de energia das luzes infravermelhas e intolerância a outras fontes de luz PIV, que podem afetar negativamente a imagem capturada e portanto o desempenho de um rastreador. Por essa razão rastreadores com iluminação ativa não conseguem ser usados fora de ambientes controlados durante o dia, por conta da iluminação proveniente do Sol.

Hansen e Ji[HJ10] revisaram a literatura de rastreadores de olhar em 2010. Eles classificaram métodos de detecção do olho como baseados em características, em modelos, ou em aparência, e se usam ou não iluminação infravermelha. Também classificam métodos de estimação do olhar de um modo análogo. Segundo eles, algoritmos que trabalham com iluminação ativa (rastreadores que usam iluminação infravermelha) podem usar a luz infravermelha em praticamente todos estágios do rastreador (detecção e rastreamento do olhar) e dominam a área de rastreadores de olhar, tanto em pesquisas atuais quanto em rastreadores comerciais. Outra contribuição importante deste artigo são pontos a serem considerados em futuros trabalhos de rastreadores de olhar a fim de chegarmos em um rastreador "ideal": de baixo custo, fácil de configurar, fácil de usar (pouca ou nenhuma calibração), boa precisão de estimação do olhar, e robusto a mudanças de iluminação e movimentos naturais do usuário. Alguns desses pontos são considerados neste trabalho, como rastreadores vestíveis se tornando mais interessantes para o desenvolvimento de interfaces que não necessitam que o usuário use as mãos. Outro ponto é o custo de rastreadores, que continuam inacessíveis para uso generalizado pelo público em grande parte devido ao custo de equipamento. Por outro lado, segundo Hansen e Ji, rastreadores de iluminação passiva são o caminho para o futuro para eliminar as limitações práticas de rastreadores ativos.

Em sua revisão da literatura em 2005, Morimoto e Mimica [MM05] argumentam que há muito tempo tem sido pensado que rastreadores de olhar tem o potencial para se tornarem importantes dispositivos de interação humano-computador, mas que há sérios problemas de usabilidade que atrapalham seu uso generalizado. Apesar da revisão focar mais em métodos remotos de rastreamento (métodos estáticos), as características definidas pelos autores como sendo requerimentos para um "rastreador ideal" não impedem o uso de sistemas vestíveis.

Song et al.[STCZ13] também apresentaram uma revisão da literatura, mas se focaram em métodos de detecção dos olhos, que são muitas vezes necessários em algoritmos de detecção de faces e rastreadores de olhos. Eles revisaram principalmente algoritmos baseados em aparência usando técnicas de aprendizado de máquina, e argumentam que localizar olhos em imagens de baixa resolução ainda é um desafio. Também apresentaram comparações da complexidade de alguns métodos, tentando buscar um algoritmo que seja genérico e eficiente.

\subsection{Rastreadores de Olhar}

Em rastreadores vestíveis, utiliza-se uma câmera localizada próxima ao olho. Para ela não se tornar uma obstrução à visão do usuário, nem ser obstruída por óculos que o usuário pode usar, ela tem que estar posicionada "fora" da lente do óculos, em volta da armação. Isso faz as imagens terem uma certa distorção perspectiva por conta do ângulo largo entre os eixos óticos do olho e da câmera, como mostrado nas Figuras 2.2 e 2.1 .

Swirski et al.[SBD12] desenvolveram um método para ser usado em rastreadores vestíveis nessas condições. O método inicialmente usa um detector de característica Haar-like para localizar a região inicial aproximada da localização da pupila, modelada como uma área escura cercada por uma região clara da imagem. Após essa localização inicial, o histograma de intensidade dos pixels dessa região é segmentado em duas classes: pixels da pupila e pixels do fundo, usando KMeans. A região da pupila é 


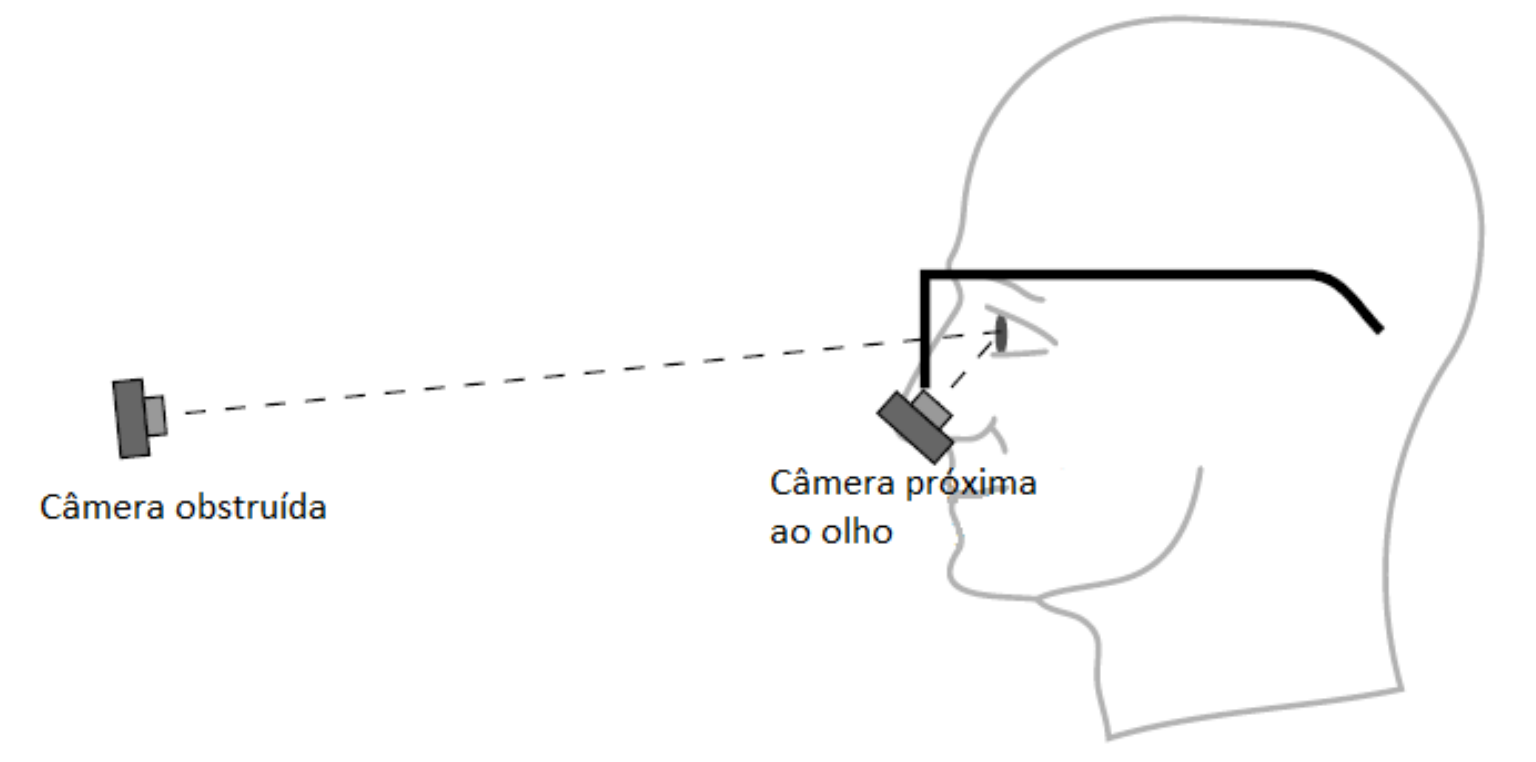

Figura 2.2: Diagrama da diferença entre uma câmera remota e uma montada próxima ao olho. Fonte: Swirski et al. [SBD12]

então binarizada com esse limiar de intensidade para detectar a pupila. Finalmente, o contorno da pupila é refinado usando Random Sample Consensus (RANSAC), que é um algoritmo que refina pontos seguindo a conformidade deles com um modelo (no caso uma elipse), filtrando os pontos que não correspondem ao modelo desejado. O artigo também apresenta uma comparação de precisão com outros dois algoritmos: Starburst e ITU.

Como um exemplo de rastreador vestível de iluminação passiva, Tsukada et al.[TSDK11] desenvolveram um rastreador que usa um modelo 3D do olho para determinar o olhar do usuário. Com o modelo e a posição da íris na imagem de entrada eles conseguem determinar a elipse do contorno externo da íris e estimar o olhar. $\mathrm{O}$ modelo em si representa as estruturas do olho mas também a relação entre o modelo e a câmera. O sistema é robusto a oclusões, tem uma precisão de $\approx 1^{\circ}$ e consegue rodar a $25 \mathrm{~Hz}$. Em particular, os autores compararam seu método com o Starburst e tiveram resultados significativamente melhores. Porém eles supõem que a transformação câmera-olho é fixa, o que só vale para dispositivos vestíveis montados na cabeça - e nem nesse caso é estritamente válido pois o dispositivo ainda pode se mexer levemente na cabeça do usuário. Outro grande problema do método é que ele tem vários parâmetros a serem definidos manualmente, incluindo os valores do modelo do olho. Um ano depois, Tsukada e Kanade[TK12] criaram um método para determinar automaticamente os parâmetros do modelo de olho, para facilitar o uso do seu método. Usando esse modelo configurado automaticamente eles obtiveram resultados ainda melhores com seu sistema do que usando os modelos manuais. Infelizmente, esse processo ainda precisa de alguns parâmetros a serem definidos pelo usuário, e em particular necessita de várias imagens do olho para calcular o modelo, o que pode levar algumas horas para ser completado. Mesmo sendo uma operação que um usuário executaria apenas uma vez para gerar seu modelo, o alto tempo de execução atrapalha bastante a utilização do método.

Pires et al.[PDTK13] continuou o trabalho de Tsukada et al.[TSDK11] apresentando um rastreador do olhar vestível que é ainda mais preciso e robusto que o método de Tsukada et al. O rastreador usa o mesmo modelo de olho, mas agora calcula o modelo automaticamente (e eficientemente) baseando-se na posição dos dois cantos do olho na imagem. Além disso, em vez de procurar elipses na imagem do olho, ele usa o modelo do olho para planificar a imagem da câmera e procurar um círculo nessa imagem (veja 

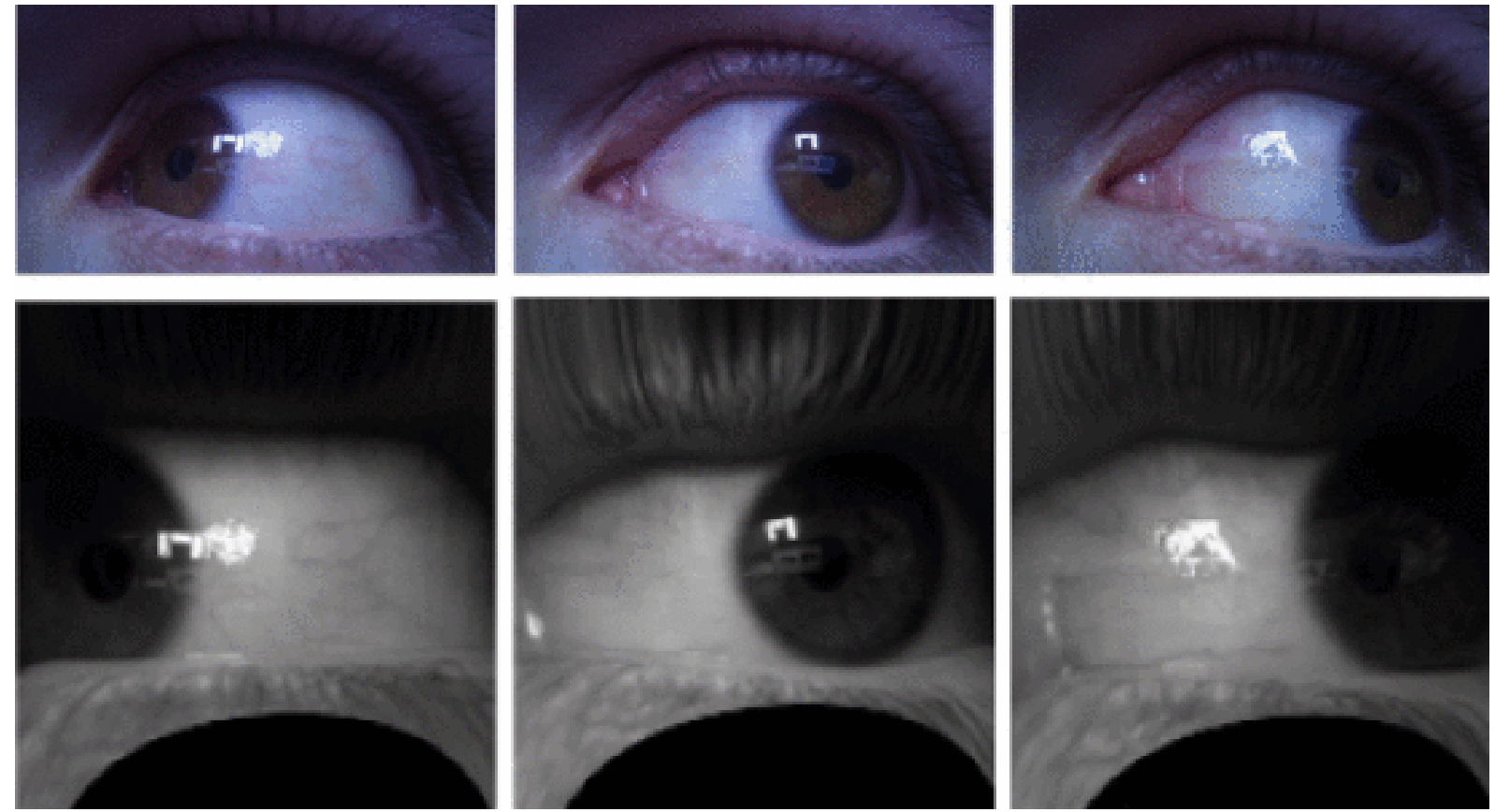

Figura 2.3: Exemplos do processo de planificação. No topo as imagens originais do olho, abaixo as imagens planificadas. Note que nas imagens planificadas a íris tem um formato circular, enquanto as pálpebras seguem aproximadamente uma linha horizontal e os cílios seguem linhas verticais. Fonte: Pires et al. [PDTK13]

Figura 2.3), essencialmente procurando o círculo da íris na superfície do olho em vez de uma elipse na imagem da câmera. Essa solução tem o benefício de simplificar o espaço de parâmetros buscados, das 5 dimensões de uma elipse para 3 de um círculo. No entanto o sistema ainda supõe que a transformação câmera-olho é fixa, e executa a $15 \mathrm{~Hz}$. Apesar de esse valor ser suficiente para rodar em tempo real, a frequência baixa pode não dar o suporte temporal necessário para algumas aplicações e dar a impressão de "ser lento" para alguns usuários.

Rastreadores de olhar devem funcionar adequadamente com qualquer tipo de pessoa, e particularmente crianças apresentam dificuldades para usarem rastreadores atuais pois dependendo de sua idade, seu entendimento sobre um rastreador de olhar ou capacidade de seguir instruções de um adulto pode ser limitado. Alia-se a isso o fato que crianças tendem a mudar muito sua atenção sem focar em um ponto específico por muito tempo, e etapas de calibração tendem a não ser realizadas direito, o que é uma necessidade para a maioria dos rastreadores de olhar. Além disso, crianças tem olhos menores e menos características faciais marcantes (como cílios, rugas ou outras marcas na pele e pálpebra). Com isso em mente, Noris et al.[NKB11] desenvolveram um rastreador de olhar vestível, composto de 2 câmeras coloridas e um pequeno espelho controlado por um motor que pode ser preso na cabeça por tiras ou em um chapéu (Figura 2.4). O método é baseado na aparência dos olhos para determinar, usando um método de aprendizagem de máquina chamado Support Vector Regression (SVR), a direção do olhar. $\mathrm{O}$ rastreador atingiu uma precisão de $1-2^{\circ}$ graus para adultos em ambientes internos, e $2-3^{\circ}$ para adultos em ambientes externos e crianças. Um aspecto notável do sistema é que mesmo necessitando de centenas de pontos de calibração, o rastreador consegue rodar a $25 \mathrm{~Hz}$, e é possível adquirir os dados necessários para a calibração em alguns segundos (para adultos). Os autores realizaram experimentos para avaliar a precisão do algoritmo a fim de determinar os parâmetros ideais para o método. Em particular, avaliaram o efeito da resolução e descobriram que a resolução máxima da câmera usada não obtinha os melhores resultados (em precisão). No caso particular desse método baseado em aparência, resoluções maiores resultam em mais ruído na imagem, e em mais dimensões na entrada do SVR, o que implica em 

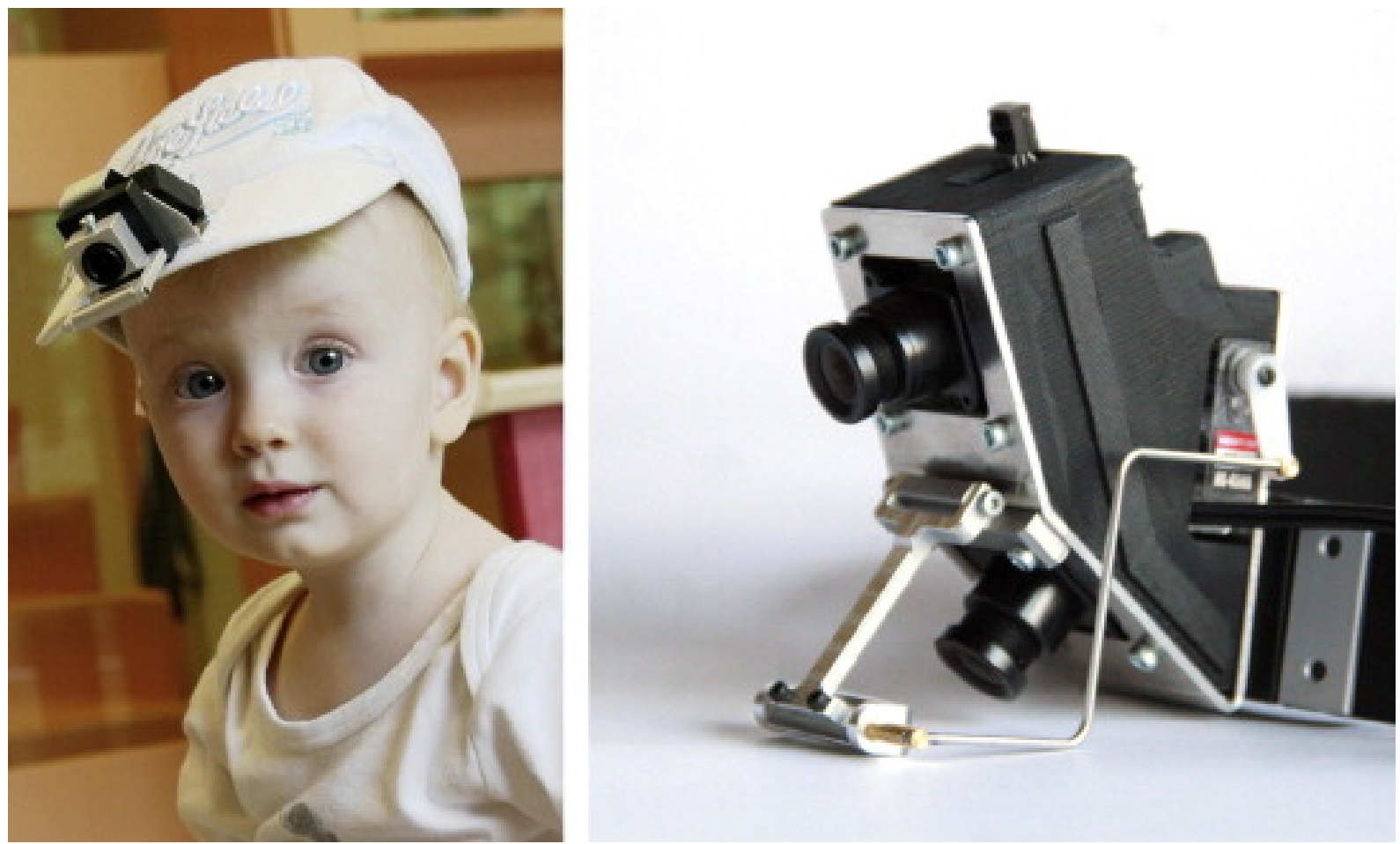

Figura 2.4: Na esquerda, o dispositivo WearCam de Noris et al., usado por uma criança de 14 meses. Na direita, o dispositivo sozinho, mostrando as 2 câmeras e o espelho rotacionável. Fonte: Noris et al. [NKB11]

necessitar de mais dados para conseguir ignorar informação inútil. Esse fenômeno é tipicamente chamado de "a maldição da dimensionalidade" e afeta muitos algoritmos que tratam dados de alta dimensão.

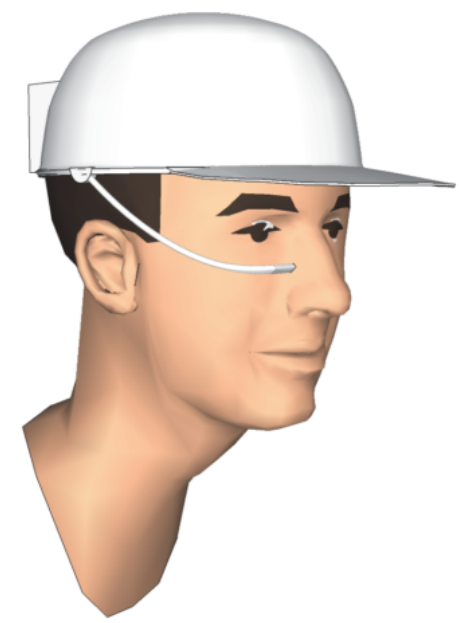

Figura 2.5: Ilustração conceito do dispositivo do Knopp. A câmera é posicionada abaixo de um olho. Fonte: Simon Knopp [KBW $W^{+}$12]

Knopp et al. em $\left[\mathrm{KBW}^{+} 12\right]$ apresentam um dispositivo vestível que não chega a rastrear o olhar, mas detecta o nível de obstrução da pupila para determinar fechamento das pálpebras e portanto determinar nível de atenção/sonolência dos usuários. A ideia é que esse dispositivo, junto com outros sensores, formaria um sistema para detectar e alertar sobre lapsos de atenção para usuários em tarefas de risco. Seus requerimentos incluem o detector funcionar sobre diversas condições de iluminação (ambientes internos, 
externos com luz do Sol, no escuro) e que o dispositivo não tenha cabos para não restringir o movimento do usuário. Com esses requisitos, o objetivo do dispositivo, e a própria ilustração conceito do dispositivo (Figura 2.5), é razoável supor que será um dispositivo vestível que funcionará sozinho ou transmitindo dados para outro computador. Logo, ele deverá funcionar pela duração da tarefa de risco do seu usuário, que potencialmente pode durar diversas horas.

Em $\left[\mathrm{NBM}^{+} 15\right]$, Nehani et al. afirma que dispositivos vestíveis só serão de fato ubíquos quando atingirem neutralidade de energia - isto é, quando praticamente não gastarem energia, ou gastarem o mesmo que geram. Dispositivos "neutros" dessa forma têm baterias que duram meses ou mais sem necessitar de recarga, mesmo com uso diário comum. Para mostrar como é possível atingir neutralidade de energia atualmente com design cuidadoso, os autores desenvolveram um simples dispositivo vestível que tira fotos de baixa resolução do ambiente e as mostra em uma tela em escala de cinza. Para tal eles combinam microprocessador e câmera de baixo consumo com uma tela eletroforética (como a tela de $e$-Readers atuais) e memória ferroelétrica. Telas eletroforéticas mudam pigmentos na tela aplicando campos elétricos, e só necessitam de energia para renderizar uma imagem. Após a renderização, a imagem fica na tela indefinidamente sem gastar energia extra. Memória ferroelétrica (FRAM) é um novo tipo de memória de acesso aleatório (RAM) que é não-volátil, ou seja, guarda dados persistentemente, o que é desejável em um dispositivo onde a energia disponível pode mudar muito (para menos ou mais) ao longo do tempo. Além disso, definiram novos métodos para atualizar a imagem na tela, reduzindo aproximadamente $50 \%$ do consumo de energia do processo e permitindo mais níveis de cinza na tela. Também mudaram o método de aquisição de imagens da câmera, reduzindo em $91 \%$ a energia usada e em 5 vezes o tempo de aquisição. Finalmente, usam 8 pequenas células solares que geram, em média, $0.6 \mathrm{~J} / \mathrm{h}$ de energia em um ambiente interno (das 11 AM - 7 PM), o que é suficiente para esse dispositivo ser neutro com um pequeno número de operações (adquirir e renderizar uma imagem) por hora: 54 imagens renderizadas em preto-e-branco, ou 12 com 9 níveis de cinza. Esse sistema mostra como podemos atingir neutralidade de energia ou ao menos uma grande economia de energia com o respectivo aumento de duração de uma bateria com design cuidadoso de software e hardware, aproveitando formas móveis de geração de energia.

Em $\left[\mathrm{MHM}^{+}{ }^{14}\right]$ Mayberry et al. argumentam que rastreadores atuais são fundamentalmente falhos em relação ao seu consumo de energia pois separam aquisição de imagens do processamento delas para determinar o estado do olho. Se ambas partes fossem realizadas em conjunto, diversas otimizações de amostragem de pixels e processamento poderiam ser implementadas pela aplicação para economizar recursos computacionais e, portanto, energia. O método apresentado por Mayberry et al. se baseia na ideia de que imagens do olho contêm uma grande quantidade de dados (pixels) redundantes, e que deve ser possível estimar o olhar em cada quadro somente com um pequeno conjunto de pixels. Dessa forma, usando menos pixels o pipeline de processamento é mais simples (computacionalmente), permitindo o método inteiro ser executado em um microprocessador simples (de baixo processamento e consumo de energia). Menos pixels também implica em uma latência menor, possibilitando processamento em tempo real com frequência alta. Baseando-se nessa ideia, o método de Mayberry et al., chamado de iShadow, primeiramente necessita de alguns minutos para coletar dados para calibração para um usuário e, depois, usando-se desses dados, treina de forma offline em outra máquina, um modelo de rede neural para estimação do olhar. Além de treinar o modelo, esse processo também determina o menor conjunto de pixels da câmera a serem usados na estimação, reduzindo consumo de energia sem perder precisão. Finalmente, o modelo deve ser enviado para o dispositivo do rastreador, composto por um pequeno dispositivo de processamento montado em um óculos, com uma câmera apontada para um olho e outra para a cena que o usuário vê. Esse rastreador vestível então estima em tempo real o olhar do usuário através do modelo gerado, usando o valor de alguns pixels para estimar a posição do olhar. Como esse procedimento para rastrear o olho com poucos pixels é simples, ele é trivial de implementar e otimizar 
diretamente no hardware do rastreador.

Um aspecto importante do método de Mayberry et al. é a câmera usada no rastreador. É uma câmera digital de baixo custo e baixo consumo de energia. Porém ela tem uma característica incomum para câmeras digitais desse estilo: ela usa pixels logarítmicos (que dão uma resposta logarítmica à variação de intensidade da luz) e permite acesso aleatório aos pixels da câmera. Portanto o algoritmo pode amostrar os pixels usados diretamente sem ter que adquirir a imagem inteira da câmera, contribuindo fortemente para a economia de energia. Esse fato influenciou o design do rastreador e do algoritmo desde o início, e permitiu que o custo computacional do algoritmo e o consumo de energia sejam lineares em relação ao número de pixels usados. Pelos experimentos dos autores, usar somente $10 \%$ dos pixels reduz drasticamente o consumo de energia, sem afetar significativamente a precisão da estimação do olhar. iShadow conseguiu ser executado em tempo real a $30 \mathrm{~Hz}$, gastando somente em torno de $70 \mathrm{~mW}$ de energia, com um erro médio de $3^{o}$ de ângulo visual. Enquanto esse valor de erro médio seja maior se comparado ao $1^{\circ}$ de erro (ou menos) de rastreadores comerciais, os autores argumentam que a precisão é suficiente para diversas aplicações. Os problemas encontrados com esse método se devem em grande parte à câmera usada, que por ser muito sensível à mudanças de iluminação, não pode ser usada em ambientes externos - algo que usualmente rastreadores com iluminação passiva podem. Além disso, o posicionamento da câmera (situada bem em frente ao olho direito) atrapalha a visão do usuário, como é mostrado na Figura 2.6.
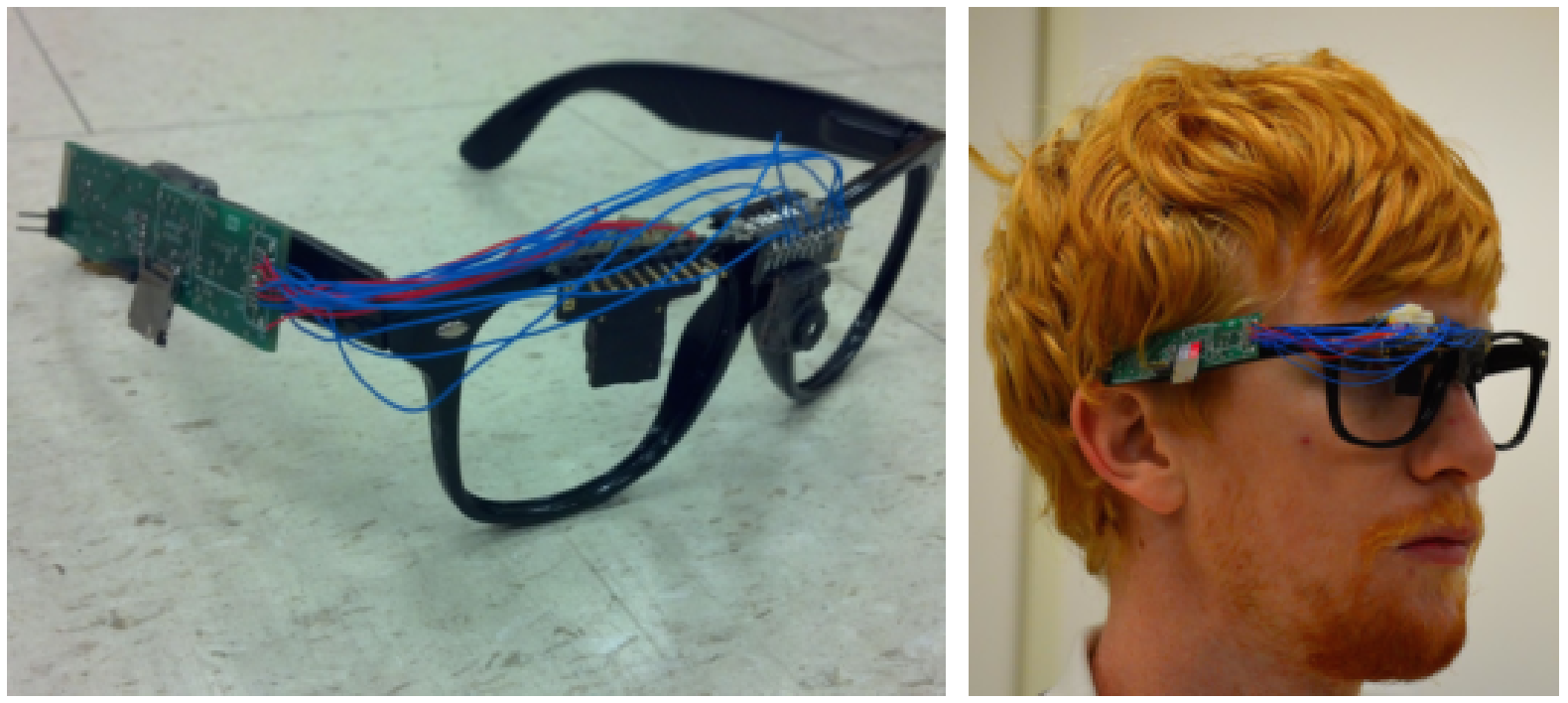

Figura 2.6: Diferentes visões do protótipo do iShadow. O dispositivo contém uma câmera para o olho, e outra no centro da armação para a cena, e a placa eletrônica ficam ao lado. Baterias ficam localizadas atrás da orelha, mas não são visíveis nessa imagem. Fonte: Mayberry et al. [MHM+14]

Mayberry et al. continuaram seu trabalho no iShadow em um sistema novo chamado CIDER (CIrcle Detection of Edges with Reinforcement) [ $\left.\mathrm{MTH}^{+} 15\right]$. Neste novo sistema, cuja visão geral é apresentada na Figura 2.7, Mayberry et al. se focaram em balancear robustez e consumo de energia, tentando resolver alguns dos empecilhos encontrados com o iShadow. Para tal, usaram o mesmo sistema que o iShadow, com algumas mudanças: um fotorreceptor mede o nível de luz PIV ambiente para determinar se o usuário está em um ambiente interno ou externo, e mudam os parâmetros da câmera e o modelo da rede neural de acordo. Em ambientes internos, luzes PIV (com voltagem reduzida para economizar energia) são usadas quando pixels forem amostrados da câmera, e o método principal de rastreamento do olhar é um algoritmo de refinamento da pupila que amostra uma coluna e uma linha de pixels em formato de cruz para detectar o círculo da pupila. Esse método de refinamento é muito rápido, efetivamente rastreando o olho a centenas de Hz. Quando o método não acha a pupila por alguma razão, ou quando ele ainda não tem dados de 


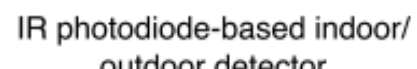
outdoor detector
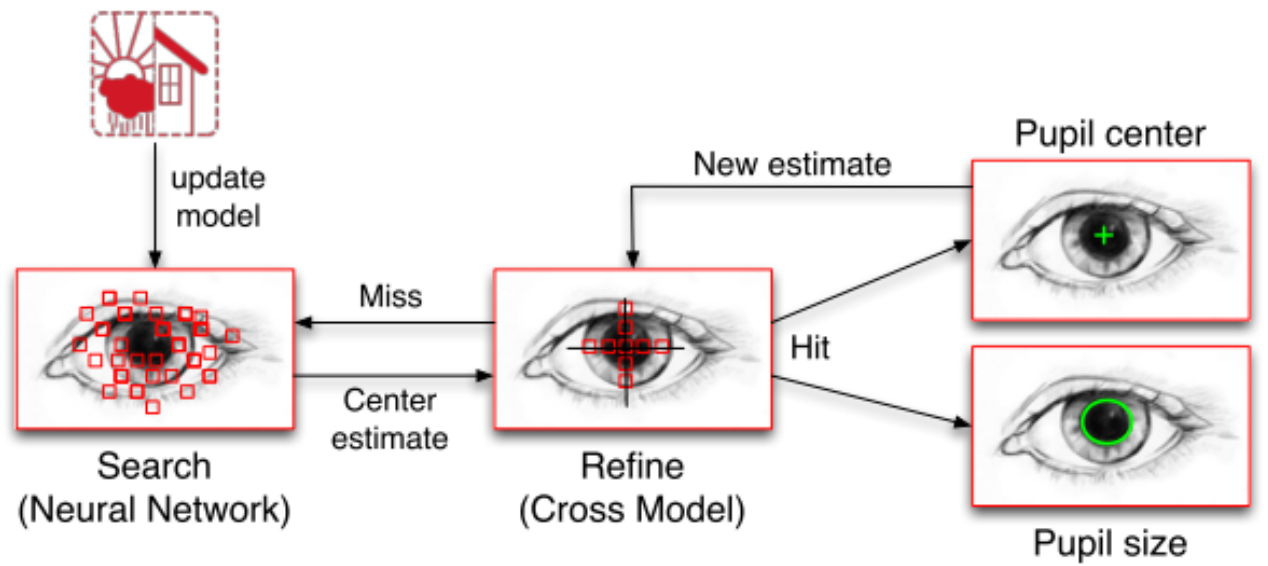

Figura 2.7: Visão geral do CIDER. (1) Um fotorreceptor PIV para detectar estado atual e atualizá-lo. (2) Estágio de busca usando rede neural para calcular uma estimação inicial da pupila. (3) Estágio de refinamento para determinar precisamente a pupila em altas frequências até não achar a pupila em algum quadro. Fonte: Mayberry et al. [MTH ${ }^{+}$15]

um quadro anterior o rastreador usa a rede neural para achar a pupila de forma similar à rede usada no iShadow, mas determinando posição e tamanho da pupila.

Em ambientes externos, as luzes PIV são desligadas e o método de refinamento não é executado. O modelo da rede usado nesse estado é mais complexo que no estado interno, amostrando mais pixels para aumentar a robustez da detecção. O modo de calibração, para gerar os modelos das redes neurais para estados interno e externo também foi melhorado para ser um processo automático que não necessita de entrada do usuário. O sistema é capaz de, em condições boas (quando está carregado, por exemplo), enviar dados para outro dispositivo móvel que realiza o treinamento off-line dos modelos. A câmera foi movida na armação vestível, para ficar abaixo do olho. Isso tem algumas vantagens para a qualidade da imagem, principalmente quando o usuário olha para baixo, mas ainda obstrui a visão da pessoa. No geral, CIDER teve resultados bem melhores que o iShadow. Sua precisão é menor que $1^{\circ}$ em ambientes internos, e aproximadamente $1^{\circ}$ em ambientes externos. Ou seja, em ambientes externos tem precisão melhor que o iShadow em ambientes internos, e é comparável a dispositivos comerciais que são caros e pesados. O consumo de energia também foi reduzido, assim como a frequência do rastreador foi aumentada. Rodando a $4 \mathrm{~Hz}, 7$ miliwatts são consumidos, enquanto a $270 \mathrm{~Hz}$ somente $31 \mathrm{~mW}$ são usados, que é menos da metade do consumo do iShadow a $30 \mathrm{~Hz}$. Mesmo usando duas luzes PIV, diminuindo sua voltagem e ativando-as somente quando necessário foi suficiente para diminuir o consumo de energia das luzes por duas ordens de magnitude, para a casa de alguns microwatts.

CIDER ainda pode ser melhorado: tentando repensar o design do dispositivo vestível para não obstruir a visão, usando um FPGA $A^{1}$ para otimizar ainda mais o algoritmo, ou permitindo ainda mais estados de funcionamento (além do interno e externo) dependendo do nível de luz PIV ambiente. No entanto, o sistema já é desenvolvido o suficiente para ter um desempenho comparável a sistemas comerciais, mas consumindo muito menos energia e sendo de baixo custo. Tanto o iShadow quanto o CIDER foram desenvolvidos desde o início do seu design pensando no consumo de energia.

Um ponto comum na maioria dos trabalhos estudados aqui é que eles não tratam sobre o consumo de

\footnotetext{
${ }^{1}$ Circuito integrado especializado na qual um usuário pode reprogramar o hardware após a produção do circuito
} 
energia de seus métodos de rastreamento e de seus dispositivos vestíveis. Muitos desses trabalhos também não mencionam os parâmetros básicos, como resolução e frequência, da câmera usada, nem como esses parâmetros, o gasto de energia e a precisão do rastreador estão relacionados. Esse fato mostra como esse relacionamento de parâmetros da câmera, precisão e gasto de energia não tem sido abordado em detalhes no estado da arte.

\subsection{Algoritmos Detectores e Algoritmos Rastreadores}

Os métodos de rastreamento do olhar estudados neste trabalho não são rastreadores de fato. Eles detectam a pupila novamente a cada quadro, usando pouca ou nenhuma informação sobre a pupila detectada anteriormente. Em outras palavras, a cada quadro eles executam o mesmo procedimento de detecção da pupila novamente. Existem algoritmos que detectam a pupila ou o olho em um quadro caso ela não tivesse sido detectada antes, mas após isso usam de outras operações de processamento de imagens para "rastrear a pupila ao longo do tempo", ou seja, rastrear a pupila se movimentando pela imagem ao longo de quadros sequenciais. Isso envolve a detecção do movimento de um objeto conhecido na imagem (a pupila), e não a detecção de um objeto novamente. No entanto tais algoritmos são um tanto quanto raros se comparados à algoritmos "detectores" como os que iremos avaliar neste trabalho. Por causa disso não vamos entrar em mais detalhes sobre eles. 
14 FUNDAMENTOS 


\section{Capítulo 3}

\section{Metodologia}

A proposta deste trabalho é investigar o desempenho de algoritmos de rastreamento do olhar já existentes, variando parâmetros que afetam o consumo de energia, tais como resolução e frequência da câmera. O objetivo é analisar o efeito de valores diferentes desses parâmetros na precisão, acurácia e consumo dos algoritmos de rastreamento Starburst, ITU Gaze Tracker e Pupil Labs, a fim de mostrar que mudanças simples de parâmetros em algoritmos de rastreadores atuais comuns já permitem uma grande economia de energia enquanto mantém precisão e acurácia similar.

Por meio de um estudo com usuários coletamos dados do olhar de vários participantes. As coletas foram feitas em uma única configuração de resolução e frequência. Cada coleta é subamostrada, tanto no domínio espacial (resolução) quanto no temporal (frequência) para obter as demais configurações.

Para isso, criamos uma plataforma de experimentos que permite realizar coletas com usuários, processar coletas e analisar os dados processados. O processamento das coletas executa os algoritmos de rastreamento disponíveis, sob cada configuração de resolução e frequência.

\subsection{Coletas}

As coletas contém os dados necessários para a estimação do olhar e validação de tais dados de forma genérica para serem usadas com diversos algoritmos de rastreamento. Vídeos dos olhos dos participantes assim como informações de onde o participante está olhando em um quadro do vídeo são dados suficientes para nosso propósito de estimar o olhar usando algoritmos diferentes, e validar os pontos estimados, respectivamente.

Além dos parâmetros de configuração próprios, um algoritmo de rastreamento necessita de uma sequência de imagens do olho, no caso, o vídeo do olho. Para validação, além da estimação do olhar é necessário a informação para onde o usuário estava olhando no momento (quadro do vídeo) que essa estimação foi feita. Como o processo de coleta é conhecido e envolve o usuário olhar para determinados pontos no monitor, sabemos para onde ele deveria estar olhando para comparar o resultado e calcular o erro da estimação.

Para gerar tais dados, o procedimento de uma coleta consiste em um participante olhar para uma sequência de alvos conhecidos em uma superfície - o monitor. Também foram afixados marcadores visuais nos cantos do monitor para ser possível, de forma simples, detectá-lo nas imagens da cena.

Os vídeos foram feitos em uma única configuração de resolução e frequência comum a um rastreador móvel, para poderem ser convertidos em resoluções e frequências menores por subamostragem do vídeo original:

- Resolução: a subamostragem espacial consiste em reduzir a resolução dos quadros. Esse processo 
é feito escalando a imagem nas duas dimensões, mantendo a proporção original. Dessa forma o resultado é um quadro similar ao original, mas com resolução menor. Dizemos similar e não idêntico pois informações são perdidas ao diminuir a resolução.

- Frequência: a subamostragem temporal é feita ignorando certos quadros da sequência do vídeo original. Dependendo da frequência que queremos atingir, uma quantidade fixa de quadros é pulada a cada quadro processado. Por exemplo, como o vídeo original foi feito a $30 \mathrm{~Hz}$, para subamostrar para $15 \mathrm{~Hz}$ nós processamos um quadro, e pulamos o seguinte - repetindo isso para a duração inteira do vídeo.

\subsection{Algoritmos de Rastreamento}

Analisamos o desempenho dos algoritmos Starburst, ITU e Pupil-Labs, que serão detalhados a seguir. Os algoritmos foram usados em suas linguagens de programação originais (de implementação pública dos autores), porém foram alterados para poderem ser executados seguindo uma interface genérica de processamento. Tal alteração permite que cada algoritmo seja executado seguindo a mesma interface de aplicação (ou API, do inglês Application Programming Interface), o que facilita o uso deles no processamento dos dados (vide próxima seção). Única exceção para isso foi o ITU, que convertemos da sua linguagem original em $\mathrm{C} \#$ para $\mathrm{C}++$ para poder ser usado pelas ferramentas em Python assim como o Starburst. Os parâmetros de configuração de cada algoritmo foram escolhidos empiricamente. Eles foram definidos para cada configuração quando necessários para que os algoritmos sejam executados com bom desempenho.

Esses algoritmos foram escolhidos pois representam alguns dos principais tipos de algoritmos de rastreamento, funcionam sob as mesmas condições (imagem do olho e luz PIV) e são todos open-source, o que nos permite usá-los livremente. Como mencionado no capítulo anterior, focamos em métodos para rastreadores vestíveis que usam iluminação perto-do-infravermelha (PIV), pois são os mais pesquisados e usados comercialmente.

\subsubsection{Starburst}

O Starburst [WPL05] é um algoritmo clássico de rastreamento do olhar desenvolvido como um rastreador vestível em 2005 por Winfield, Li e Parkhurst. O nome do algoritmo vem da forma com que ele determina a pupila, que será detalhada nas subseções a seguir.

O funcionamento deste algoritmo é divido em quatro etapas executadas em cada imagem vinda da câmera: detecção e remoção de reflexões na córnea $(\mathrm{RC})$, detecção de características, refinamento, e otimização. Elas serão explicadas em detalhes nas subseções a seguir.

\section{Detecção e Remoção de Reflexões na Córnea}

Reflexões na córnea são reflexões especulares de fontes de luz na superfície da córnea. Elas se caracterizam na imagem como uma pequena região aproximadamente circular de pixels saturados. Essas reflexões podem ser usadas de várias formas, como mencionadas em [MM05]. No caso do Starburst, a posição delas é detectada para formar o vetor do centro da pupila até a reflexão para estimação do olhar, e depois a reflexão é removida da imagem para a etapa seguinte não confundir essa região de alto contraste com a borda da pupila.

A detecção da reflexão é feita em uma pequena janela (aproximadamente do tamanho da íris) ao redor do ponto inicial do quadro atual. O ponto inicial é dado como parâmetro para o algoritmo e idealmente deve ser um ponto na imagem dentro da pupila. Em quadros seguintes o ponto inicial será o centro da 
pupila detectada no quadro anterior. A imagem é inicialmente binarizada usando o valor máximo de um pixel (que no caso é 255), o que resultará normalmente em uma imagem com uma região ou nenhuma. O limiar é iterativamente diminuído até que mais de uma região de pixels saturados apareça na imagem, nesse caso a maior região é dada como a reflexão na córnea. O centro da reflexão é definido como o centro geométrico dessa região.

Após detectar a posição da reflexão, o algoritmo calcula seu raio. Embora o tamanho poderia ser determinado pela região detectada, ela pode não corresponder à forma real da reflexão. O algoritmo então supõe que a RC segue a forma de um círculo, e que sua distribuição de intensidade de pixels segue uma distribuição Gaussiana bi-variada. O processo tenta achar o raio onde o declínio médio de intensidade é máximo, relacionando-o com a curva Gaussiana. Para isso eles determinam o raio r que minimiza a equação:

$$
\frac{\int I\left(r+\delta, x_{c}, y_{c}, \theta\right) d \theta}{\int I\left(r-\delta, x_{c}, y_{c}, \theta\right) d \theta}
$$

Onde $\delta=1$ e $I(r, x, y, \theta)$ é a intensidade do pixel no ângulo $\theta$ no contorno de um círculo definido pelo ponto $(x, y)$ e raio $r$. A busca é inicializada com $r=\sqrt{\text { area } / \pi}$, onde area é o número de pixels na região detectada.

Finalmente, interpolação radial é usada para remover a reflexão da imagem. Primeiramente o pixel central da reflexão detectada é definido como a intensidade média dos pixels no contorno do círculo. Cada pixel dentro do círculo é definido como a interpolação linear entre o centro e o ponto correspondente no contorno, traçando uma linha entre o pixel sendo alterado e o centro.

\section{Detecção de Características em Dois Estágios}

A cada quadro essa etapa faz várias iterações. A cada iteração, o algoritmo primeiramente traça raios uniformemente em todas direções ao redor de um ponto inicial. Para cada raio, ele determina o primeiro ponto no traçado onde o gradiente da imagem passa de um determinado limiar. Tais pontos são chamados de pontos de borda. Depois de traçados todos os raios, para cada ponto detectado mais raios são traçados, mas dessa vez eles são executados em um cone de $50^{\circ}$ em torno da direção do ponto detectado para o ponto inicial, e mais pontos de borda são encontrados. Finalmente com todos os pontos de borda em mãos, o algoritmo calcula o centro geométrico deste conjunto e usa este ponto como o valor inicial da próxima iteração.

Quando o ponto central do conjunto de pontos de borda começa a convergir, o algoritmo interrompe essa rotina e vai para a próxima etapa com o conjunto atual de pontos. Os autores notam que usualmente um pequeno número de iterações (5 quando o ponto inicial não é ideal) é necessário para atingir a convergência. E mesmo assim, se mais de 10 iterações forem executadas, o algoritmo termina o processamento e vai para o próximo quadro.

A ideia desta etapa é que partindo de um ponto na pupila, os pontos detectados pelos raios deverão ser pontos no contorno da pupila. Quando algum raio passa pela borda da pupila ou caso o ponto inicial esteja fora, o processo de dois estágios melhora a robustez do algoritmo, garantindo que mais pontos na borda da pupila sejam adquiridos (como mostra a Figura 3.1). É desse funcionamento do algoritmo, como visto na figura, que vem o nome "Starburst".

No entanto, este processo tem seus problemas. Ele é altamente dependente de parâmetros de configuração do Starburst: ponto inicial, limiar do gradiente e número de raios a serem traçados. Cada um afeta, de maneiras diferentes, o desempenho e o custo computacional:

- Ponto inicial: É preciso ser alterado a cada execução do Starburst para garantir que o valor continue correto. Ao ser ajustado corretamente, o desempenho é melhorado pois serão detectados 


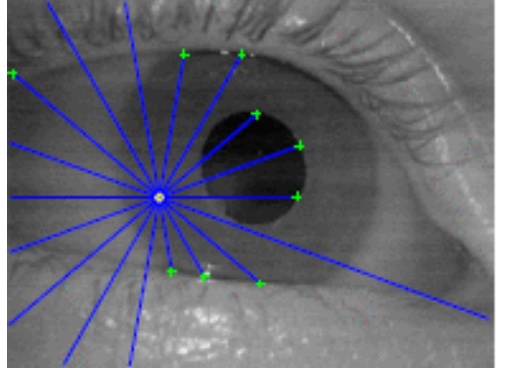

(a)

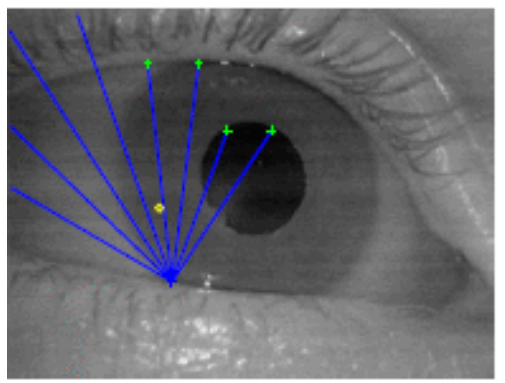

(c)

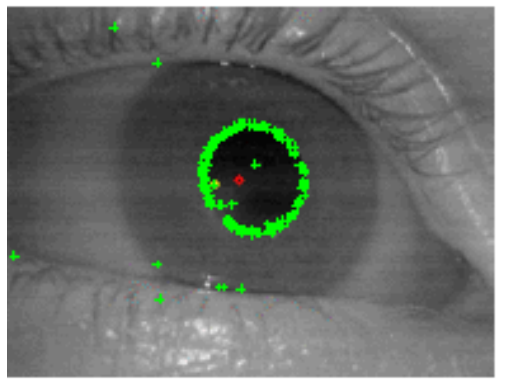

(e)

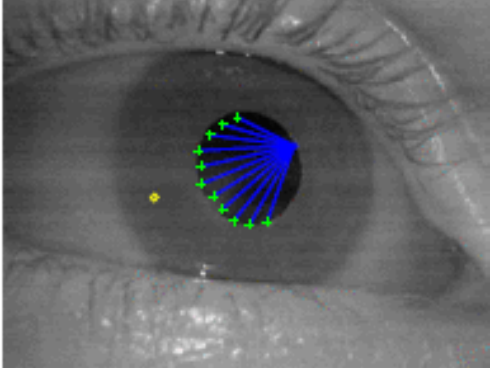

(b)

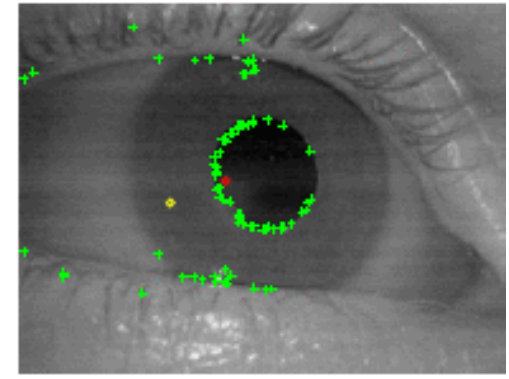

(d)

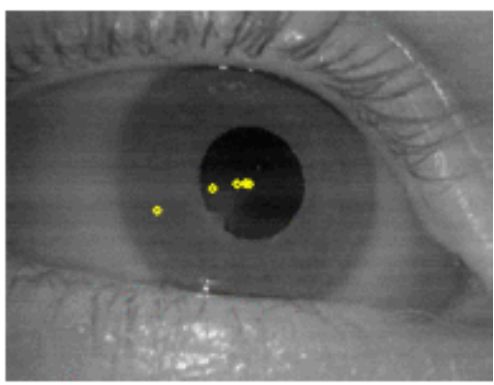

(f)

Figura 3.1: Detecção de características do Starburst. (a) O ponto inicial original (em amarelo) solta raios (traços azuis) para gerar pontos candidatos (cruzes verdes). (b,c) Pontos candidatos atiram raios de volta ao ponto inicial para detectar mais pontos. (d) Todos os pontos candidatos detectados na primeira iteração. O ponto central é mostrado como um círculo vermelho, que será o ponto inicial da próxima iteração. (e) Resultados da segunda iteração. (f) Posições iniciais de várias iterações mostram uma convergência rápida. Fonte: Winfield et al. [WPL05]

mais pontos na borda da pupila e menos pontos fora. O custo computacional também diminui pois menos iterações serão necessárias para o centro do conjunto convergir.

- Limiar do Gradiente: É preciso ser alterado quando as condições de iluminação no ambiente onde o algoritmo será executado mudam. O limiar depende dos valores de intensidade da imagem da câmera, e portanto alterando a iluminação irá afetar o valor desse limiar. Quando ajustado apropriadamente, o desempenho do algoritmo é melhorado pois irá melhorar a detecção de pontos em bordas significativas como a pupila, mas isso também depende da qualidade da imagem. Em relação ao custo computacional, se o limiar for baixo o algoritmo irá detectar mais pontos não necessariamente corretos (mais falso positivos), mas o custo irá diminuir pois em média os raios terão que percorrer menos pixels. Se o limiar for alto, menos pontos serão detectados, mas eles serão relativos a bordas de maior contraste, como é o caso quando ocorre o efeito da pupila escura. Nesse caso, mantendo o mesmo número de raios, o custo tenderá a aumentar pois em média os raios terão que percorrer uma distância maior. Em ambos os casos o quanto um raio terá que percorrer para achar um ponto também irá depender da região da imagem da onde o raio está partindo. Por 
exemplo, se o ponto inicial estiver no centro da pupila, independentemente do valor do limiar, os raios provavelmente irão parar na borda da pupila e portanto o custo será o mesmo.

- Número de Raios: Este parâmetro basicamente balanceia desempenho com custo computacional. Menos raios implicam em menos pontos, o que significa menos robustez na detecção mas custo menor. Mais raios implicam o contrário: mais pontos, mais robustez, e custo maior. Portanto este parâmetro tem um grande efeito no desempenho e custo computacional.

- Número Minimo de Pontos de Borda: caso uma iteração de traçado dos raios ache menos pontos de borda que esse número, o algoritmo irá abaixar o limiar do gradiente e tentar novamente. Ele irá repetir esse processo até achar mais pontos de borda, ou não conseguir abaixar mais o limiar - caso no qual o algoritmo irá parar sem ter achado o centro da pupila.

- Tamanho da Janela de RC: área de interesse na imagem, ao redor do ponto inicial desse quadro, no qual será procurado as reflexões na córnea. Caso seja pequena, o algoritmo poderá não detectar as RCs. Caso seja grande, ele poderá detectar outras regiões saturadas que não sejam a reflexão na córnea, como reflexos no canto do olho. Esse valor afeta diretamente quantos pixels serão processados para procurar as reflexões, então afeta diretamente o custo computacional. Todavia, como o Starburst "apaga" da imagem as RCs antes de detectar a pupila, a detecção equivocada das reflexões pode afetar o desempenho do algoritmo também, mesmo que o usuário do rastreador não use a posição das reflexões na córnea para estimação do olhar.

- Área máxima de uma RC: tamanho máximo, em pixels, que uma reflexão na córnea pode ter. Durante a detecção das reflexões, onde o algoritmo busca regiões de pixels saturados na imagem, caso a região seja maior que esse valor (em área), ela será ignorada. Esse parâmetro não afeta o custo computacional diretamente, mas assim como o tamanho da janela, ele afeta o desempenho do algoritmo pois contribui para a detecção adequada das reflexões na córnea.

- Número de RCs: número de reflexões na córnea que serão procuradas. O algoritmo só permite que nenhuma até duas reflexões sejam detectadas, e para determinar duas reflexões ele funciona da mesma forma, mas também detectando e considerando uma segunda maior região de pixels saturados para ser a segunda reflexão. Como é de se esperar, quanto mais reflexões são procuradas maior será o custo computacional.

Além disso, os raios se propagam até achar um ponto de borda ou até passar dos limites da imagem, nesse caso nenhum ponto é adicionado. Isso é problemático pois a borda íris-pupila não é a única borda de alto contraste em uma imagem com efeito de pupila escura. Cílios-pálpebra ou sobrancelha-pele são bordas de contraste semelhante em região próxima. Como o Starburst não tem nenhum método para validar se uma elipse detectada é de fato a pupila, nem algum pré-processamento para detectar a região do olho ou piscadas, é possível que a elipse que ele detecta desvie da posição real da pupila e até do olho em casos onde a pupila não pode ser vista. E uma vez que esse desvio aconteça, é muito provável que ele continue detectando uma elipse nessa posição errada até algum outro evento ocorrer que faça a detecção desviar novamente.

\section{Refinamento da Pupila}

Após detectar um conjunto de pontos candidatos da borda da pupila, o Starburst refina esse conjunto de pontos usando Random Sample Consensus (RANSAC) para determinar um subconjunto de pontos classificados como inliers, isto é, pontos que pertencem ao modelo, que no caso é a elipse da borda da pupila. Dessa forma o RANSAC estima uma elipse baseando-se nos pontos de bordas, ignorando pontos 
fora do modelo (outliers). Essa etapa tem o problema de não ser determinística, ou seja, para uma mesma imagem e mesmo conjunto de parâmetros iniciais, duas execuções do algoritmo podem não devolver a mesma elipse, pois o RANSAC usa métodos estatísticos que sorteiam subconjuntos aleatórios de cinco pontos para determinar uma elipse. Aliando-se a isso o fato que a elipse escolhida é o modelo que teve mais pontos inliers, o que nem sempre é a melhor opção, o resultado é que a elipse devolvida por essa etapa é instável. Ela varia muito a cada quadro (mesmo que o quadro seja igual) em torno da borda detectada, algumas vezes erroneamente estimando elipses maiores que a pupila.

\section{Otimização do Resultado}

Dada sua instabilidade, a precisão do resultado da etapa anterior pode ser suficiente para algumas aplicações de rastreamento do olhar, mas isso pode ser melhorado, permitindo que o algoritmo seja usado com aplicações que necessitam de mais precisão e estabilidade. O propósito desta etapa é, partindo da elipse calculada pelo RANSAC, fazer uma busca pelos parâmetros ideais para uma elipse que segue as bordas na imagem, seguindo um modelo de elipse e modelo da pupila escura na imagem sem detectar características pontuais. Para achar os parâmetros $a, b, x, y, \alpha$ da melhor elipse, a seguinte equação é minimizada:

$$
-\frac{\int I(a+\delta, b+\delta, \alpha, x, y, \theta) d \theta}{\int I(a-\delta, b-\delta, \alpha, x, y, \theta) d \theta}
$$

Onde $\delta=1$ e $I(a, b, \alpha, x, y, \theta)$ é a intensidade do pixel no ângulo $\theta$ no contorno de uma elipse definida pelos seguintes parâmetros:

- $a, b$ são o tamanho dos eixos (maior e menor eixo, respectivamente);

- $(x, y)$ é o ponto central;

- $\alpha$ é a angulação da elipse (ângulo do maior eixo).

Essencialmente a equação compara a intensidade do contorno de duas elipses. A minimização então acha a elipse que tem a maior diferença de intensidade (gradiente) no contorno em relação a uma elipse na mesma posição e ângulo, mas levemente $(\delta)$ menor. No prática, se o resultado do RANSAC foi uma elipse pelo menos próxima da pupila esta etapa tende a corrigí-la, detectando a elipse correta e contribuindo para estabilizar o resultado do algoritmo.

\section{Métodos Relacionados}

Sendo um algoritmo antigo com desempenho adequado e fácil de implementar, o Starburst já foi citado por diversos trabalhos para comparar o seu método com o Starburst, ou para propor um método novo que é baseado no Starburst.

Por exemplo, Li e Parkhurst adaptaram-no para funcionar sem iluminação PIV, detectando a íris em vez da pupila em imagens no espectro visível de cores [LP06]. Para tal, modificaram a etapa que traça raios para só lançar raios em direções perto do eixo horizontal pois é comum a íris estar parcialmente obstruída na área de cima ou de baixo pelas pálpebras. Outra mudança foi que antes do refinamento dos pontos de borda pelo RANSAC, eles filtram os pontos pela distância dos mesmos para o centro, removendo os pontos nos quais $D_{p}>1,5 \sigma+M$, onde $D_{p}$ é a distância do ponto $p$ para o centro; $M$ e $\sigma$ são a média e desvio padrão, respectivamente, de $D=\left\{D_{1}, D_{2}, D_{3}, \ldots\right\}$. O ponto inicial é alterado para o centro geométrico dos pontos restantes, e o processo é repetido. Em geral, o desempenho desse algoritmo é similar ao Starburst original e ele tem os mesmos problemas.

Outro trabalho, de Ryan et al. [RWDB08], adaptou o Starburst para detectar o contorno da pupila e da íris, e também adicionou uma etapa para detecção da borda das pálpebras. O propósito do algoritmo é 
segmentar a íris da imagem sem obstruções da pupila nem das pálpebras para métodos de reconhecimento de íris em imagens off-axis.

Esses trabalhos são significativos para aplicações em dispositivos vestíveis, e mostram o quão amplamente usado o Starburst é na literatura. Infelizmente, assim como discutimos no Capítulo 2, eles não consideram a relação entre desempenho, consumo de energia e parâmetros da câmera usada.

\subsubsection{ITU Gaze Tracker}

O ITU Gaze Tracker é outra solução de rastreamento de olhar aberta ao público, apresentada em 2010 por San Agustin et al [SSM $\left.{ }^{+} 10\right]$. A motivação dos autores era criar um sistema de rastreamento de olhar acessível, criando software que qualquer usuário poderia alterar para seus objetivos e usando hardware de baixo custo encontrados em lojas de componentes eletrônicos. Com isso o sistema seria barato e teria flexibilidade para um usuário adaptar o algoritmo ou o hardware de acordo com suas necessidades.

O software consiste de uma biblioteca com as rotinas de rastreamento e estimação do olhar, e um programa de interface gráfica para um usuário testar o algoritmo e definir os diferentes parâmetros do sistema.

O algoritmo do ITU possui os seguintes passos:

1. Usando o efeito da pupila escura e um valor de limiarização definido pelo usuário, a imagem da região de interesse é binarizada. A região de interesse inicial ou de quando a pupila não é encontrada é definida como a imagem inteira. Caso contrário, ela é definida como uma sub-região da imagem envolvendo a área da pupila detectada no quadro anterior.

2. Monta uma lista de blobs da imagem binarizada. Um blob é uma região continua de pixels que estavam abaixo do threshold usado na binarização, procurando blobs de pixels escuros já que usa o efeito da pupila escura.

3. Ordena os blobs por área, do maior pro menor.

4. Filtra os blobs seguindo algumas funções diferentes:

(a) Remove blobs "externos" (que estejam pra fora da imagem).

(b) Filtra blobs pelas suas áreas, para estarem dentro do intervalo de tamanho minimo e máximo definidos pelo usuário.

(c) Filtra blobs pela distância deles para o centro da região de interesse da imagem. Só o blob mais perto é mantido.

(d) O blob que sobrou é tido como sendo o blob da pupila.

5. Ajusta os parâmetros originais de detecção da pupila determinados pelo usuário baseando-se na pupila detectada, ou nos blobs detectados caso nenhum deles tenha sido escolhido como sendo a pupila.

Reflexões na córnea são detectadas de forma similar, com parâmetros diferentes e invertendo a binarização, após detectar a pupila. A princípio, o software do ITU não usa as reflexões para estimar o olhar. Os parâmetros de configuração do algoritmo são os seguintes:

- Limiar da Pupila: o valor de limiar, em intensidade de um pixel, para binarizar um quadro e achar a pupila. Esse parâmetro afeta o custo computacional, pois afeta quantos pixels serão processados, e também afeta significativamente o desempenho do algoritmo - valores altos e outras regiões, já não tão escuras, serão detectadas. Valores pequenos e possivelmente nem a pupila seja encontrada. Como 
explicado acima, o algoritmo ajusta esse parâmetro (e outros) de acordo com os blobs detectados, porém ele faz somente um pequeno ajuste a cada quadro, então possivelmente poderá levar vários quadros para ajustar os parâmetros para valores adequados.

- Intervalo de Tamanho da Pupila: tamanhos mínimo e máximo, em área, que um blob pode ter para poder ser considerado como sendo a pupila. De forma similar ao limiar, esse parâmetro também afeta tanto o custo computacional quanto o desempenho pois afeta como os blobs são filtrados, e portanto, afeta que possíveis regiões detectadas serão comparadas para determinar qual é a pupila.

- Número de Reflexões na Córnea: número de reflexões na córnea que serão detectadas.

- Limiar de RCs: valor de limiar, em intensidade de um pixel, para binarizar a imagem e detectar as reflexões na córnea. Funciona de forma idêntica ao limiar da pupila, porém é usado para binarizar o quadro para detectar as reflexões na córnea e binariza de forma inversa - espera-se que seja um valor alto para detectar as regiões saturadas da imagem.

- Intervalo de Tamanho de RCs: tamanhos mínimo e máximo, em área, que um blob pode ter para poder ser considerado como sendo uma reflexão na córnea. Funciona de forma idêntica aos parâmetros de tamanho da pupila.

É afirmado em [SSM $\left.{ }^{+} 10\right]$ que o ITU usa RANSAC para estimar a elipse da pupila partindo de pontos da borda do blob da pupila. No entanto, esse passo de refinamento não existe na implementação do ITU que encontramos e usamos neste trabalho.

\subsubsection{Pupil Labs}

O rastreador de olhar do grupo Pupil Labs (Pupil) [KPB14] (Kassner et al.), é uma extensão do método de Swirski et al. [SBD12] mencionado no Capítulo 2.

O Pupil consiste em uma armação de óculos com câmeras para os olhos e para a cena e um pacote de software open-source feito em Python (com partes de custo alto em C) que contém o algoritmo de rastreamento do olhar e programas de interface gráfica para o usuário testar, gravar e reproduzir dados de estimação do olhar do algoritmo do Pupil. O objetivo era o desenvolvimento de um rastreador de olhar vestível acessível, de baixo custo e extensível por seus usuários para poderem usá-lo em diversas funções. Apesar do software ser open-source, somente partes da armação também são abertas ao público. Logo, para comprar um dispositivo da Pupil Labs com esse rastreador vestível impresso em 3D é necessário algumas centenas ou milhares de dólares, o que não é acessível a consumidores comuns.

O algoritmo usa a luz PIV somente para melhorar o contraste da imagem, não usando informações da reflexão na córnea. O método, exemplificado na Figura 3.2, detecta a estimação de região inicial da pupila pela mesma forma como em [SBD12], pela maior resposta a uma característica centro-arredores. Bordas são detectadas usando o algoritmo detector de Canny, e então são filtradas de acordo com a intensidade dos pixels da vizinhança. O método depois disso tenta refinar a região da pupila especificando uma região de pixels escuros, usando um intervalo (definido pelo usuário) a partir do primeiro pico de baixa intensidade no histograma da imagem do olho, e depois filtrando os pixels fora desse intervalo. Esse refinamento contribui para remover da imagem as bordas vindas de regiões saturadas, como as reflexões na córnea.

As bordas que sobram depois da filtragem são transformadas em contornos usando uma rotina de componentes conexos, os quais são filtrados e divididos em sub-contornos de acordo com um critério de continuidade da curvatura do contorno para garantir que tal contorno representa uma única curva (como esperada em um círculo ou elipse), e não curvas que alteram de direção (como um "S"). Elipses candidatas 

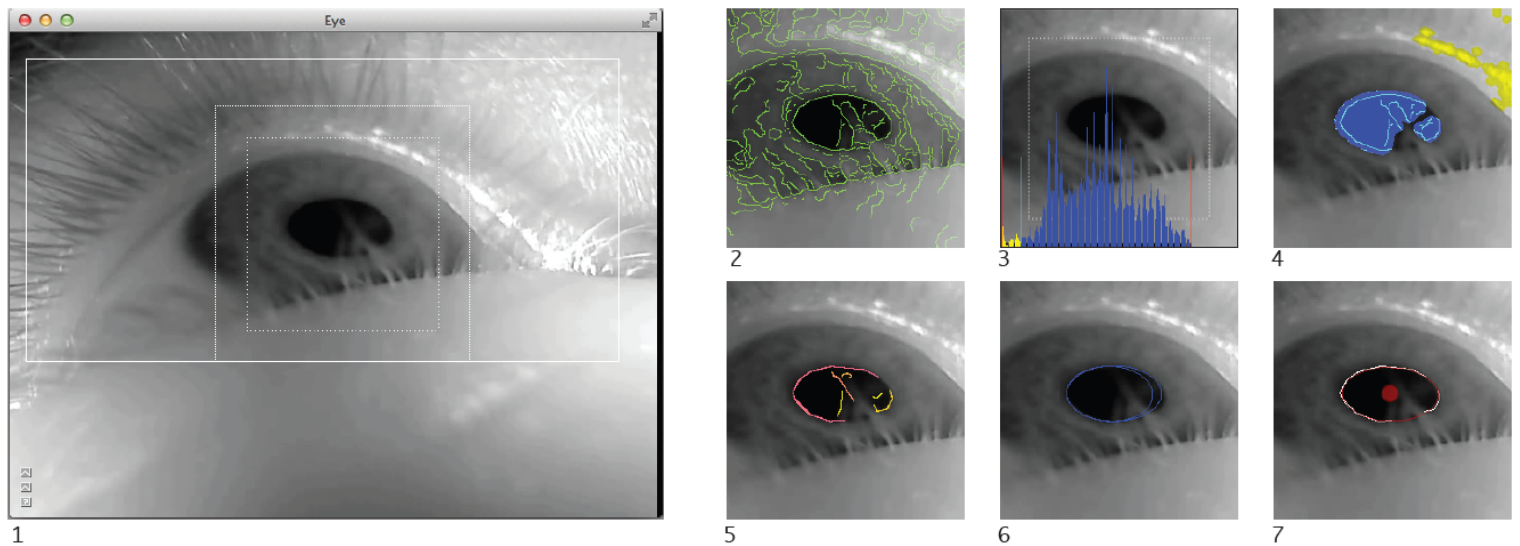

Figura 3.2: Funcionamento do algoritmo Pupil. (1) Imagem da câmera do olho convertida para escala de cinza. (2) Detector de bordas Canny (linhas verdes). (3) Define região escura como um intervalo fixo do menor pico do histograma da imagem do olho. (4) Filtra bordas para ignorar reflexões especulares (região amarela) e bordas fora de regiões escuras (área azul). (5) Bordas sobrando são transformadas em contornos usando componentes conexos e divididas em sub-contornos baseados na continuidade da curvatura (linhas coloridas). (6) Elipses (azuis) candidatas à pupila. (7) Elipse final (vermelha) detectada pela busca combinatória, pixels de suporte da borda em branco. Fonte: Kassner et al. [KPB14]

à pupila são geradas ajustando elipses em subconjuntos dos contornos detectados, procurando por bons resultados de acordo com parâmetros definidos pelo usuário (como tamanho mínimo e máximo da pupila). Uma busca combinatória procura por contornos que podem ser adicionados como suporte para as elipses candidatas. Os resultados são avaliados pela quantidade de pixels do contorno da elipse que casam com pixels das bordas que a geraram. O algoritmo só indica que uma pupila foi encontrada se a confiança da elipse detectada passa de um certo limiar definido pelo usuário. De forma similar à [SBD12], o Pupil foi avaliado comparando contra o Starburst e ITU, além de contra o próprio algoritmo de Swirsky et al. do qual eles se basearam. Em sua avaliação, o Pupil foi significativamente melhor que os outros algoritmos.

Os parâmetros de configuração do Pupil são os seguintes:

- Tamanho Mínimo de Contorno: na etapa de filtragem das bordas detectadas com Canny, parte do processo de filtragem é separar as bordas de acordo com o tamanho do contorno. Ele precisa ter mais pixels do que esse valor. Esse parâmetro afeta tanto o desempenho quanto o custo computacional, pois afeta quantos bordas serão processadas para a determinação dos contornos. Um valor maior implica em menos contornos a serem processados, o que por sua vez diminui o custo computacional mas pode afetar negativamente o desempenho caso isso faça o contorno real da pupila ser ignorado. Valores menores aumentam o custo computacional, mas diminuem a probabilidade do contorno real ser ignorado enquanto aumentam a chance de ocorrer falsos positivos.

- Intervalo de Tamanho da Pupila: esse parâmetro determina o tamanho mínimo e máximo que maior eixo de uma elipse pode ter. $\mathrm{O}$ algoritmo usa isso para filtrar as elipses candidatas durante a etapa de busca combinatória para determinar a elipse da pupila. Quanto mais restrito for esse intervalo, menos elipses serão aceitas como candidatas, o que diminuirá o custo computacional. No entanto, se esse intervalo não conter os tamanhos reais da pupila, como ela pode ter pela variação ao longo da sequência de quadros, o desempenho será negativamente afetado. Se o intervalo for mais abrangente o efeito será similar ao que acontece com o parâmetro do tamanho mínimo de contorno com valores pequenos, como explicado acima.

- Intervalo de Tamanho do Filtro: valores mínimo e máximo de tamanho da característica centroarredores, usada no início do algoritmo para determinar a região de interesse na imagem onde 
se encontra a pupila. Quanto maior o intervalo, maior será o custo computacional devido a mais iterações da detecção de característica centro-arredores. Consequentemente há mais chance da região da pupila ser detectada corretamente, assim como aumenta a probabilidade de regiões falso positivas. O resultado da deteç̧ão da região também afeta tanto o desempenho (dependendo se a pupila existe na região de interesse) quanto o custo computacional (regiões menores implicam em menos pixels a serem processados nos passos seguintes).

\subsection{Processamento dos Dados}

Para processar as coletas e gerar os dados de estimação do olhar e consumo de energia dos algoritmos para análise, implementamos uma única ferramenta que executa todos os algoritmos sob todas configurações de resolução e frequência. Dado que todas as coletas seguem o mesmo protocolo, e os algoritmos podem ser executados por uma interface genérica, essa única ferramenta de processamento executa cada caso de teste.

\subsection{Análise de Dados}

Após processar os dados, realizamos as seguintes análises:

1. Erros de estimação dos Algoritmos: média e desvio padrão do erro de estimação do olhar variando frequência e resolução para cada algoritmo em cada posição. Isso nos permitirá ver como a resolução e frequência afetam a precisão e acurácia dos rastreadores de olhar.

2. Consumo de CPU dos Algoritmos: média e desvio padrão do tempo total de execução de um algoritmo em um caso de teste, variando frequência e resolução para cada algoritmo. Essa análise nos mostrará como a resolução e frequência afetam o gasto de energia (aproximado) dos algoritmos.

Comparando os resultados dessas análises é o suficiente para o nosso objetivo de mostrar como variar a frequência e resolução da câmera de um rastreador afeta a precisão, acurácia e consumo de energia de um rastreador.

\subsubsection{Consumo de Tempo da CPU ou Consumo de Energia?}

$\mathrm{Na}$ seção anterior explicamos como analisamos o consumo de CPU (tempo gasto pela CPU) pelos algoritmos para ver como alterar resolução e frequência afeta o gasto de energia deles. Entretanto, consumo de CPU e consumo de energia não são a mesma coisa. O consumo de CPU é o tempo gasto pela CPU para realizar algum processamento, enquanto consumo de energia é o gasto real de energia (medido em joules ou watts) do hardware para realizar esse mesmo processamento.

Medir o consumo real de energia é uma tarefa usualmente complicada, necessitando uso ou acesso a sensores específicos para detectar o gasto de energia. Medir o consumo de tempo da CPU no entanto é trivial em comparação - basta medir quanto tempo o código levou para executar uma função, e isso usa operações simples que são comuns a praticamente todos os principais sistemas operacionais e linguagens de programação existentes.

Nós podemos supor que o tempo de execução de uma função é diretamente proporcional ao gasto de energia dado que a frequência de processamento da CPU tenha se mantido constante durante esse tempo. Com frequência da CPU constante, o consumo de energia da CPU também é constante ao longo do tempo, e portanto temos uma relação direta entre tempo de execução e energia gasta. 
Na prática nem sempre podemos supor que a frequência da CPU está constante, pois processadores modernos tem mecanismos de mudar a frequência em tempo real de acordo com a necessidade de processamento para economizar energia. Porém neste trabalho supomos que a frequência se manteve constante durante o processamento dos dados, e, consequentemente, durante o período de amostragem do tempo de execução dos algoritmos, pois observamos que durante esse tempo todas as CPUs disponíveis indicavam $100 \%$ de uso no monitor do sistema operacional.

\section{Sobre analisar o consumo em vídeos gravados}

Em nosso experimento estamos analisando o consumo de energia vendo o consumo de tempo da CPU dos algoritmos ao executá-los em vídeos dos olhos gravados durante a coleta de dados. Explicamos acima como usamos consumo de tempo da CPU para estimar o consumo de energia, mas como fica isso sabendo que um usuário não irá usar um rastreador processando vídeos de forma offline, mas sim com fluxos de imagens de uma câmera em tempo real?

Temos que adicionar ao consumo de energia do processamento do algoritmo o consumo oriundo da câmera adquirindo um quadro de imagem. Não consideramos isso na nossa análise pois supomos que o consumo de energia de uma câmera é constante. Deveras, dado que todas as coletas foram feitas com a mesma câmera, o que diferencia o consumo de energia é somente o processamento dos algoritmos. Além disso, supomos que o consumo de energia da câmera é constante pois para uma câmera específica C, ela deve gastar X de energia para adquirir um quadro de resolução $\mathrm{R}$ numa frequência F. Para resoluções ou taxas menores, ela deverá gastar $\mathrm{X}$ ou menos de energia para adquirir um quadro. 


\section{Capítulo 4}

\section{Experimento}

Neste capítulo descrevemos o experimento com usuários que foi realizado para coletar dados sobre estimação do olhar. As coletas, como explicado na seção 3.1, nos provêm os dados necessários para calcular e validar a estimação do olhar de alguns algoritmos de rastreamento sob condições diferentes, para diversos usuários. O experimento, de forma geral, foi dividido em três partes: a coleta de dados com usuários, o processamento dos dados, e a sua análise.

\subsection{Coletas com Usuários}

Nessa seção iremos descrever as coletas de dados de usuários. O objetivo é gravar vídeos do olho e da cena que o usuário está olhando para permitir a estimação do olhar e validação dessa estimativa em qualquer algoritmo de rastreamento. Iremos detalhar esse estudo nas próximas subseções: equipamento e ambiente, participantes, e aquisição de dados.

\subsubsection{Equipamento e Ambiente}

Para a coleta de dados foi usado um rastreador de olhar monocular da Pupil-Labs (Figura 4.1). O rastreador da Pupil-Labs consiste em uma armação de óculos ergonômica, feita por impressão 3D. Ela contém um braço ajustável que posiciona uma câmera de alta qualidade que captura em resolução de $640 \times 480$ pixels a $30 \mathrm{~Hz}$, usualmente posicionada logo abaixo do olho. O braço também contém um LED infravermelho que ilumina o olho a partir de uma posição fora do eixo da câmera.

O dispositivo também tem um suporte acima do olho direito que contém outra câmera de alta qualidade, que adquire quadros de $1280 \times 720$ pixels numa frequência de $25 \mathrm{~Hz}$ com um ângulo visual (diagonal) de $90^{\circ}$. Essa câmera é apontada para a frente, a fim de capturar o que o usuário está olhando, e ela pode ser rotacionada no eixo horizontal, permitindo mudar sua direção vertical. Dois cabos USB conectam o dispositivo a um computador que irá executar o rastreador de olhar, ou no nosso caso, a coleta de dados. Nossas ferramentas de coleta, processamento e análise foram executados na mesma máquina: um notebook com uma CPU Intel i7 com 8 núcleos lógicos de processamento de $1.73 \mathrm{GHz}$ e 12 GB de memória RAM, usando Windows 10 como sistema operacional.

A coleta foi feita num laboratório com iluminação controlada (somente luzes fluorescentes). Os participantes sentaram à frente de um monitor de 23 polegadas (resolução $1920 \times 1080$ pixels) em uma cadeira com apoio de braços mas sem rodas. Ao começar as coletas, a cadeira era posicionada num ponto fixo à frente do monitor de forma que a face do usuário estivesse a cerca de $70 \mathrm{~cm}$ de distância do monitor. O usuário era instruído a se manter ereto e confortável na cadeira. A câmera do olho era ajustada para tentar deixar o olho no centro da imagem, e o mesmo era feito com a câmera da cena para centralizar 

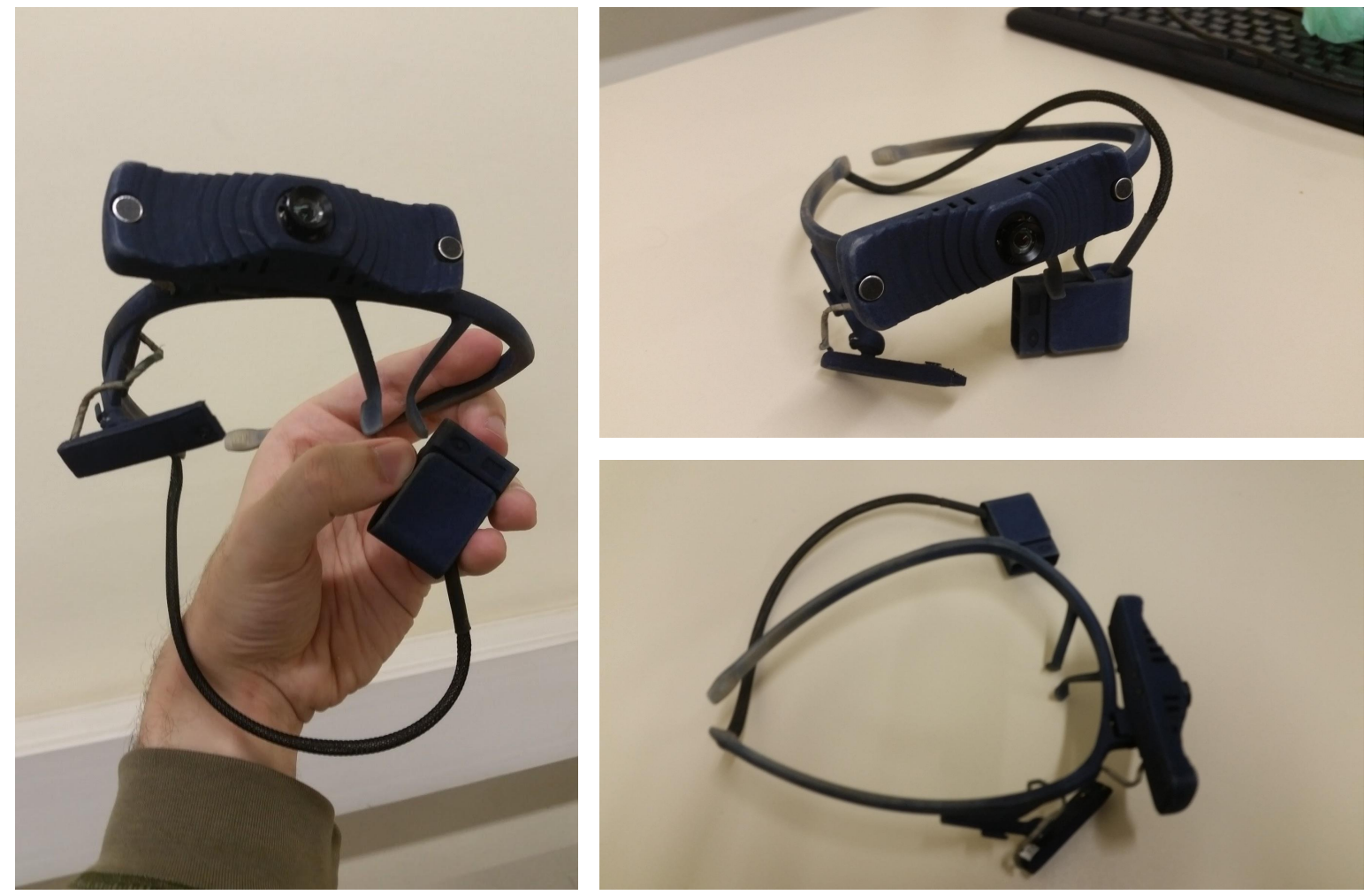

Figura 4.1: Rastreador de Olhar Monocular Pupil-Labs usado no experimento.

o monitor. O usuário então realizava a coleta nessa posição, e quando terminasse o monitor era movido $15 \mathrm{~cm}$ para uma das quatro direções cardinais (a partir dessa posição central) para o usuário realizar a coleta nessa outra posição. Esse processo de mover o monitor e realizar a coleta era repetido até termos as coletas das cinco posições (centro, norte, sul, leste e oeste). Um diagrama das posições de coleta é apresentado na Figura 4.2, enquanto a Figura 4.3 mostra um dos participantes realizando o experimento. Escolhemos $15 \mathrm{~cm}$ como o montante de movimento do monitor para as posições dos cantos pois isso representa o volume comum de espaço onde um usuário tende a mover sua cabeça na frente do computador que está usando.

Foram impressos e fixados nos cantos do monitor quatro marcadores de $4 \times 4 \mathrm{~cm}$. Eles são usados pelo processamento dos dados para determinar a superfície do monitor na imagem da cena, e com isso determinar a homografia entre a imagem da cena e o monitor. Além disso, os marcadores também são usados para estimar a pose do usuário em relação ao monitor, dado que calibramos a câmera da cena.

\subsubsection{Participantes}

O experimento foi realizado com 11 participantes voluntários, todos homens, entre alunos de graduação e pós-graduação do Instituto de Matemática e Estatística da USP. Todos tinham visão normal ou corrigida com óculos de grau, mas durante a coleta nenhum participante usou óculos corretivo após avaliarem que ainda conseguiam enxergar os alvos adequadamente.

\subsubsection{Aquisição de Dados}

A aquisição de dados seguiu o fluxo mostrado na Figura 4.4 (Coleta de Dados). Um novo usuário ao iniciar o experimento sentava na cadeira, vestia o rastreador, recebia as instruções e realizava o 


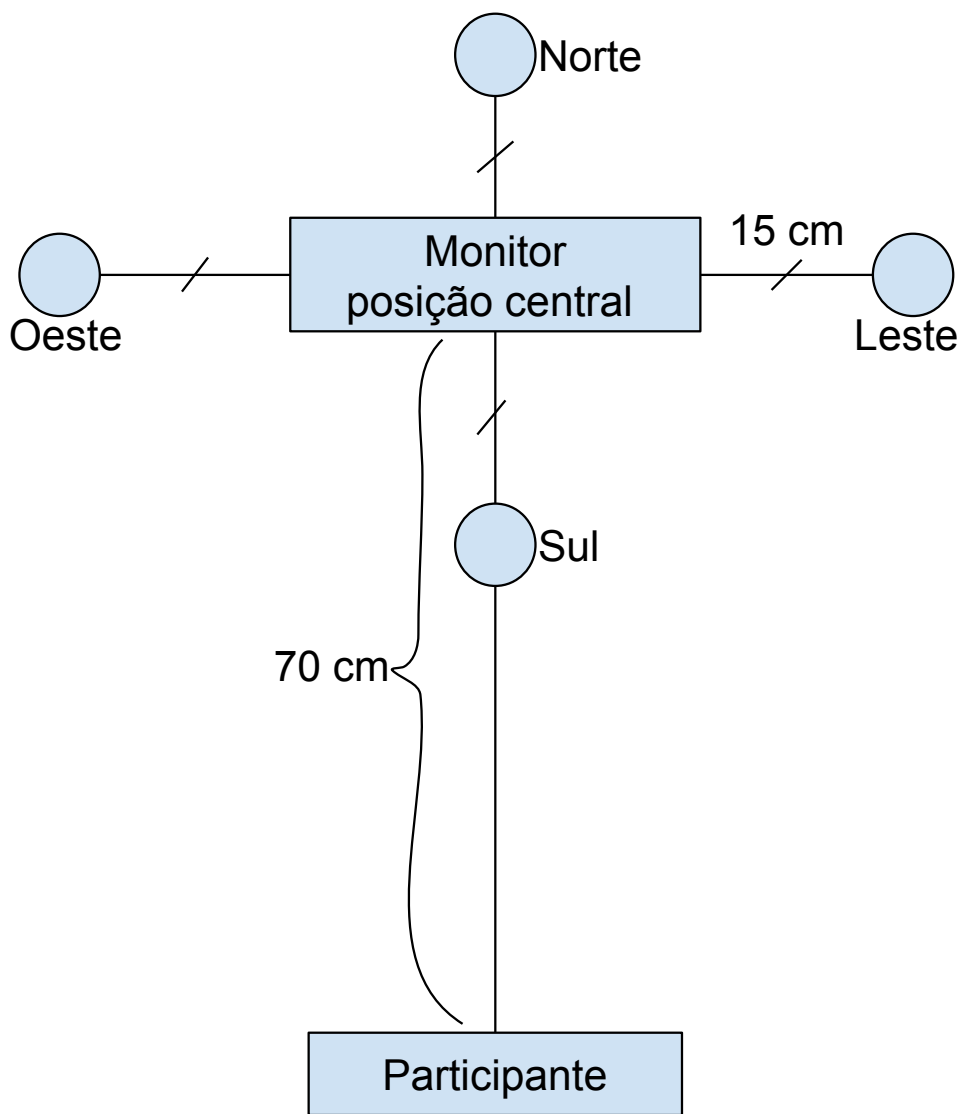

Figura 4.2: Diagrama das posições onde coletas foram realizadas em relação ao monitor. Não está em escala.

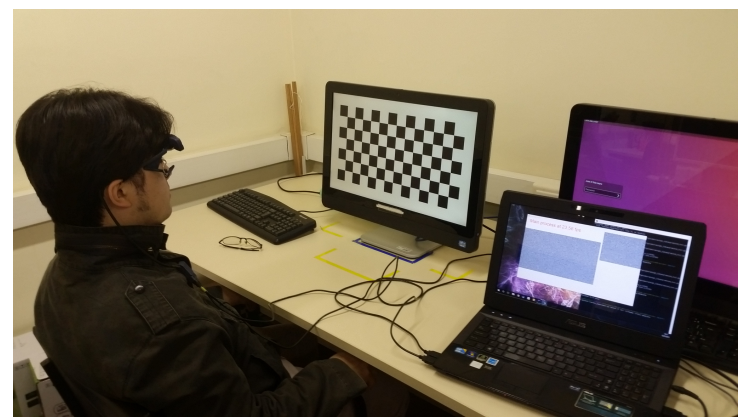

(a) Coleta na etapa inicial de grade quadricular.

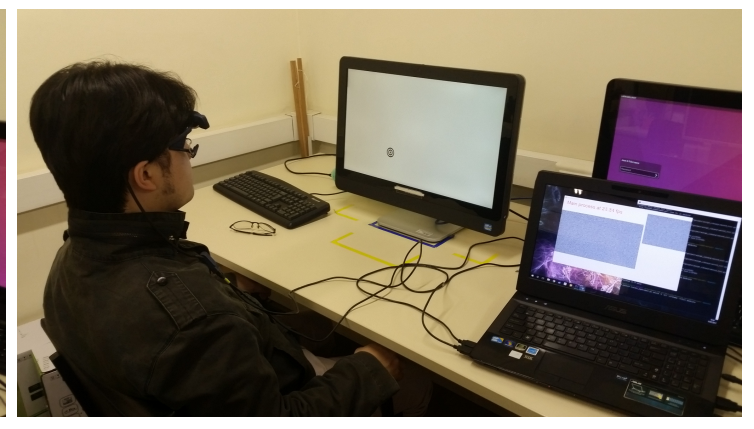

(b) Coleta em um dos alvos próximos do centro.

Figura 4.3: Participante realizando o experimento na posição central.

experimento. Cada participante fazia, em sequência, um total de cinco coletas de dados, sob condições de posicionamento diferentes (como mostradas na Figura 4.2):

1. Na condição central o usuário está posicionado de frente ao monitor, a aproximadamente $70 \mathrm{~cm}$ de distância, e era instruído a tentar se manter parado.

2. Na posição norte, o monitor era movido $15 \mathrm{~cm}$ para o norte a partir da posição central, ou seja, mais longe do usuário.

3. Na posição sul, o monitor era movido $15 \mathrm{~cm}$ para o sul a partir da posição central, ou seja, mais perto do usuário. 

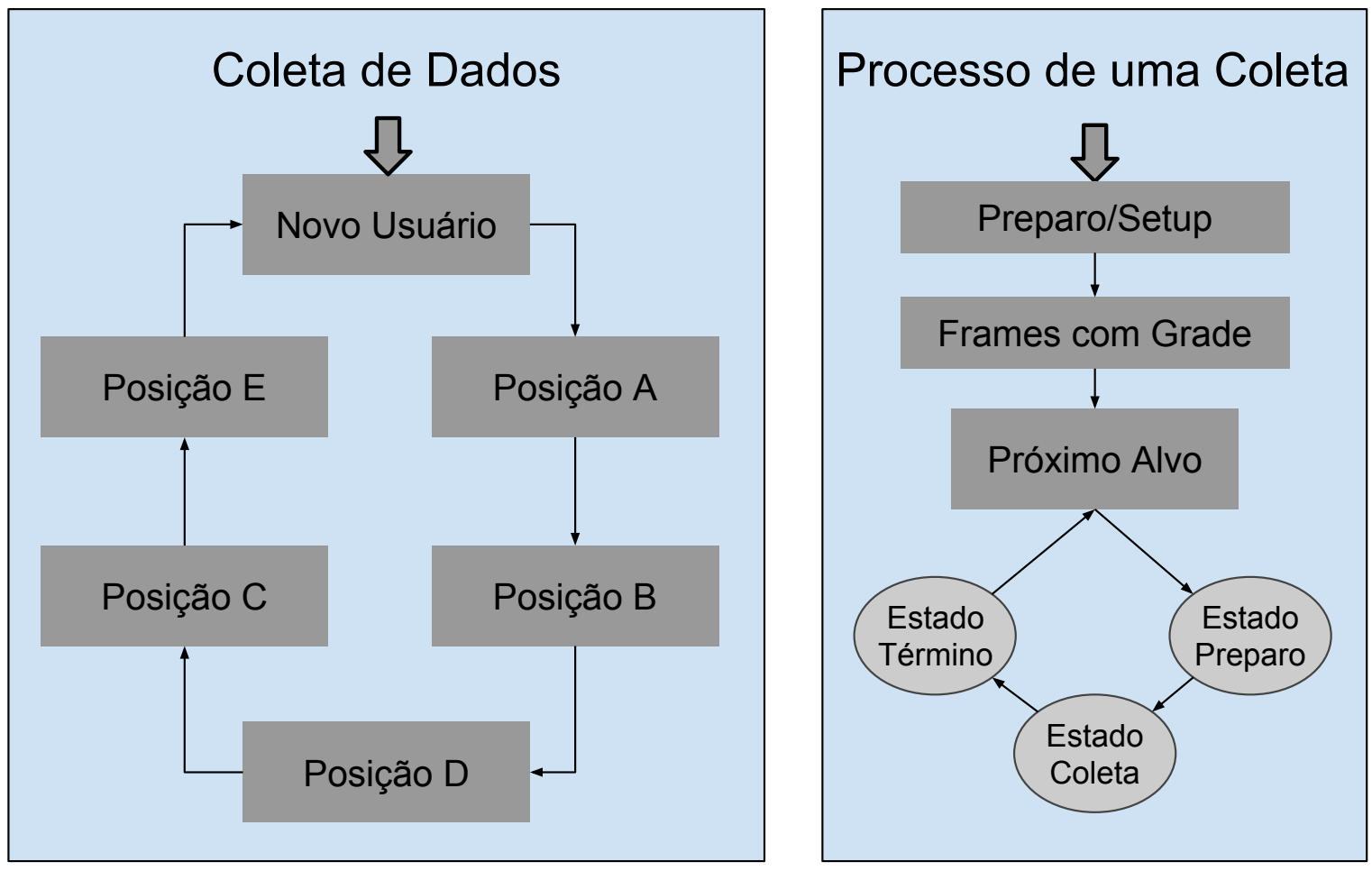

Figura 4.4: Diagrama do fluxo da aquisição de dados do experimento; e o diagrama do processo de uma coleta específica.

4. Na posição leste, o monitor era movido $15 \mathrm{~cm}$ para a direita da posição central.

5. Na posição oeste, o monitor era movido $15 \mathrm{~cm}$ para a esquerda da posição central.

As coletas não foram feitas numa ordem específica de posições, por isso a imagem 4.4 mostra nomes A até E para as posições ao invés dos nomes detalhados acima.

Quanto ao processo de uma coleta especifica, a imagem 4.4 também mostra o fluxo deste procedimento. No início há uma etapa de preparo onde a coleta ainda não iniciou, e movemos o monitor para a posição certa de tal coleta assim como deixamos o participante se preparar e vemos se não há nenhum problema com as câmeras.

Após isso, o monitor mostra uma grade $16 \times 9$ quadriculada por 5 quadros. A informação dessas grades, detectadas com a câmera da cena, são usadas para calibrar tal câmera e permitir a estimação de pose do usuário. Depois disso, 35 alvos pontuais são mostrados em sequência no monitor. A Figura 4.3a mostra um dos participantes vendo a grade quadriculada no inicio da coleta, enquanto que 4.3b mostra ele já vendo um dos alvos. Além disso, a Figura 4.5 mostra a disposição dos alvos, com os de borda verde sendo aqueles cujos dados serão usados para a calibração da estimação do olhar. O processo de aquisição, como explicado aos usuários, era fixar o olhar no centro de um alvo até ele desaparecer, mostrando o próximo alvo. Isso era repetido até passarem os 35 pontos. Essa sequência de alvos foi escolhida para ser fácil de explicar aos participantes, e para minimizar o movimento da sacada que os usuários devem fazer para focarem em um alvo ao ocorrer a troca, e com isso minimizar fadiga dos participantes durante o experimento. A coleta grava o vídeo da câmera do olho e da cena enquanto passa os marcadores pelo monitor, mas ela também usa informações da câmera da cena para determinar se o alvo atual é visível e qual é sua posição.

Cada alvo na tela tem um comportamento seguindo os estados ilustrados na Figura 4.6. Inicialmente o alvo está em um modo de "preparo", no qual ele está aparecendo no monitor mas o sistema não coleta seus 


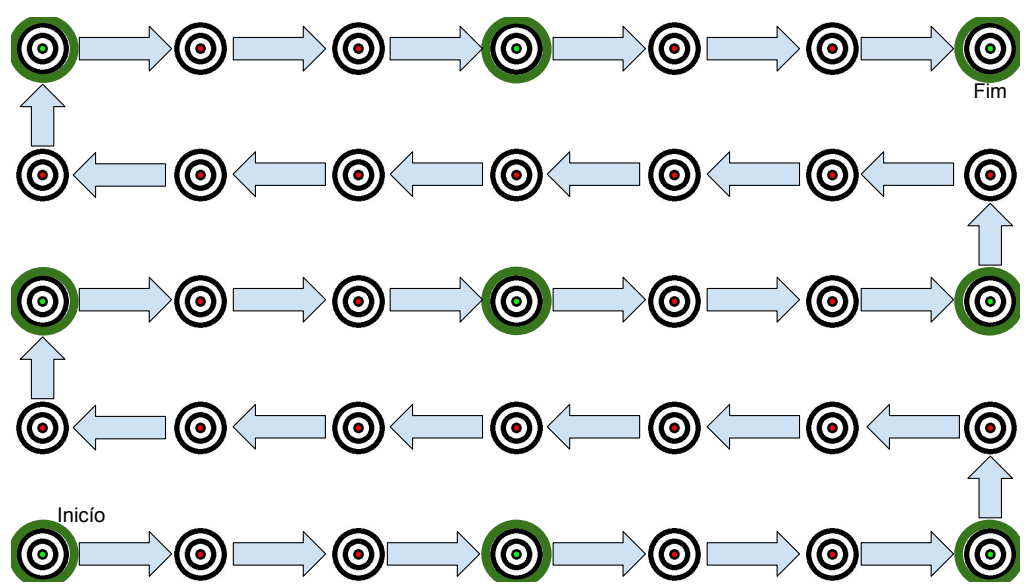

Figura 4.5: Alvos no monitor para a aquisição de dados. Alvos com borda verde foram usados para a calibração da estimação do olhar. As setas indicam a sequência de alvos como foram mostrados ao usuário. Tanto as bordas verdes como as setas e os textos foram adicionados na imagem aqui para facilitar a visualização e não eram mostradas ao usuário durante o experimento.

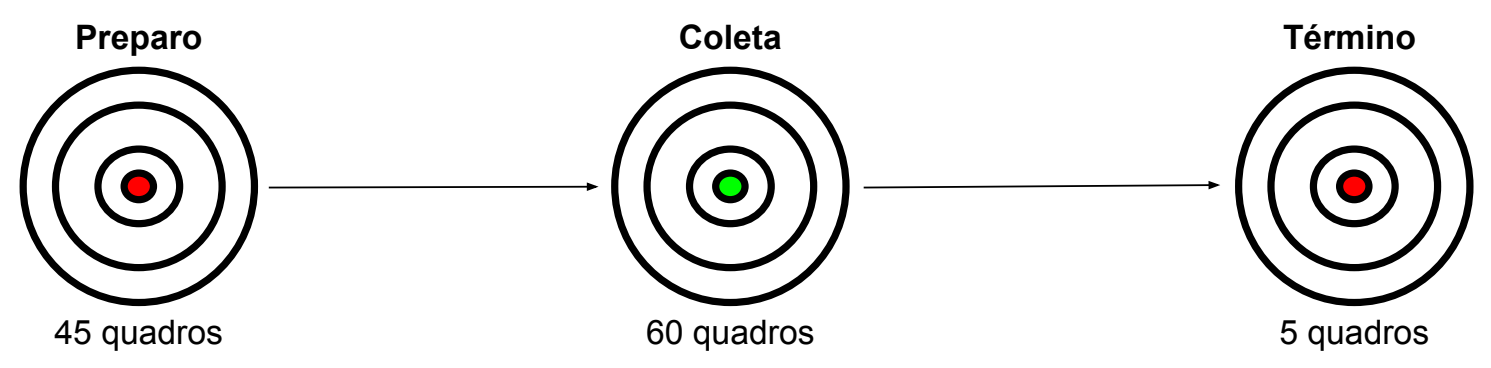

Figura 4.6: Progresso dos estados de um alvo durante uma coleta.

dados. Nesse estado o usuário tem tempo para se preparar para focar este novo alvo, e para piscar o olho. Após 45 quadros (aproximadamente 2 segundos), o alvo muda para o estado de coleta, ou amostragem dos dados. Serão os dados gravados durante os 60 quadros desse estado que serão usados pelos algoritmos de rastreamento e consequentemente pela nossa análise de dados. Caso o alvo não seja localizado durante esse estado, a aquisição dos 60 quadros é interrompida enquanto espera detectar o alvo e durante esse período a "luz" interna do alvo volta a ficar vermelha. Finalmente, durante os 5 quadros finais nenhum dado é coletado, e o alvo desaparece para mostrar o próximo marcador.

Pela instruções recebidas e indicação da cor interna do alvo o participante consegue diferenciar os estados e saber quando pode piscar ou não. Idealmente os usuários não deveriam piscar durante o estado de amostragem dos dados, mas não enforçamos essa condição. O processo inteiro de coleta de um participante, incluindo tempo para explicar o processo levava 16 minutos em média. Entretanto o experimento inteiro levou alguns dias ao longo de uma semana para terminar devido a conseguir chamar voluntários e marcar horários compatíveis para realizar a coleta.

Para a aquisição de dados, usamos nossa própria ferramenta, desenvolvida como parte da plataforma de experimentos. Ela foi feita baseando-se no Pupil Capture, o software da Pupil-Labs que permite o usuário ver o rastreador de olhar Pupil executar em tempo-real, assim como permite calibrar a estimação de olhar do Pupil e gravar os vídeos das câmeras para visualização posterior. A nossa ferramenta abre 2 janelas gráficas, uma para o usuário (mostrando a grade quadriculada e os alvos no monitor do experimento), e outra para o pesquisador, num monitor secundário, mostrando os vídeos sendo gravados pelas câmeras em tempo real. Com um sinal do pesquisador (depois de uma confirmação com o usuário), 
a coleta é iniciada seguindo o protocolo explicado acima.

Essa necessidade do sinal do pesquisador para iniciar o processo da coleta, mesmo quando a ferramenta de gravação já está sendo executada, é importante pois permite que o pesquisador veja que as imagens das câmeras não estão com nenhum problema, assim como permite ajustar as câmeras do Pupil-Labs e ver o resultado em tempo real antes de começar uma coleta de fato. Também usamos esse período para explicar o processo da coleta para o usuário e permitir que ele se acostume um pouco com o óculos. Ao executar a ferramenta de gravação o pesquisador indica qual coleta está sendo feita (qual usuário e posição), e o programa usa isso para salvar os dados da coleta.

\subsection{Processamento de Dados}

O processamento de dados é uma etapa automática (em grande parte) mas que consome muito tempo para completar. Ela consiste em executar os algoritmos de rastreamento do olhar em cada coleta, para cada configuração de resolução e frequência, sub-amostrando o vídeo como necessário para atingir essa configuração. Optamos por sub-amostragem em vez de definir a resolução ou frequência da câmera pois permite que com uma só coleta possamos executar diversos casos de teste. Os dados gerados durante esse processo, tais como marcação de tempo do quadro, posição do alvo, centro da pupila e estimação do olhar, são gravados em arquivos binários para análise posterior.

No geral, temos centenas de casos de teste, variando os seguintes parâmetros:

- Usuário: O participante dessa coleta, identificado por uma palavra (pode ser desde seu nome a uma unica letra).

- Posição: A posição da coleta, identificada como centro, leste, oeste, norte e sul (ou de forma abreviada, C, L, O, N e S, respectivamente).

- Resolução: A resolução das imagens do olho. As possibilidades são: 480 linhas (original), 240, 120 e 60 linhas. O proporção da imagem era mantida em 4 colunas para 3 linhas.

- Frequência: A frequência da câmera do olho. O conjunto de valores possíveis é 30 (original), 15, 10 e 5 quadros por segundo.

- Algoritmo: O algoritmo de rastreamento usado. Os algoritmos Starburst, ITU e Pupil foram descritas no Capítulo 3.2.

Totalizando são $11 \times 5 \times 4 \times 4 \times 3=2640$ casos de teste, mas como processamos e gravamos os dados para cada caso juntando os resultados dos algoritmos num único arquivo, na prática temos $11 \times 5 \times 4 \times 4=880$ casos salvos separadamente em arquivos pela ferramenta de processamento.

A Figura 4.7 exemplifica o fluxo da ferramenta de processamento, para todos os casos de teste de um usuário. Os passos gerais da ferramenta são explicados a seguir:

1. Pré-processamento das Cenas: como os vídeos da cena não são alterados com a resolução dos casos de teste, tais vídeos são processados antes e seus dados copiados para cada caso de teste desse usuário/posição a fim de reduzir a quantidade de processamento necessária nesse passo.

2. Calibração da Câmera da Cena: com as cenas processadas, os dados das grades quadriculadas no inicio de cada coleta de um usuário são usados para calibrar a câmera da cena para ele. Somente grades das posições centro, leste e oeste são usadas pois usando a norte/sul aumenta o erro de re-projeção da calibração por causa da geometria da cena. Como a calibração da câmera é feita para cada usuário e é um procedimento rápido, a ferramenta testa todas possibilidades de 


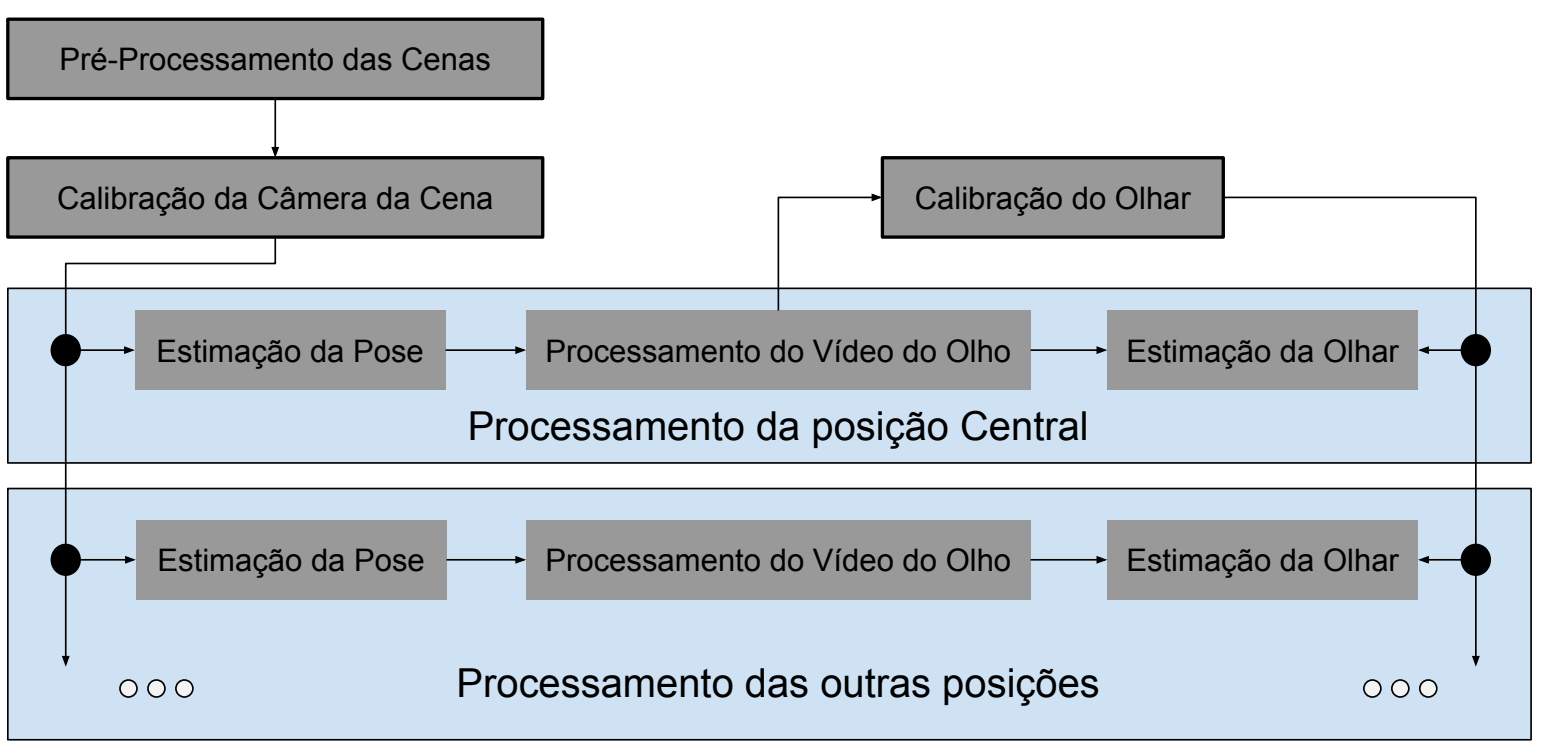

Figura 4.7: Diagrama do fluxo de processamento dos dados das coletas.

calibração alterando a grade usada de cada posição (já que temos 5 cinco grades em cada posição), e escolhe aquela com o menor erro de re-projeção. Após calibrar a câmera, os parâmetros intrínsecos calculados são passados para cada caso de teste de tal usuário.

3. Processamento da posição Central: Processamos as coletas centrais antes das outras pois usamos a calibração da estimação do olhar da posição central para estimar o olhar nas outras posições, e com isso simular que o usuário calibrou o rastreador de olhar numa posição "normal" e depois se moveu. Portanto nesse passo a ferramenta não só calibra a estimação do olhar como já processa os casos de teste das posições centrais. Após o processamento, os parâmetros calculados do mapeamento do olhar são passados para os outros casos de teste com mesmo usuário, resolução e frequência, mas em outras posições.

4. Processamento das outras posições: Finalmente, todos os casos de teste restantes (das posições norte, sul, leste e oeste) são processados.

Além dos passos gerais da ferramenta, a Figura 4.7 também mostra as etapas de processamento de um caso de teste. A ferramenta realiza essas etapas para cada caso de teste seguindo seu fluxo. Essas etapas são:

1. Pré-processamento da Cena: esse passo é executado separadamente pela etapa de mesmo nome da ferramenta, e portanto nunca é executado junto com o processamento geral de um caso de teste. Ele consiste em ler o vídeo da cena, guardando as grades quadriculadas encontradas, assim como o alvo e marcadores do monitor detectados em cada amostra (cada quadro de amostragem, como explicado em 4.1.3).

2. Estimação de Pose: com os parâmetros intrínsecos da câmera, esse passo estima a pose do usuário em cada amostra a partir dos dados dos marcadores do monitor. Como isso depende da calibração da câmera da cena que depende de dados de diversas coletas do usuário, a ferramenta faz um pré-processamento das cenas.

3. Processamento do Vídeo do Olho: esse passo processa o vídeo do olho do caso de teste, fazendo subamostragem como necessário e executando os três algoritmos de rastreamento do olhar para 
cada quadro. Tais dados do olho são salvos numa determinada amostra do caso de acordo com as marcações de tempo do quadro do olho e da amostra (que vieram do quadro da cena), efetivamente sincronizando os dados dos quadros do olho com os da cena gravadas num mesmo momento. Como as taxas de quadros das câmeras da cena e do olho diferem, não temos um mapeamento 1 : 1 de seus quadros, por isso sincronizamos com as marcações temporais dos quadros, e portanto uma amostra pode ter zero ou até mais de um quadro de olho relacionado.

4. Calibração do Olhar: esse passo usa os dados dos olhos de alvos específicos (definidos em 4.1.3) e os dados de onde o usuário deveria estar olhando para calibrar a estimação do olhar, definindo os parâmetros da função de mapeamento de posição da pupila para posição na cena em que o usuário está olhando. Só executamos isso para as coletas centrais, e passamos o mapeamento calculado para as outras posições.

5. Estimação do Olhar: com o mapeamento da estimação do olhar, esse passo finalmente completa o processamento de um caso de teste calculando onde que o usuário estava olhando em cada quadro de olho em cada amostra.

O processamento de todas as coletas de um único usuário na máquina usada para o experimento foi necessário em média 20 minutos. Para processar todos dados do experimento foram necessários 220 minutos (3 horas e 40 minutos). A ferramenta de processamento funciona de forma paralelizada, executando cada caso de teste (da etapa atual de processamento) independentemente em um dos núcleos de processamento do computador. Portanto, sem essa otimização, a ferramenta deverá levar significativamente mais tempo para completar o processamento. Dizemos que essa é uma etapa praticamente automática pois basta o pesquisador executar a ferramenta de processamento passando alguns parâmetros que definem quais coletas devem ser processadas.

A análise dos resultados, como apresentada na seção 3.4 do capítulo anterior, é realizada por outra ferramenta desenvolvida na plataforma de experimentos - a ferramenta de análise. Esse programa lê os dados salvos das coletas processadas, fazendo a análise estatística dos resultados da estimação do olhar variando parâmetros como resolução e frequência da câmera. Após fazer essas análises, a ferramenta gera os gráficos e tabelas relacionados para apresentar os resultados do experimento de forma intuitiva. As tabelas e gráficos apresentando resultados do experimento deste trabalho foram geradas desta forma.

\subsubsection{Calibração da Estimação do Olhar}

Os algoritmos de rastreamento do olhar detectam a pupila. Para determinar para onde o usuário está olhando, ou seja, para estimar o olhar, precisamos relacionar esse dado com a posição do ponto que ele está olhando numa superfície. Usualmente rastreadores usam como superfície de visão o monitor sendo usado pelo dispositivo do rastreador. No entanto, rastreadores vestíveis com câmeras da cena tendem a usar a imagem da câmera da cena, que tem uma grande intersecção com a visão do usuário independentemente de onde ele está olhando, como superfície de visão para a estimação do olhar. Neste trabalho repetimos esse método, estimando o olhar dos participantes em pontos nas imagens da cena.

A calibração da estimação do olhar é o processo no qual determinamos a homografia entre pontos no espaço da imagem do olho para pontos no espaço da imagem da cena. Ou seja, o mapeamento de um centro da pupila para o ponto de olhar. Para isso usamos neste trabalho o mesmo método usado pelo Pupil (em [KPB14]). Esse método define a homografia como um polinômio bi-variado de segundo grau com sete coeficientes que mapeia pontos na imagem do olho para pontos na imagem da cena. Os coeficientes são determinados usando os dados dos pontos de calibração da coleta (os pontos verdes em 4.5). 
Temos para esses alvos a posição deles como detectada na imagem da cena, e a posição da pupila nos quadros correspondentes do olho, lembrando que o usuário em tal momento deveria estar olhando para esse alvo. Portanto temos um conjunto de dados que relaciona pontos entre os dois espaços de imagens. Esse conjunto então é usado para determinar os coeficientes do polinômio de mapeamento do olhar.

Na prática temos esses dados para os 35 alvos de uma coleta. Usamos só 9 pontos para a calibração, justamente os cantos e o centro, pois eles já provêm um bom suporte para a região do monitor na imagem da cena para calibrar a estimação. Além disso, mais pontos poderiam causar overfitting dos dados, e assim temos uma boa proporção de aproximadamente 3 pontos "normais" (não usados para calibração) que usamos somente para determinar o erro da estimação do olhar para cada ponto de calibração.

Após a calibração, a estimação do olhar em qualquer quadro do vídeo é uma operação simples: basta passar o centro da pupila (que foi detectado no quadro da imagem do olho) para este polinômio, e ele devolve a posição estimada do olhar na imagem da cena.

\subsubsection{Parâmetros dos Algoritmos de Rastreamento do Olhar}

Neste experimento, os parâmetros dos algoritmos foram definidos por testes funcionais realizados manualmente para a resolução original (480p) e depois calculados seguindo a proporção para as outras resoluções do experimento. Como os algoritmos usam pouca informação do quadro anterior para processar um quadro, julgamos que não era necessário alterar os parâmetros de acordo com a frequência da câmera. Também mantivemos idênticos os parâmetros de um algoritmo em uma resolução para todos usuários e posições de coleta avaliadas.

\begin{tabular}{r|cccc}
\hline Parâmetro & $\mathbf{4 8 0 p}$ & $\mathbf{2 4 0 p}$ & $\mathbf{1 2 0 p}$ & $\mathbf{6 0 p}$ \\
\hline Limiar do Gradiente & & 20 & \\
\hline Número de Raios & 20 & 18 & 16 & 12 \\
\hline Número Minimo de Pontos de Borda & 3 & 3 & 2 & 2 \\
\hline Tamanho da Janela de RC & $170 \times 130$ & $90 \times 65$ & $45 \times 34$ & $24 \times 18$ \\
\hline Área máxima de uma RC & \multicolumn{5}{|c}{20} \\
\hline
\end{tabular}

(a) Parâmetros do Starburst.

\begin{tabular}{r|cccc}
\hline Parâmetro & $\mathbf{4 8 0 p}$ & $\mathbf{2 4 0 p}$ & $\mathbf{1 2 0 p}$ & $\mathbf{6 0 p}$ \\
\hline Limiar da Pupila & \multicolumn{4}{|c}{60} \\
\hline Intervalo de Tamanho da Pupila & {$[30,70]$} & {$[15,40]$} & {$[7,20]$} & {$[3,10]$} \\
\hline Limiar de RCs & \multicolumn{4}{|c}{210} \\
\hline Intervalo de Tamanho de RCs & {$[4,15]$} & {$[3,10]$} & {$[2,5]$} & {$[1,3]$} \\
\hline
\end{tabular}

(b) Parâmetros do ITU.

\begin{tabular}{r|cccc}
\hline Parâmetro & $\mathbf{4 8 0 p}$ & $\mathbf{2 4 0 p}$ & $\mathbf{1 2 0 p}$ & $\mathbf{6 0 p}$ \\
\hline Tamanho Mínimo de Contorno & 60 & 30 & 15 & 8 \\
\hline Intervalo de Tamanho da Pupila & {$[40,150]$} & {$[20,65]$} & {$[12,30]$} & {$[3,15]$} \\
\hline Intervalo de Tamanho do Filtro & {$[100,400]$} & {$[50,200]$} & {$[25,100]$} & {$[13,50]$} \\
\hline
\end{tabular}

(c) Parâmetros do Pupil.

Tabela 4.1: Parâmetros dos algoritmos usados no experimento. 
As tabelas em 4.1 apresenta os parâmetros usado nos algoritmos durante o experimento. As tabelas 4.1a, 4.1b e 4.1c mostram os parâmetros do Starburst, ITU e Pupil, respectivamente. O parâmetro de Ponto Inicial do Starburst foi definido como o centro da imagem na resolução em questão, e tanto no Starburst como no ITU o número de reflexões na córnea foi definido como um.

\subsection{Tecnologias Usadas}

Para a execução de todos passos do experimento usamos vários softwares diferentes, e até hardware específicos (que foram detalhados na subseção 4.1.1). Nesta seção iremos detalhar as tecnologias utilizadas para a implementação do plataforma de testes.

\subsubsection{Linguagens de Programação}

Alguns algoritmos de rastreadores de olhar estão implementados, ou têm parte implementada em $\mathrm{C} / \mathrm{C}++$ e outras partes em Python. O uso de $\mathrm{C} / \mathrm{C}++$ se deve ao fato que os algoritmos são computacionalmente pesados - usando essas linguagens a execução deles aproveita melhor os recursos do computador, melhorando o tempo de processamento.

Tanto o sistema para coleta de dados do experimento quanto o de processamento e análise de dados foram implementados em Python. Como nesta linguagem o foco é simplicidade do código e facilidade de implementação, e não tempo de processamento, Python é mais indicada que C++ para essa tarefa.

\subsubsection{Bibliotecas}

A principal biblioteca usada é OpenCV $\mathbf{C V}^{1}$. Trata-se de uma biblioteca open-source multi-plataforma de aprendizagem e visão computacional, com muitas funcionalidades relativas a essas áreas, além de rotinas de cálculo matricial, álgebra linear e outras utilidades usualmente necessárias para criação de programas nessas áreas. Ela já existe desde o ano 2000, é ativamente melhorada pela sua equipe de desenvolvimento e pela comunidade e é frequentemente usada por estudantes, pesquisadores e pela indústria para criação de programas que usem aprendizagem ou visão computacional. Esta biblioteca foi originalmente implementada em $\mathrm{C}$, mas atualmente é feita em $\mathrm{C}++$ com interfaces para diversas outras linguagens, incluindo Python. Todos os algoritmos avaliados usam essa biblioteca.

Para o processamento de dados, um conjunto de bibliotecas chamado Pylab ${ }^{2}$, que consiste nas bibliotecas NumPy, SciPy e Matplotlib, foi usado. Essas bibliotecas introduzem diversas funcionalidades para cálculo numérico, estatístico e científico em Python, além de rotinas para geração de gráficos e tabelas para análise de dados. Elas são bibliotecas open-source multi-plataforma feitas em Python, com partes de custo computacional alto implementadas em C. Essas bibliotecas também são frequentemente usadas por estudantes, pesquisadores e pela indústria, além de serem compatíveis com OpenCV, permitindo o uso de tipos (como matrizes) de uma em rotinas da outra.

A biblioteca psutil ${ }^{3}$ para monitoramento do uso de recursos do computador em Python também foi usada para medir tempo gasto dos algoritmos. Usamos a biblioteca PySFML ${ }^{4}$ para a criação de interfaces gráficas para a gravação e visualização das coletas. Essa biblioteca é um wrapper da biblioteca SFML, feita em $\mathrm{C}++$, para Python. Ambas compartilham a mesma interface, são open-source e multi-plataforma. A SFML é uma biblioteca de multimídia, provendo uma interface simples orientada

\footnotetext{
${ }^{1}$ http://opencv.org. Último acesso: 24 de Novembro de 2015

${ }^{2}$ http://scipy.org/. Último acesso: 3 de Dezembro de 2015

${ }^{3}$ https://pypi.python.org/pypi/psutil. Último acesso: 6 de Julho de 2017

${ }^{4}$ https://python-sfml.org/index.html. Último acesso: 10 de Julho de 2017
} 
a objetos aos componentes do computador relacionados com multimídia, como o sistema operacional, janelas, gráficos (renderização), áudio e rede.

Especificamente para a gravação das coletas, também usamos a biblioteca pyuvc ${ }^{5}$. Esta biblioteca é uma wrapper para a libuvc em Python criado pela equipe da Pupil-Labs, usado no seu software do Pupil. Ela também é open-source, e no começo desse ano finalmente se tornou multiplataforma, podendo ser usada em Windows além de Linux. A libuvc é uma biblioteca multi-plataforma para uso de dispositivos USB de vídeo, como as câmeras usadas pelo rastreador. Optamos por usar essa biblioteca para adquirir imagens das câmeras para gravação ao invés de usar o OpenCV, pois essa era a mesma biblioteca que o Pupil usa para adquirir as imagens. Além disso, pelos nossos testes a eficiência da pyuvc era melhor que o OpenCV para usar a câmera, permitindo adquirir e gravar mais quadros por segundo.

${ }^{5}$ https://github.com/pupil-labs/pyuvc. Último acesso: 10 de Julho de 2017 


\section{Capítulo 5}

\section{Resultados}

Este capítulo apresenta os resultados do nosso experimento.

As Figuras 5.1, 5.2 e 5.3 mostram a média e desvio padrão do erro da estimação do algoritmo Pupil, ITU e Starburst, respectivamente, em graus de ângulo visual para cada configuração de frequência e resolução na posição central de coleta. Podemos ver que reduzindo a resolução afeta pouco a precisão e acurácia nos três algoritmos. O ITU até melhora um pouco sua detecção com cada diminuição de resolução, mantendo-se viável até em 60p. O Pupil manteve praticamente a mesma precisão nas três maiores resoluções aumentando em torno de $0.25^{\circ}$ de erro em $60 \mathrm{p}$, enquanto o Starburst além de manter a mesma precisão em 240p só teve um leve aumento do erro de $0.3^{\circ}$ de ângulo visual de 240p para 120p, e um aumento de $2^{\circ}$ para $60 \mathrm{p}$. Além disso, alterar a frequência praticamente não afeta o desempenho de uma configuração a outra de frequência tivemos no geral em torno de $<0.1^{\circ}$ de diferença na média e desvio padrão do erro de estimação do olhar. Isso se deve ao fato que os três algoritmos são detectores do olho, e não rastreadores de fato, como explicado no capítulo 3.2. Por serem detectores, o resultado do algoritmo em um quadro tem pouco (ou nenhum) impacto na detecção da pupila no próximo quadro, já que o algoritmo é executado novamente para detectar a pupila em um novo quadro. Portanto a distância temporal entre quadros pouco importa para a estimação do olhar com esses algoritmos.

Com os resultados apresentados nas Figuras 5.16, 5.17 e 5.18 podemos notar o que já era esperado pelo fato que os três algoritmos são detectores: diminuindo a frequência causa uma diminuição proporcional no consumo de CPU (de 30 para 15 quadros por segundo resulta no consumo indo de 10 para 5 , por exemplo). Alterar a resolução tem efeito proporcional similar no consumo de energia. Analisando os resultados de desempenho e consumo de forma conjunta, notamos os seguintes fatos:

- O ITU se mostrou capaz de operar em resoluções de até $60 \mathrm{p}$, melhorando a precisão em $0.3^{\circ}$ de ângulo visual e diminuindo o consumo de energia em $95 \%$.

- O Pupil se mostrou capaz de operar em 120p sem afetar a precisão, mas economizando $91 \%$ de energia.

- O Starburst se mostrou capaz de operar em 120p, também sem afetar a precisão, economizando somente $4 \%$ de energia.

- Os três algoritmos podem reduzir sua frequência e diminuir seu consumo por um fator proporcional sem afetar o desempenho.

Um ponto estranho visto em 5.18 é que o Starburst manteve praticamente o mesmo consumo entre resoluções diferentes. Acreditamos que isso ocorre devido ao próprio funcionamento do Starburst, executando um número variável de iterações até conseguir determinar o centro da pupila, faz ele aumentar seu 


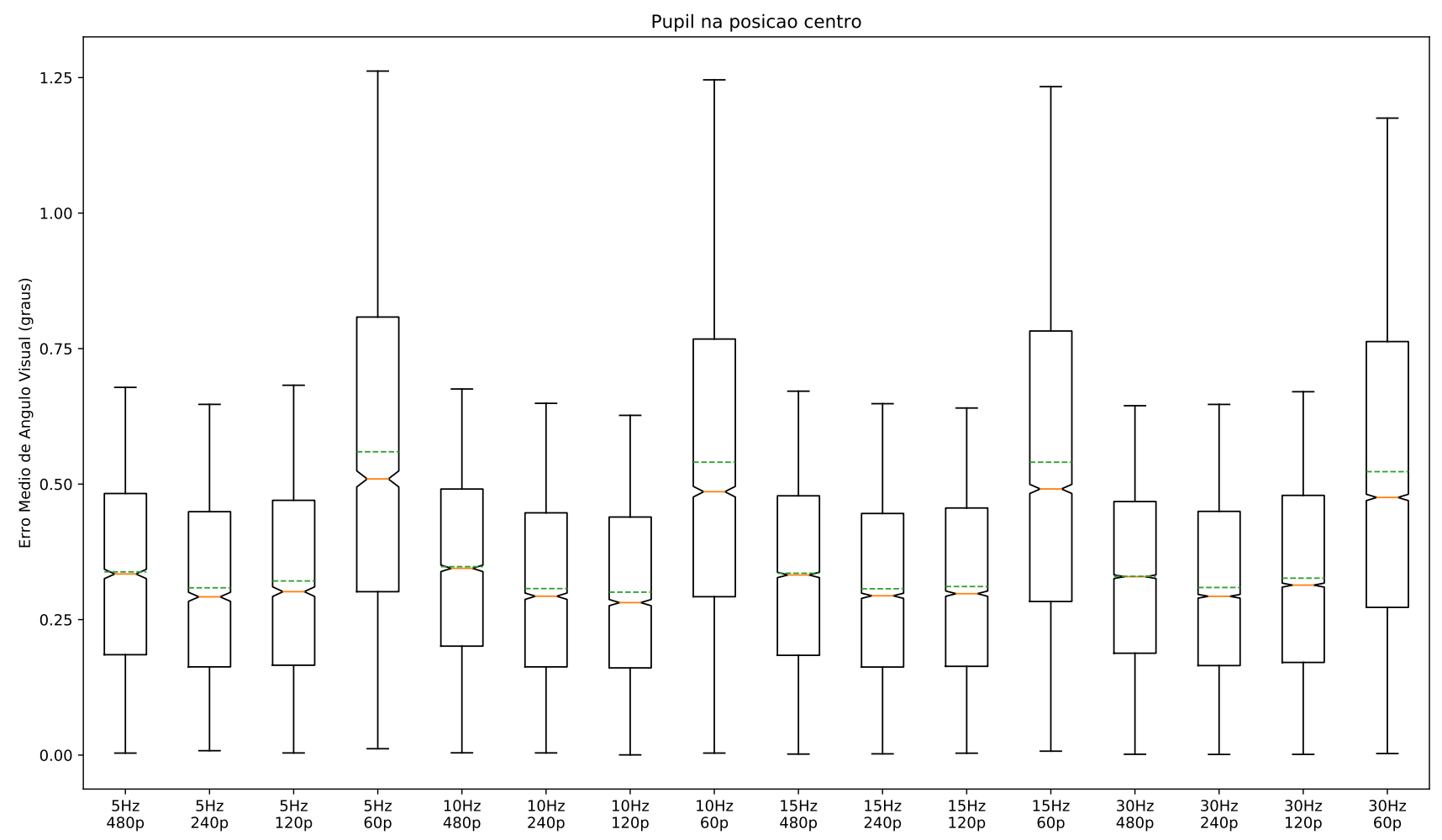

(a) Gráfico dos resultados da análise. A linha laranja é a mediana e seu intervalo de confiança, enquanto a linha pontilhada verde é a média dos dados.

\begin{tabular}{ccccc}
\hline Pupil / centro & \multicolumn{4}{c}{ Resolucao } \\
\cline { 2 - 5 } FPS & $\mathbf{4 8 0 p}$ & $\mathbf{2 4 0 p}$ & $\mathbf{1 2 0 p}$ & $\mathbf{6 0 p}$ \\
\hline 5 & $0.34( \pm 0.18)$ & $0.31( \pm 0.17)$ & $0.32( \pm 0.18)$ & $0.56( \pm 0.32)$ \\
\hline 10 & $0.35( \pm 0.18)$ & $0.31( \pm 0.17)$ & $0.30( \pm 0.17)$ & $0.54( \pm 0.31)$ \\
\hline 15 & $0.34( \pm 0.18)$ & $0.31( \pm 0.17)$ & $0.31( \pm 0.17)$ & $0.54( \pm 0.31)$ \\
\hline 30 & $0.33( \pm 0.17)$ & $0.31( \pm 0.17)$ & $0.33( \pm 0.18)$ & $0.52( \pm 0.30)$ \\
\hline
\end{tabular}

(b) Tabela de valores da análise. Cada célula indica a média ( \pm o desvio padrão) dos resultados.

Figura 5.1: Análise de erro médio do Pupil para cada configuração de frequência $\times$ resolução na posição central (de calibração).

custo computacional quanto mais dificuldade encontra para encontrar a pupila. Em outras palavras, caso tenha problemas em encontrar a pupila (por causa de parâmetros não-ideais nessa situação) o algoritmo irá gastar mais processamento para tentar chegar num resultado adequado.

Notamos nos dados dois padrões de médias de erros maiores do que o resto:

- Starburst em 60p: O Starburst em todas posições tem erro médio em 60p em torno de $2^{\circ}$ de erro, enquanto nas outras resoluções é em torno de $1^{\circ}$. Atribuímos isso à instabilidade deste algoritmo, e parâmetros de configuração inadequados.

- Posição Sul: Também pode-se notar que todos os algoritmos, independente da resolução e frequên- 


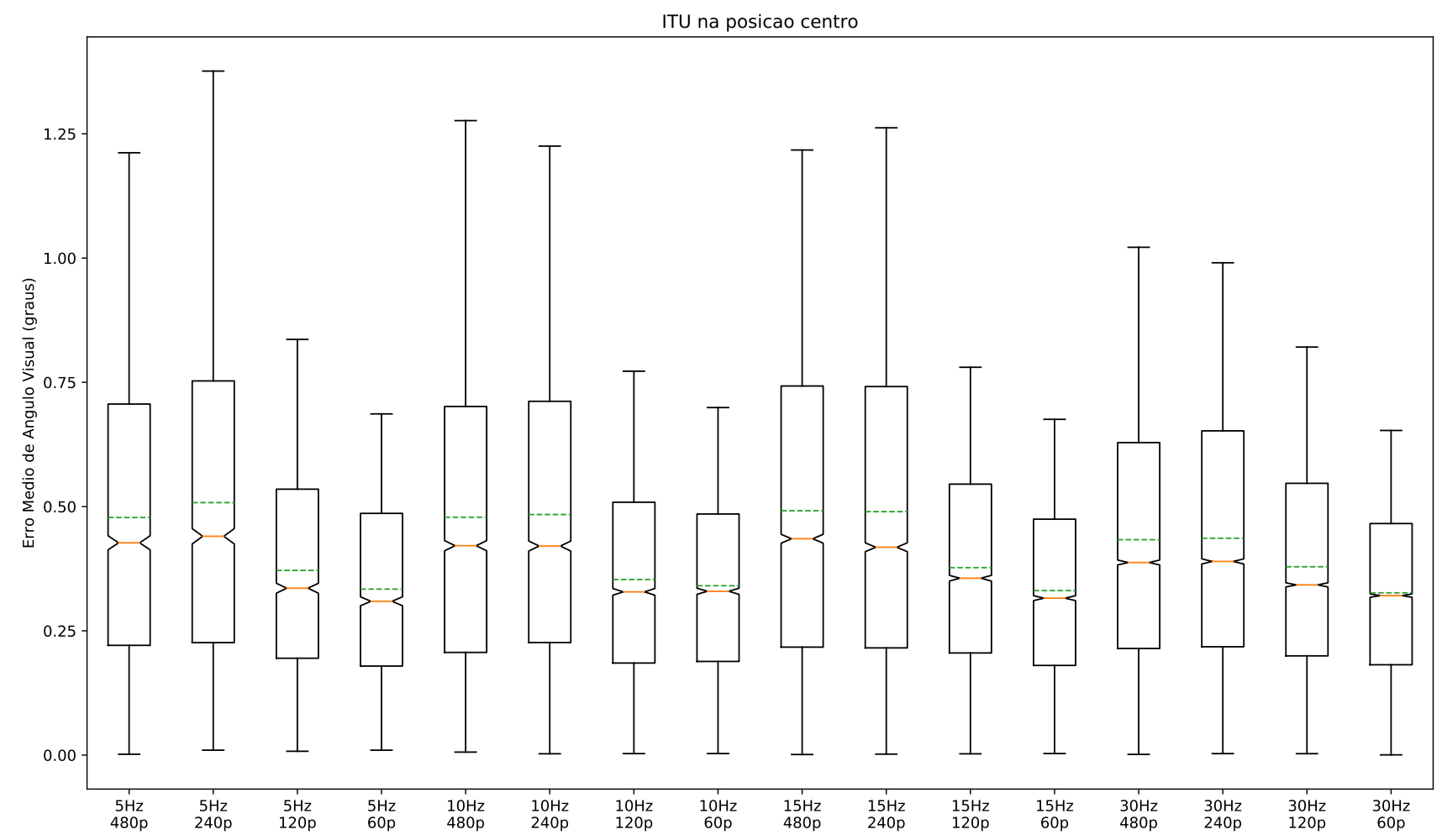

(a) Gráfico dos resultados da análise. A linha laranja é a mediana e seu intervalo de confiança, enquanto a linha pontilhada verde é a média dos dados.

\begin{tabular}{ccccc}
\hline ITU / centro & \multicolumn{4}{c}{ Resolucao } \\
\cline { 2 - 5 } FPS & $\mathbf{4 8 0 p}$ & $\mathbf{2 4 0 p}$ & $\mathbf{1 2 0 p}$ & $\mathbf{6 0 p}$ \\
\hline 5 & $0.48( \pm 0.30)$ & $0.51( \pm 0.34)$ & $0.37( \pm 0.22)$ & $0.33( \pm 0.18)$ \\
\hline 10 & $0.48( \pm 0.32)$ & $0.48( \pm 0.31)$ & $0.35( \pm 0.20)$ & $0.34( \pm 0.18)$ \\
\hline 15 & $0.49( \pm 0.32)$ & $0.49( \pm 0.32)$ & $0.38( \pm 0.21)$ & $0.33( \pm 0.18)$ \\
\hline 30 & $0.43( \pm 0.26)$ & $0.44( \pm 0.26)$ & $0.38( \pm 0.22)$ & $0.33( \pm 0.17)$ \\
\hline
\end{tabular}

(b) Tabela de valores da análise. Cada célula indica a média ( \pm o desvio padrão) dos resultados.

Figura 5.2: Análise de erro médio do ITU para cada configuração de frequência $\times$ resolução na posição central (de calibração).

cia, tiveram resultados piores na posição sul. Determinamos que isso ocorreu devido à proximidade do usuário com o monitor, o que faz pequenos movimentos da cabeça do usuário afetarem mais a imagem da cena assim como a o movimento da pupila na imagem do olho é maior. Esses fatos contribuem para aumentar a variância do erro nessa posição, causando estes resultados.

No capítulo 3.2 detalhamos os algoritmos e seus parâmetros: valores que basicamente são relacionados a algum tamanho na imagem (como tamanho da região para procurar a pupila ou reflexões na córnea; tamanho mínimo/máximo da pupila; número de pixels para pular num passo de traçado de raio; entre outros) que alteramos para cada resolução usada no experimento. Esses resultados mostram como a configuração correta desses parâmetros dos algoritmos é muito importante para seu funcionamento ideal, 


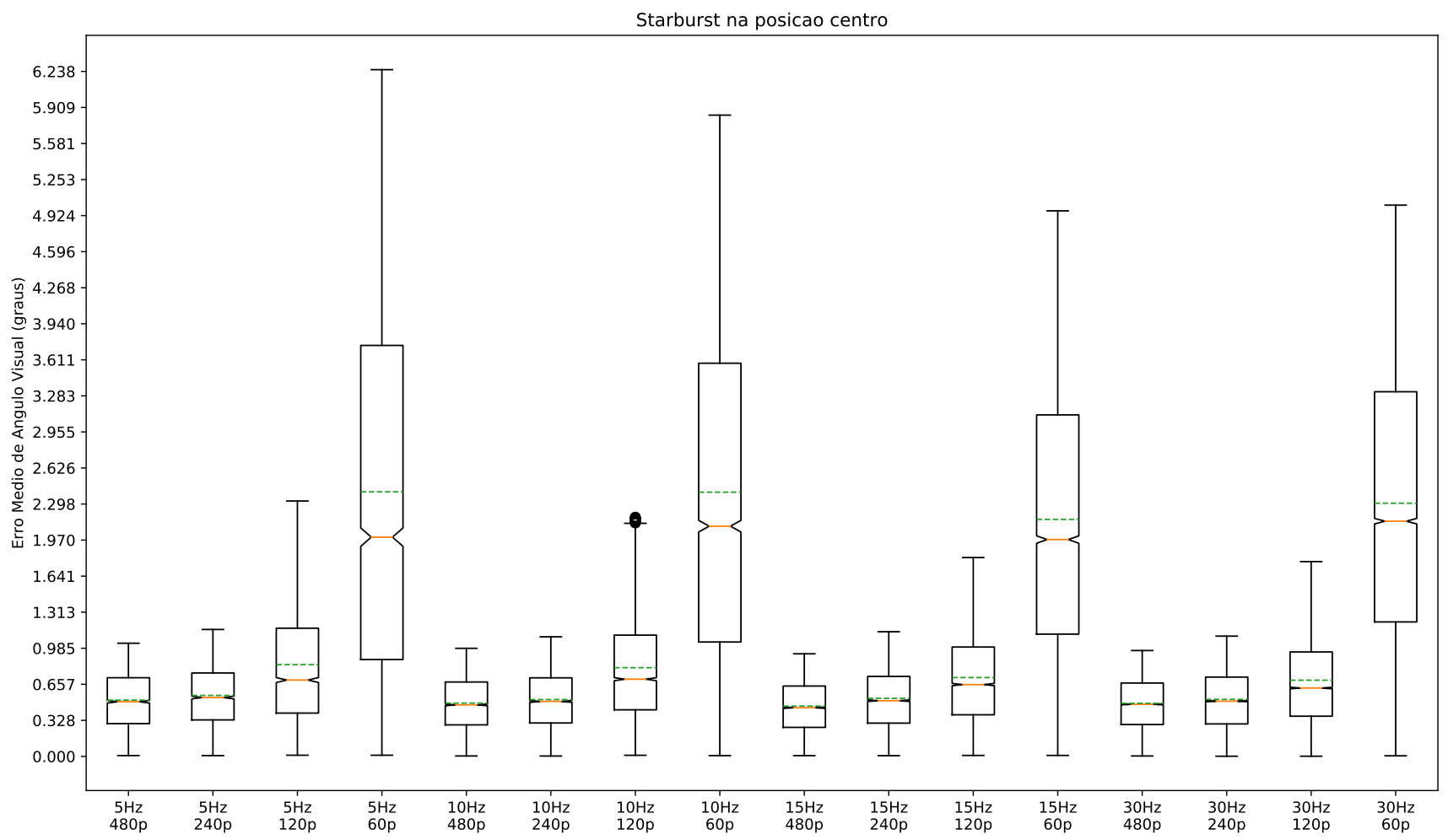

(a) Gráfico dos resultados da análise. A linha laranja é a mediana e seu intervalo de confiança, enquanto a linha pontilhada verde é a média dos dados.

\begin{tabular}{ccccc}
\hline Starburst / centro & \multicolumn{4}{c}{ Resolucao } \\
\cline { 2 - 5 } FPS & $\mathbf{4 8 0 p}$ & $\mathbf{2 4 0 p}$ & $\mathbf{1 2 0 p}$ & $\mathbf{6 0 p}$ \\
\hline 5 & $0.51( \pm 0.26)$ & $0.56( \pm 0.28)$ & $0.84( \pm 0.56)$ & $2.41( \pm 1.75)$ \\
\hline 10 & $0.49( \pm 0.25)$ & $0.52( \pm 0.26)$ & $0.81( \pm 0.50)$ & $2.41( \pm 1.57)$ \\
\hline 15 & $0.46( \pm 0.23)$ & $0.53( \pm 0.28)$ & $0.72( \pm 0.42)$ & $2.16( \pm 1.26)$ \\
\hline 30 & $0.48( \pm 0.24)$ & $0.52( \pm 0.27)$ & $0.69( \pm 0.41)$ & $2.31( \pm 1.29)$ \\
\hline
\end{tabular}

(b) Tabela de valores da análise. Cada célula indica a média ( \pm o desvio padrão) dos resultados.

Figura 5.3: Análise de erro médio do Starburst para cada configuração de frequência $\times$ resolução na posição central (de calibração).

não só para melhorar a precisão e acurácia do mesmo, mas também para o seu gasto computacional. 


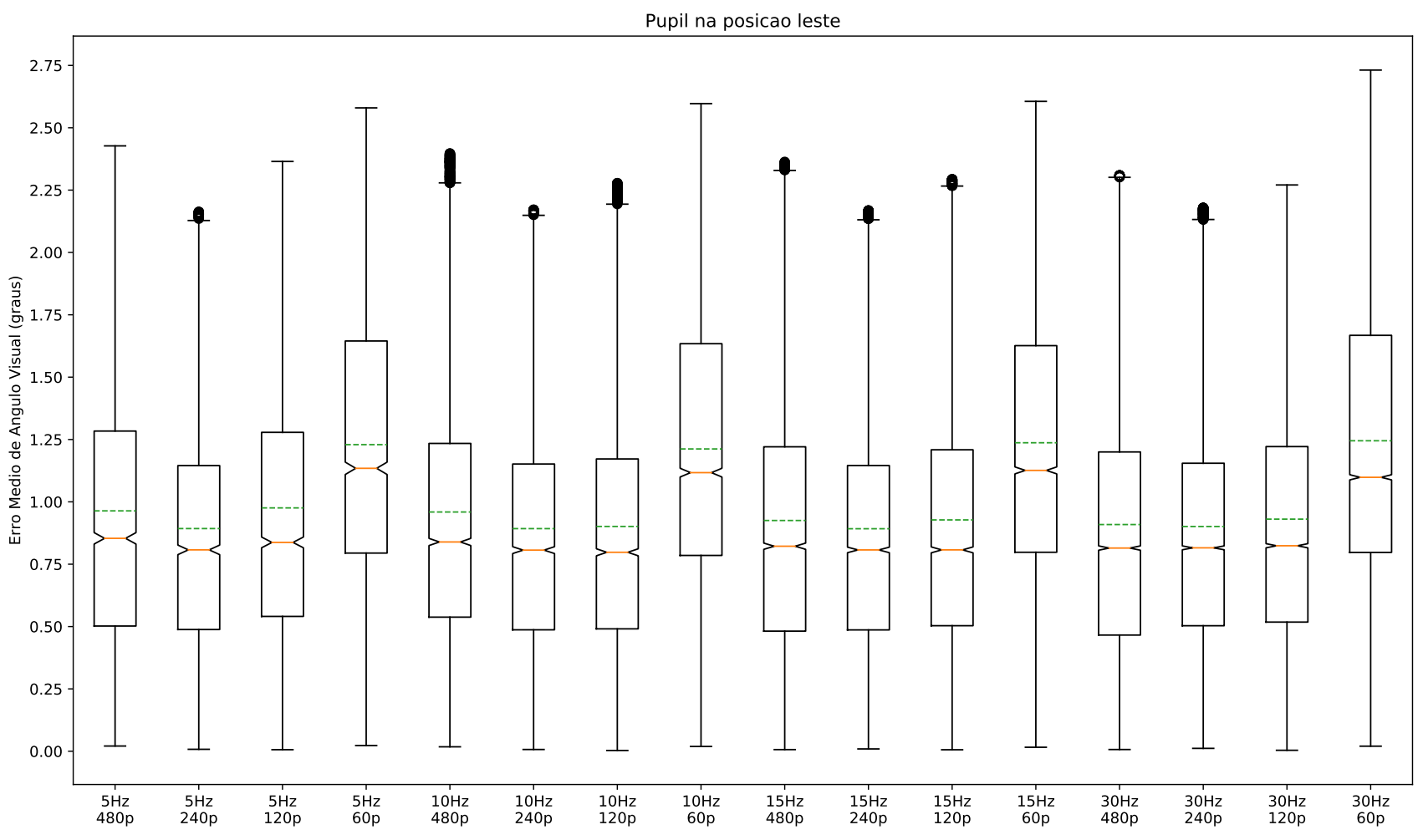

(a) Gráfico dos resultados da análise. A linha laranja é a mediana e seu intervalo de confiança, enquanto a linha pontilhada verde é a média dos dados.

\begin{tabular}{ccccc}
\hline Pupil / leste & \multicolumn{4}{c}{ Resolucao } \\
\cline { 2 - 5 } FPS & $\mathbf{4 8 0 p}$ & $\mathbf{2 4 0 p}$ & $\mathbf{1 2 0 p}$ & $\mathbf{6 0 p}$ \\
\hline 5 & $0.96( \pm 0.60)$ & $0.89( \pm 0.53)$ & $0.98( \pm 0.59)$ & $1.23( \pm 0.58)$ \\
\hline 10 & $0.96( \pm 0.57)$ & $0.89( \pm 0.53)$ & $0.90( \pm 0.56)$ & $1.21( \pm 0.57)$ \\
\hline 15 & $0.93( \pm 0.57)$ & $0.89( \pm 0.53)$ & $0.93( \pm 0.56)$ & $1.24( \pm 0.60)$ \\
\hline 30 & $0.91( \pm 0.56)$ & $0.90( \pm 0.53)$ & $0.93( \pm 0.55)$ & $1.24( \pm 0.62)$ \\
\hline
\end{tabular}

(b) Tabela de valores da análise. Cada célula indica a média ( \pm o desvio padrão) dos resultados.

Figura 5.4: Análise de erro médio do Pupil para cada configuração de frequência $\times$ resolução na posição leste. 


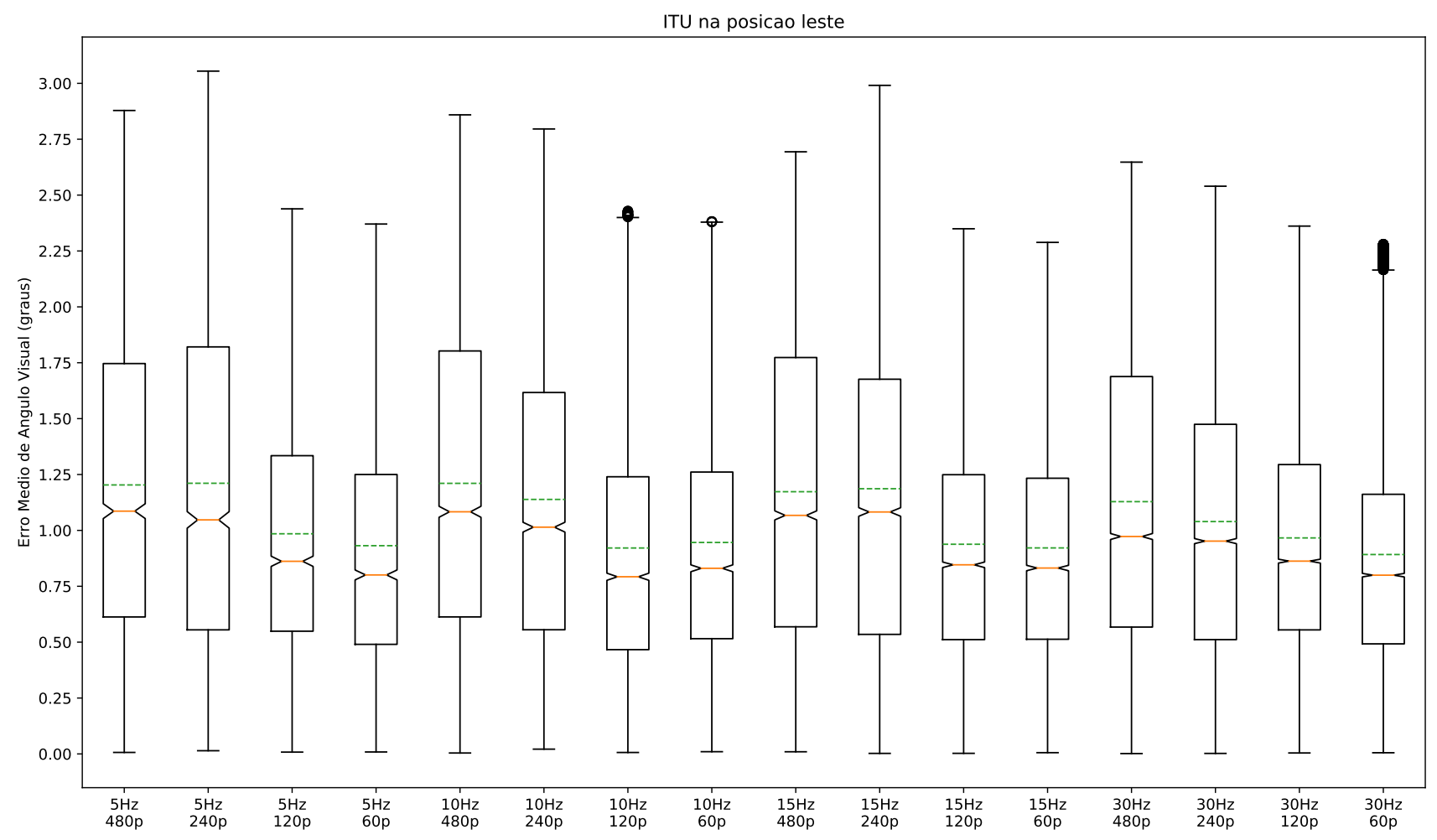

(a) Gráfico dos resultados da análise. A linha laranja é a mediana e seu intervalo de confiança, enquanto a linha pontilhada verde é a média dos dados.

\begin{tabular}{ccccc}
\hline ITU / leste & \multicolumn{4}{c}{ Resolucao } \\
\cline { 2 - 5 } FPS & $\mathbf{4 8 0 p}$ & $\mathbf{2 4 0 p}$ & $\mathbf{1 2 0 p}$ & $\mathbf{6 0 p}$ \\
\hline 5 & $1.20( \pm 0.74)$ & $1.21( \pm 0.79)$ & $0.98( \pm 0.58)$ & $0.93( \pm 0.58)$ \\
\hline 10 & $1.21( \pm 0.75)$ & $1.14( \pm 0.69)$ & $0.92( \pm 0.58)$ & $0.95( \pm 0.57)$ \\
\hline 15 & $1.17( \pm 0.72)$ & $1.19( \pm 0.76)$ & $0.94( \pm 0.55)$ & $0.92( \pm 0.54)$ \\
\hline 30 & $1.13( \pm 0.69)$ & $1.04( \pm 0.63)$ & $0.97( \pm 0.54)$ & $0.89( \pm 0.53)$ \\
\hline
\end{tabular}

(b) Tabela de valores da análise. Cada célula indica a média ( \pm o desvio padrão) dos resultados.

Figura 5.5: Análise de erro médio do ITU para cada configuração de frequência $\times$ resolução na posição leste. 


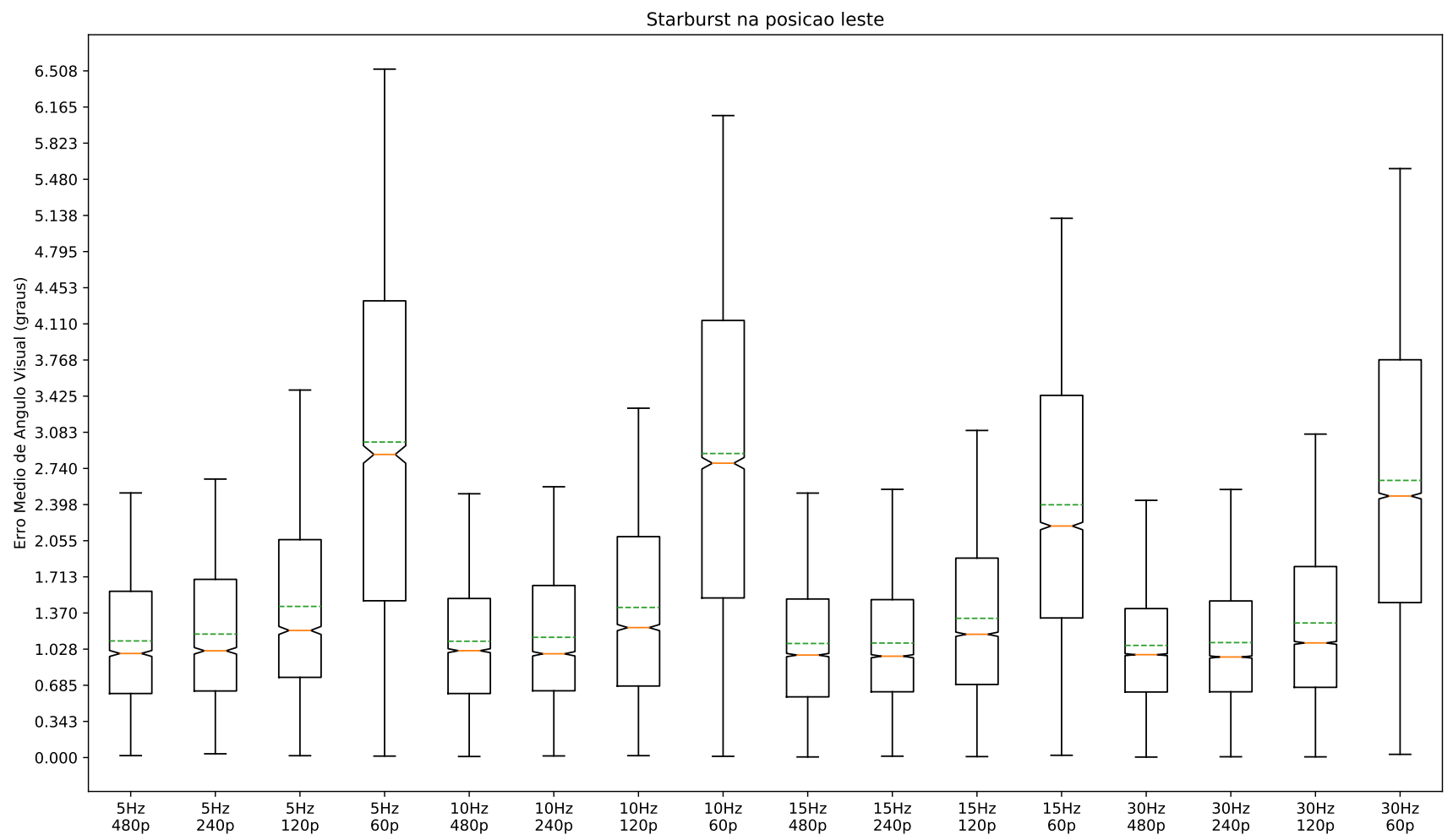

(a) Gráfico dos resultados da análise. A linha laranja é a mediana e seu intervalo de confiança, enquanto a linha pontilhada verde é a média dos dados.

\begin{tabular}{ccccc}
\hline Starburst / leste & \multicolumn{4}{c}{ Resolucao } \\
\cline { 2 - 5 } FPS & $\mathbf{4 8 0 p}$ & $\mathbf{2 4 0 p}$ & $\mathbf{1 2 0 p}$ & $\mathbf{6 0 p}$ \\
\hline 5 & $1.11( \pm 0.63)$ & $1.17( \pm 0.67)$ & $1.43( \pm 0.85)$ & $2.99( \pm 1.74)$ \\
\hline 10 & $1.10( \pm 0.62)$ & $1.14( \pm 0.65)$ & $1.42( \pm 0.88)$ & $2.88( \pm 1.57)$ \\
\hline 15 & $1.08( \pm 0.63)$ & $1.09( \pm 0.61)$ & $1.32( \pm 0.77)$ & $2.40( \pm 1.32)$ \\
\hline 30 & $1.06( \pm 0.57)$ & $1.09( \pm 0.61)$ & $1.28( \pm 0.78)$ & $2.63( \pm 1.43)$ \\
\hline
\end{tabular}

(b) Tabela de valores da análise. Cada célula indica a média ( \pm o desvio padrão) dos resultados.

Figura 5.6: Análise de erro médio do Starburst para cada configuração de frequência $\times$ resolução na posição leste. 


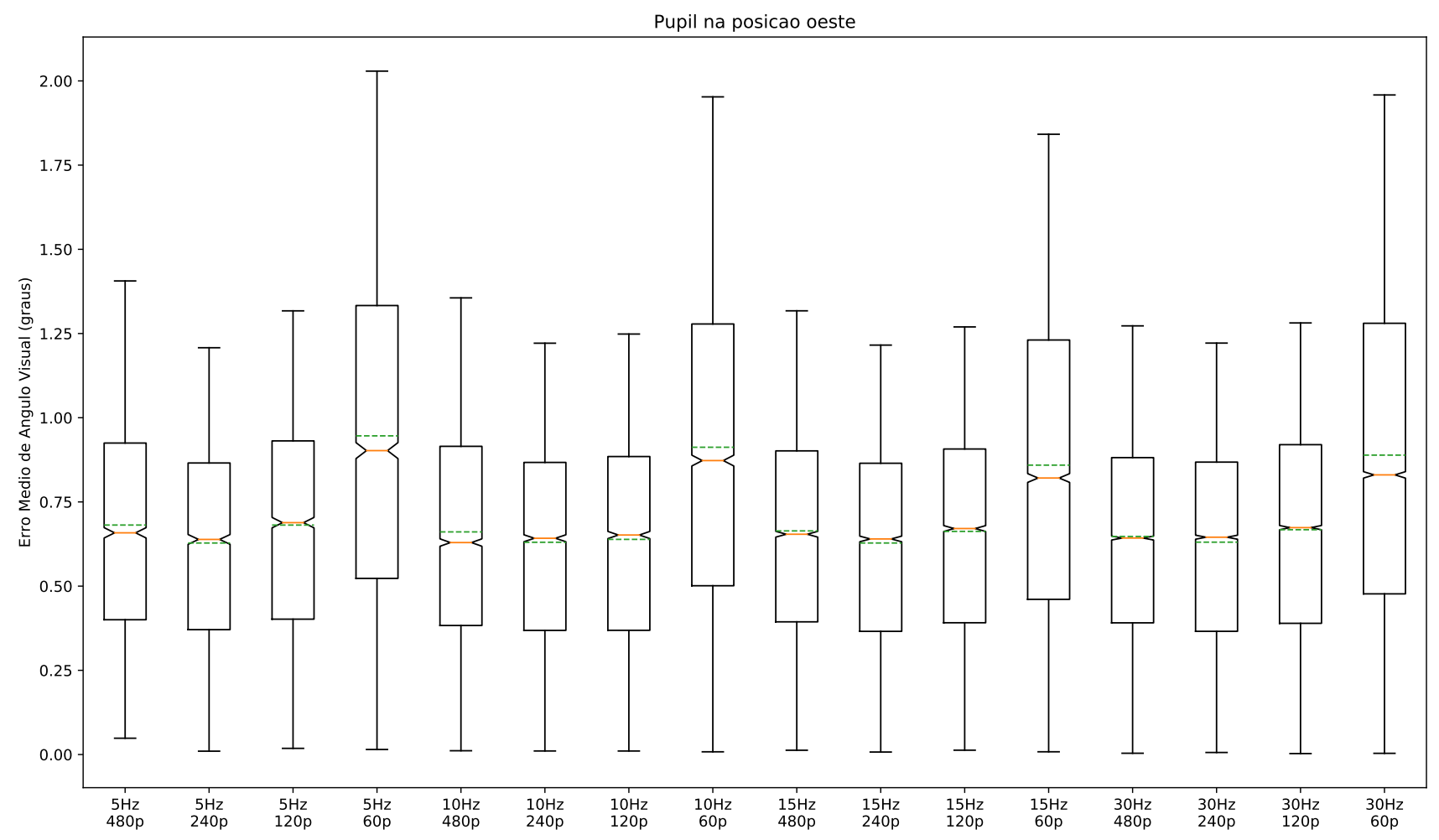

(a) Gráfico dos resultados da análise. A linha laranja é a mediana e seu intervalo de confiança, enquanto a linha pontilhada verde é a média dos dados.

\begin{tabular}{ccccc}
\hline Pupil / oeste & \multicolumn{4}{c}{ Resolucao } \\
\cline { 2 - 5 } FPS & $\mathbf{4 8 0 p}$ & $\mathbf{2 4 0 p}$ & $\mathbf{1 2 0 p}$ & $\mathbf{6 0 p}$ \\
\hline 5 & $0.68( \pm 0.34)$ & $0.63( \pm 0.30)$ & $0.68( \pm 0.34)$ & $0.95( \pm 0.51)$ \\
\hline 10 & $0.66( \pm 0.33)$ & $0.63( \pm 0.31)$ & $0.64( \pm 0.32)$ & $0.91( \pm 0.50)$ \\
\hline 15 & $0.66( \pm 0.32)$ & $0.63( \pm 0.31)$ & $0.66( \pm 0.32)$ & $0.86( \pm 0.47)$ \\
\hline 30 & $0.65( \pm 0.32)$ & $0.63( \pm 0.31)$ & $0.67( \pm 0.33)$ & $0.89( \pm 0.50)$ \\
\hline
\end{tabular}

(b) Tabela de valores da análise. Cada célula indica a média ( \pm o desvio padrão $)$ dos resultados.

Figura 5.7: Análise de erro médio do Pupil para cada configuração de frequência $\times$ resolução na posição oeste. 


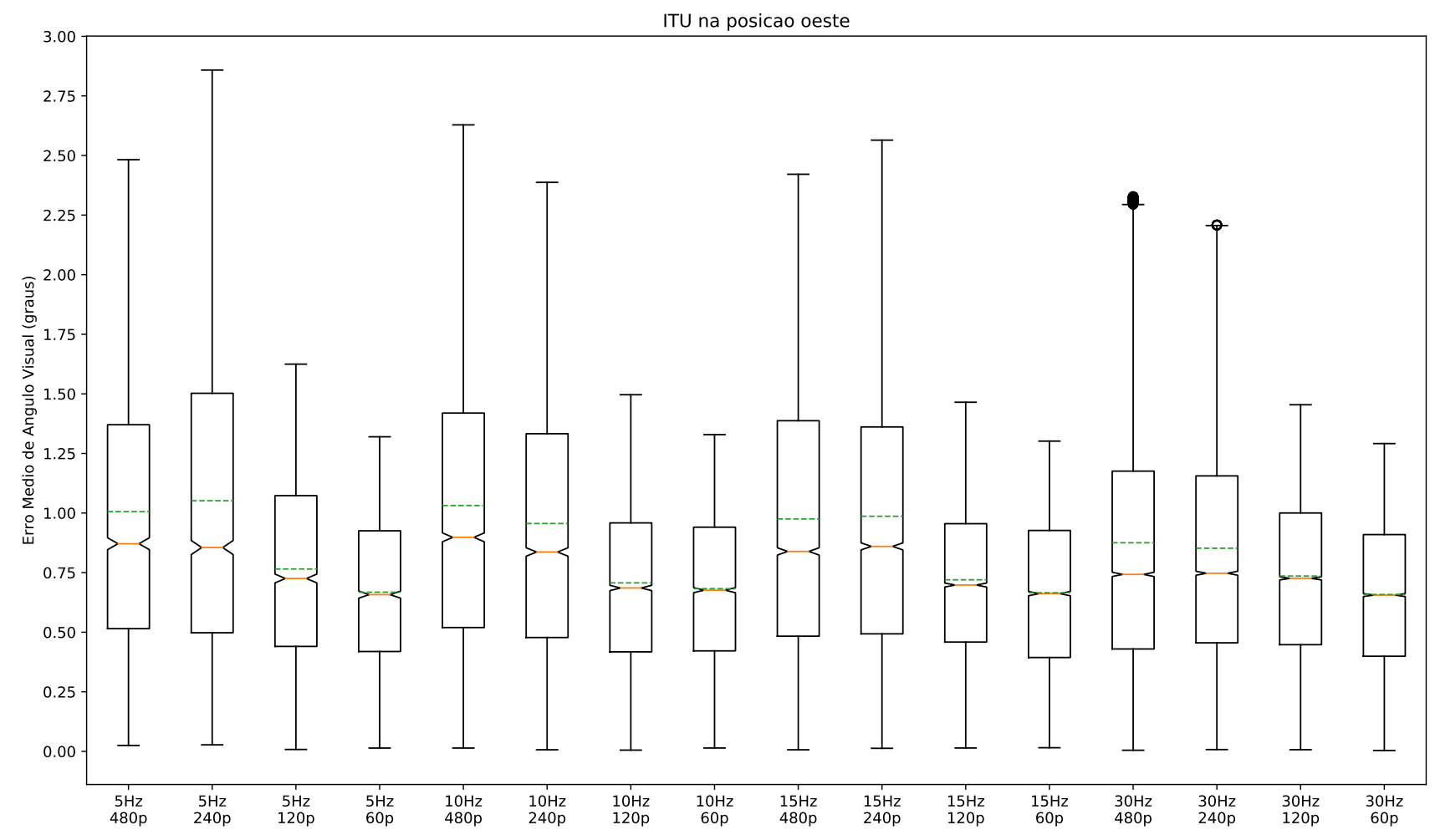

(a) Gráfico dos resultados da análise. A linha laranja é a mediana e seu intervalo de confiança, enquanto a linha pontilhada verde é a média dos dados.

\begin{tabular}{ccccc}
\hline ITU / oeste & \multicolumn{4}{c}{ Resolucao } \\
\cline { 2 - 5 } FPS & $\mathbf{4 8 0 p}$ & $\mathbf{2 4 0} \mathbf{p}$ & $\mathbf{1 2 0 p}$ & $\mathbf{6 0 p}$ \\
\hline 5 & $1.01( \pm 0.62)$ & $1.05( \pm 0.71)$ & $0.77( \pm 0.39)$ & $0.67( \pm 0.32)$ \\
\hline 10 & $1.03( \pm 0.65)$ & $0.96( \pm 0.60)$ & $0.71( \pm 0.36)$ & $0.68( \pm 0.33)$ \\
\hline 15 & $0.98( \pm 0.61)$ & $0.99( \pm 0.62)$ & $0.72( \pm 0.34)$ & $0.67( \pm 0.33)$ \\
\hline 30 & $0.88( \pm 0.57)$ & $0.85( \pm 0.52)$ & $0.74( \pm 0.35)$ & $0.66( \pm 0.32)$ \\
\hline
\end{tabular}

(b) Tabela de valores da análise. Cada célula indica a média ( \pm o desvio padrão) dos resultados.

Figura 5.8: Análise de erro médio do ITU para cada configuração de frequência $\times$ resolução na posição oeste. 


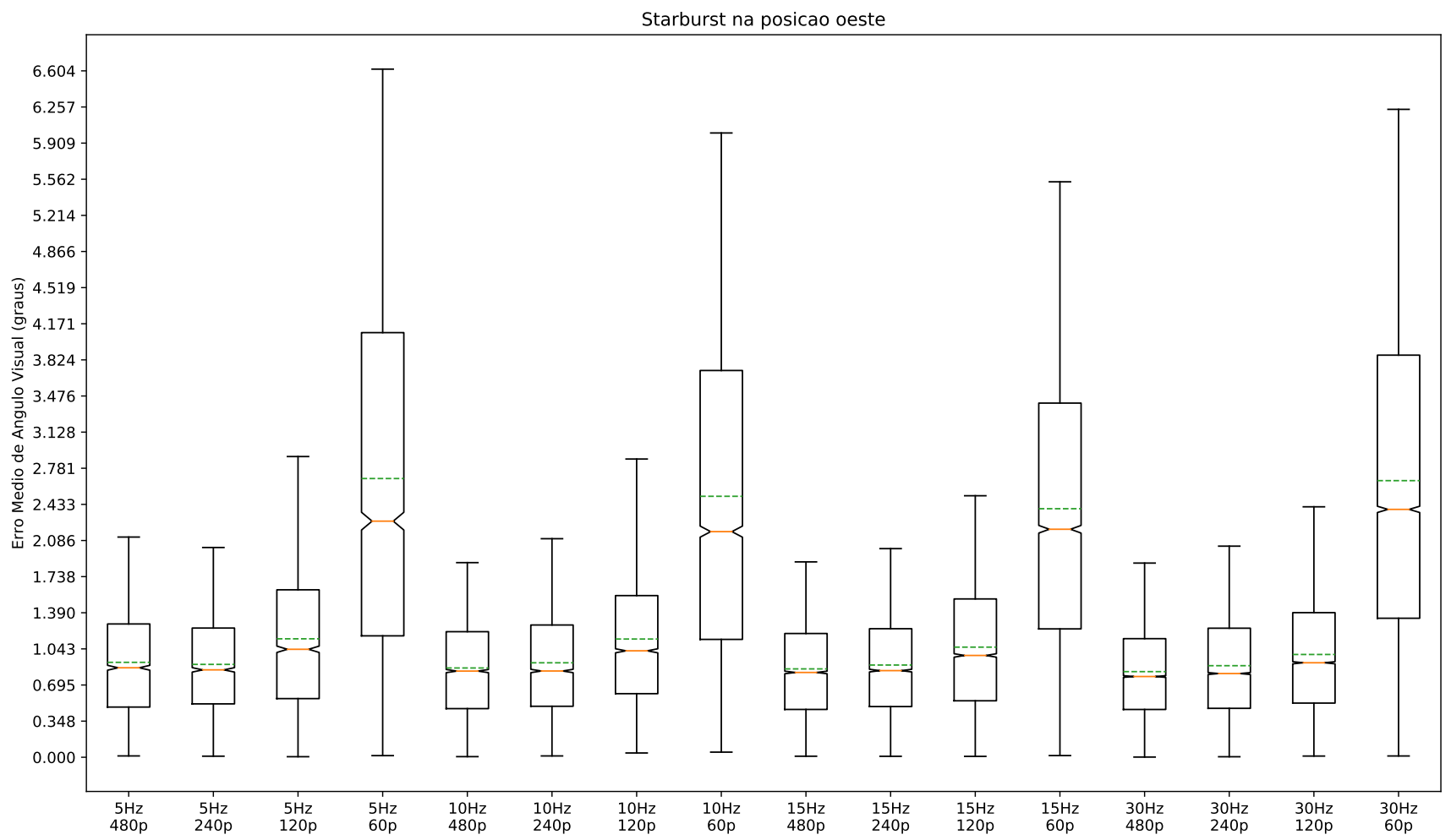

(a) Gráfico dos resultados da análise. A linha laranja é a mediana e seu intervalo de confiança, enquanto a linha pontilhada verde é a média dos dados.

\begin{tabular}{ccccc}
\hline Starburst / oeste & \multicolumn{4}{c}{ Resolucao } \\
\cline { 2 - 5 } FPS & $\mathbf{4 8 0 p}$ & $\mathbf{2 4 0 p}$ & $\mathbf{1 2 0 p}$ & $\mathbf{6 0 p}$ \\
\hline 5 & $0.91( \pm 0.52)$ & $0.89( \pm 0.49)$ & $1.14( \pm 0.70)$ & $2.68( \pm 1.79)$ \\
\hline 10 & $0.86( \pm 0.47)$ & $0.91( \pm 0.52)$ & $1.14( \pm 0.67)$ & $2.51( \pm 1.62)$ \\
\hline 15 & $0.85( \pm 0.47)$ & $0.89( \pm 0.49)$ & $1.06( \pm 0.62)$ & $2.39( \pm 1.40)$ \\
\hline 30 & $0.82( \pm 0.45)$ & $0.88( \pm 0.50)$ & $0.99( \pm 0.57)$ & $2.66( \pm 1.60)$ \\
\hline
\end{tabular}

(b) Tabela de valores da análise. Cada célula indica a média ( \pm o desvio padrão $)$ dos resultados.

Figura 5.9: Análise de erro médio do Starburst para cada configuração de frequência $\times$ resolução na posição oeste. 


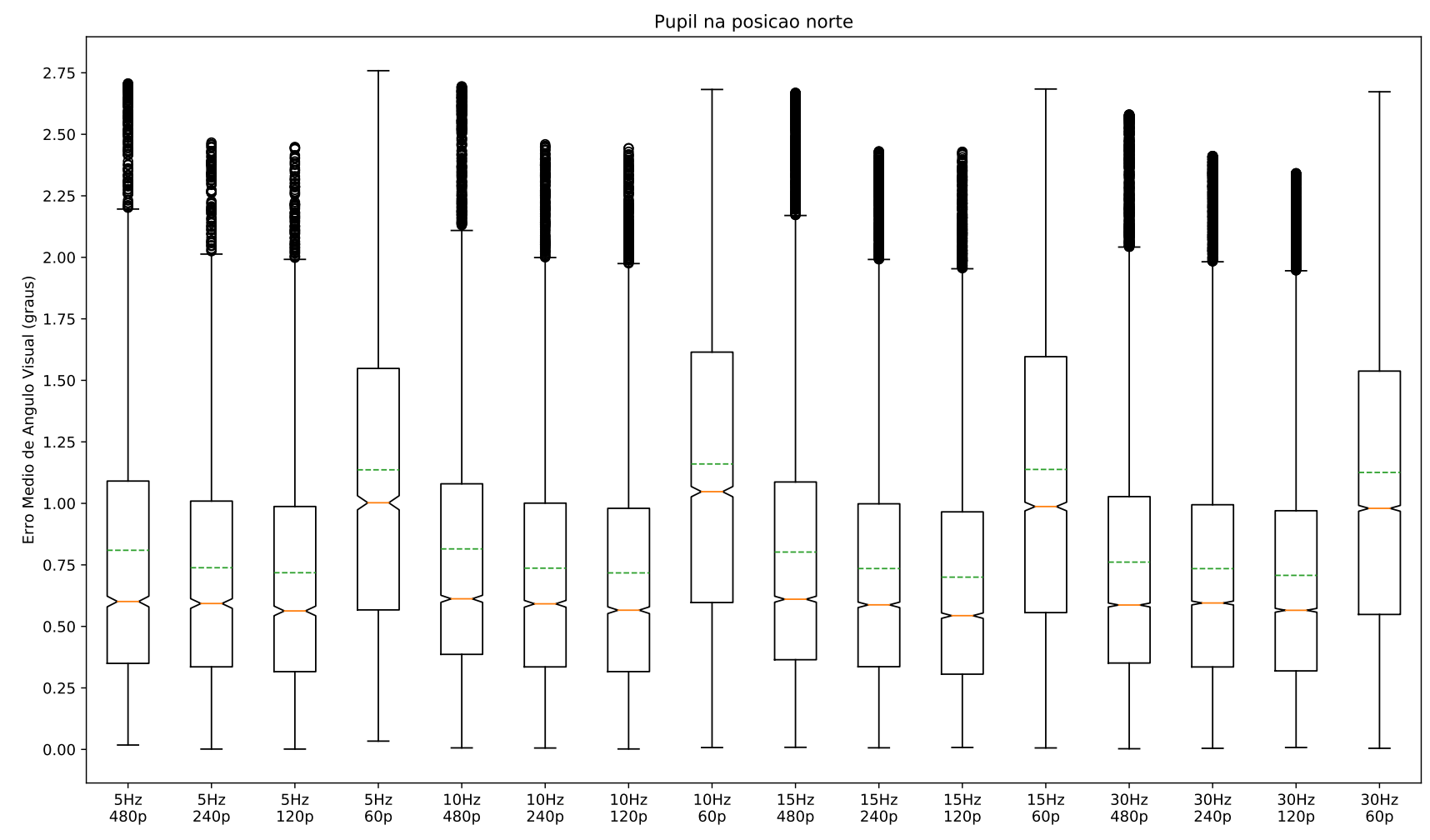

(a) Gráfico dos resultados da análise. A linha laranja é a mediana e seu intervalo de confiança, enquanto a linha pontilhada verde é a média dos dados.

\begin{tabular}{ccccc}
\hline \multirow{2}{*}{$\begin{array}{c}\text { Pupil / norte } \\
\text { FPS }\end{array}$} & $\mathbf{4 8 0 p}$ & $\mathbf{2 4 0 p}$ & $\mathbf{1 2 0 p}$ & $\mathbf{6 0 p}$ \\
\cline { 2 - 5 } & $0.81( \pm 0.62)$ & $0.74( \pm 0.53)$ & $0.72( \pm 0.53)$ & $1.14( \pm 0.72)$ \\
\hline 5 & $0.81( \pm 0.59)$ & $0.74( \pm 0.53)$ & $0.72( \pm 0.52)$ & $1.16( \pm 0.70)$ \\
\hline 10 & $0.80( \pm 0.59)$ & $0.74( \pm 0.52)$ & $0.70( \pm 0.52)$ & $1.14( \pm 0.72)$ \\
\hline 15 & $0.76( \pm 0.55)$ & $0.73( \pm 0.52)$ & $0.71( \pm 0.50)$ & $1.13( \pm 0.72)$ \\
\hline 30 & & &
\end{tabular}

(b) Tabela de valores da análise. Cada célula indica a média ( \pm o desvio padrão) dos resultados.

Figura 5.10: Análise de erro médio do Pupil para cada configuração de frequência $\times$ resolução na posição norte. 


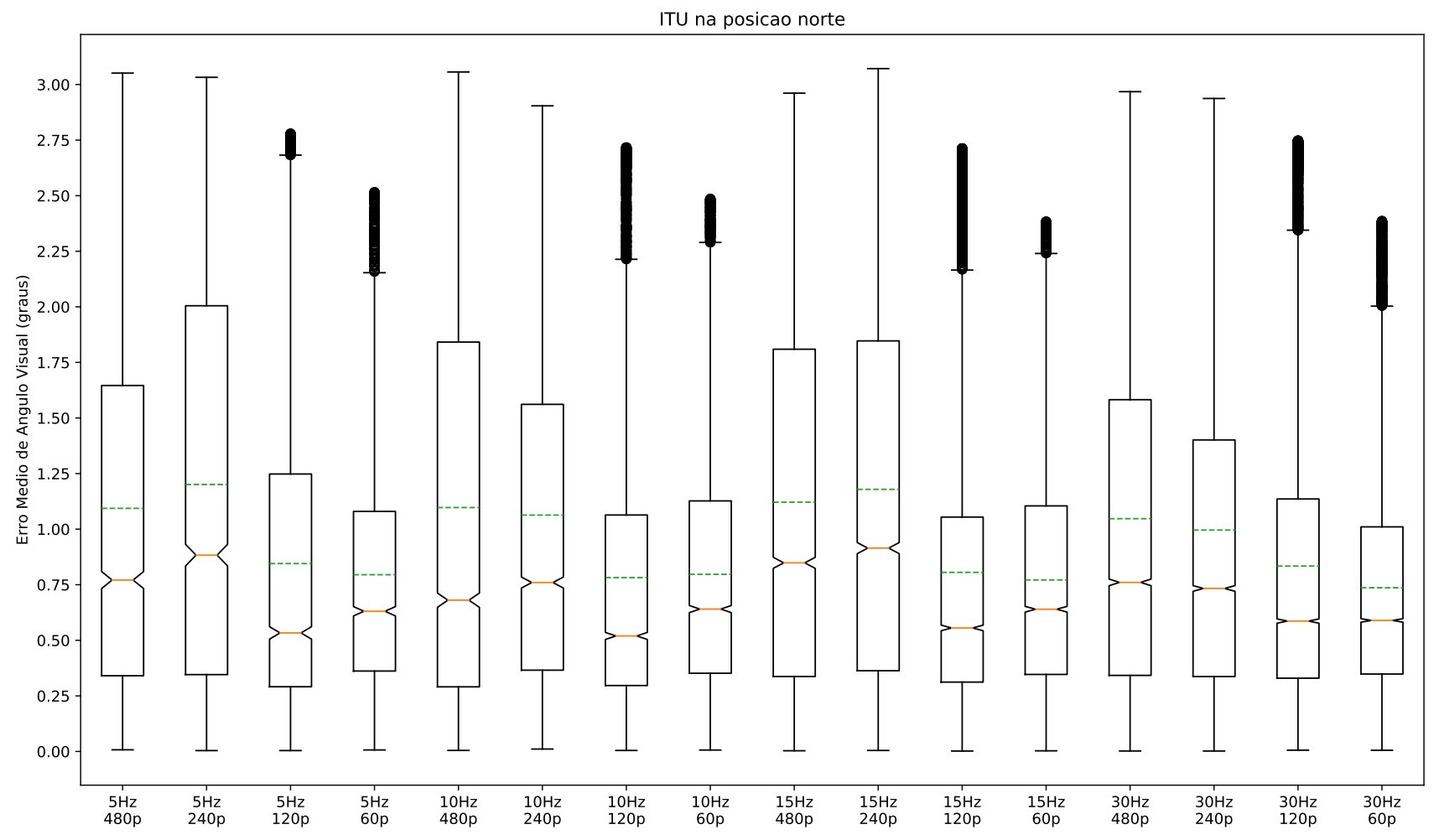

(a) Gráfico dos resultados da análise. A linha laranja é a mediana e seu intervalo de confiança, enquanto a linha pontilhada verde é a média dos dados.

\begin{tabular}{ccccc}
\hline ITU / norte & \multicolumn{4}{c}{ Resolucao } \\
\cline { 2 - 5 } FPS & $\mathbf{4 8 0 p}$ & $\mathbf{2 4 0} \mathbf{p}$ & $\mathbf{1 2 0 p}$ & $\mathbf{6 0 p}$ \\
\hline 5 & $1.09( \pm 0.92)$ & $1.20( \pm 0.95)$ & $0.85( \pm 0.76)$ & $0.80( \pm 0.57)$ \\
\hline 10 & $1.10( \pm 0.96)$ & $1.06( \pm 0.86)$ & $0.78( \pm 0.69)$ & $0.80( \pm 0.57)$ \\
\hline 15 & $1.12( \pm 0.91)$ & $1.18( \pm 0.93)$ & $0.81( \pm 0.68)$ & $0.77( \pm 0.53)$ \\
\hline 30 & $1.05( \pm 0.88)$ & $1.00( \pm 0.84)$ & $0.83( \pm 0.70)$ & $0.74( \pm 0.51)$ \\
\hline
\end{tabular}

(b) Tabela de valores da análise. Cada célula indica a média ( \pm o desvio padrão $)$ dos resultados.

Figura 5.11: Análise de erro médio do ITU para cada configuração de frequência $\times$ resolução na posição norte. 


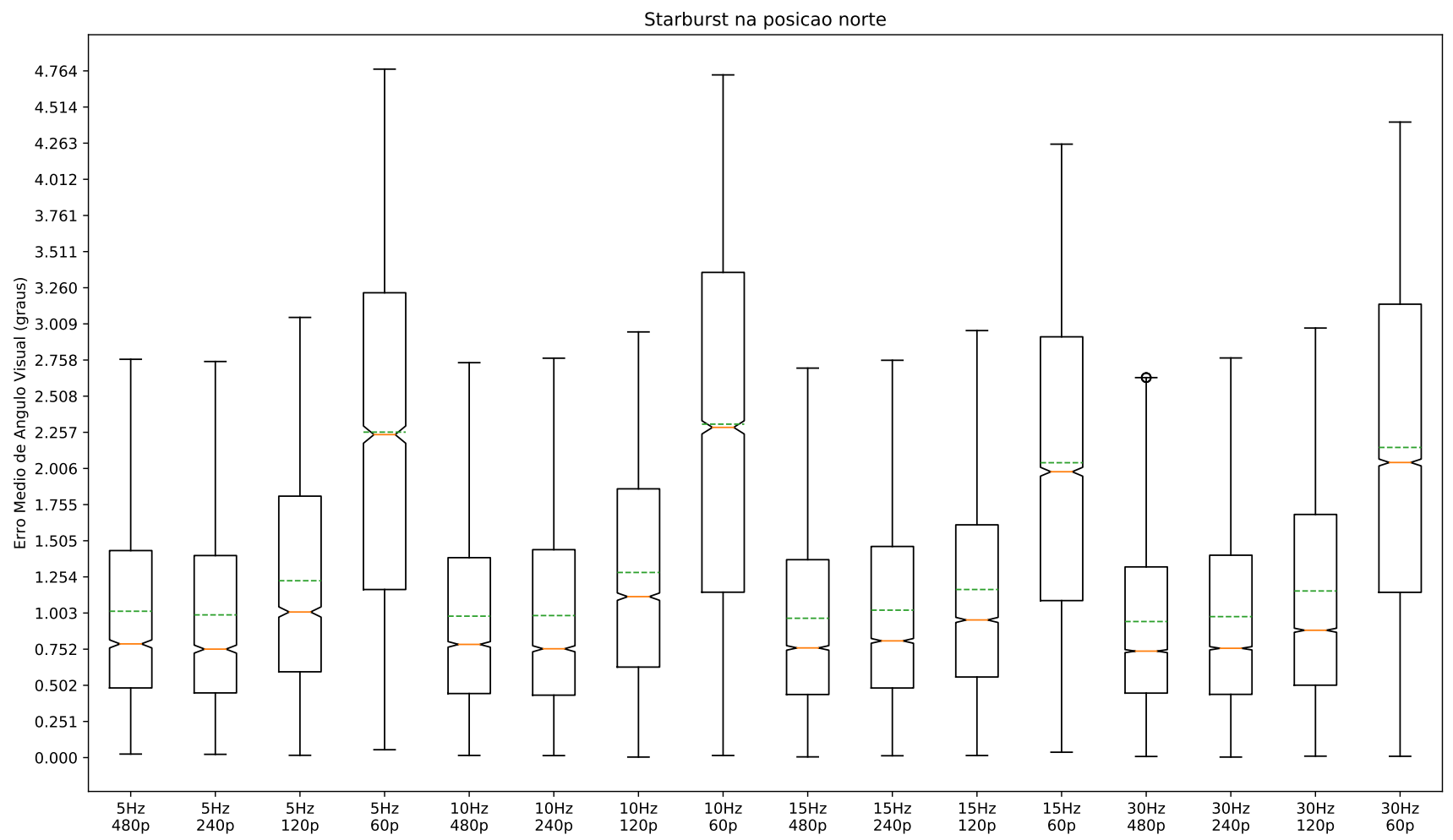

(a) Gráfico dos resultados da análise. A linha laranja é a mediana e seu intervalo de confiança, enquanto a linha pontilhada verde é a média dos dados.

\begin{tabular}{ccccc}
\hline \multirow{2}{*}{$\begin{array}{c}\text { Starburst / norte } \\
\text { FPS }\end{array}$} & $\mathbf{4 8 0 p}$ & $\mathbf{2 4 0 p}$ & $\mathbf{1 2 0 p}$ & $\mathbf{6 0 p}$ \\
\cline { 2 - 5 } & $1.02( \pm 0.70)$ & $0.99( \pm 0.70)$ & $1.23( \pm 0.81)$ & $2.26( \pm 1.24)$ \\
\hline 5 & $0.98( \pm 0.69)$ & $0.99( \pm 0.70)$ & $1.28( \pm 0.78)$ & $2.31( \pm 1.28)$ \\
\hline 10 & $0.97( \pm 0.68)$ & $1.02( \pm 0.70)$ & $1.17( \pm 0.78)$ & $2.05( \pm 1.11)$ \\
\hline 15 & $0.94( \pm 0.65)$ & $0.98( \pm 0.70)$ & $1.16( \pm 0.82)$ & $2.15( \pm 1.16)$ \\
\hline 30 & &
\end{tabular}

(b) Tabela de valores da análise. Cada célula indica a média ( \pm o desvio padrão) dos resultados.

Figura 5.12: Análise de erro médio do Starburst para cada configuração de frequência $\times$ resolução na posição norte. 


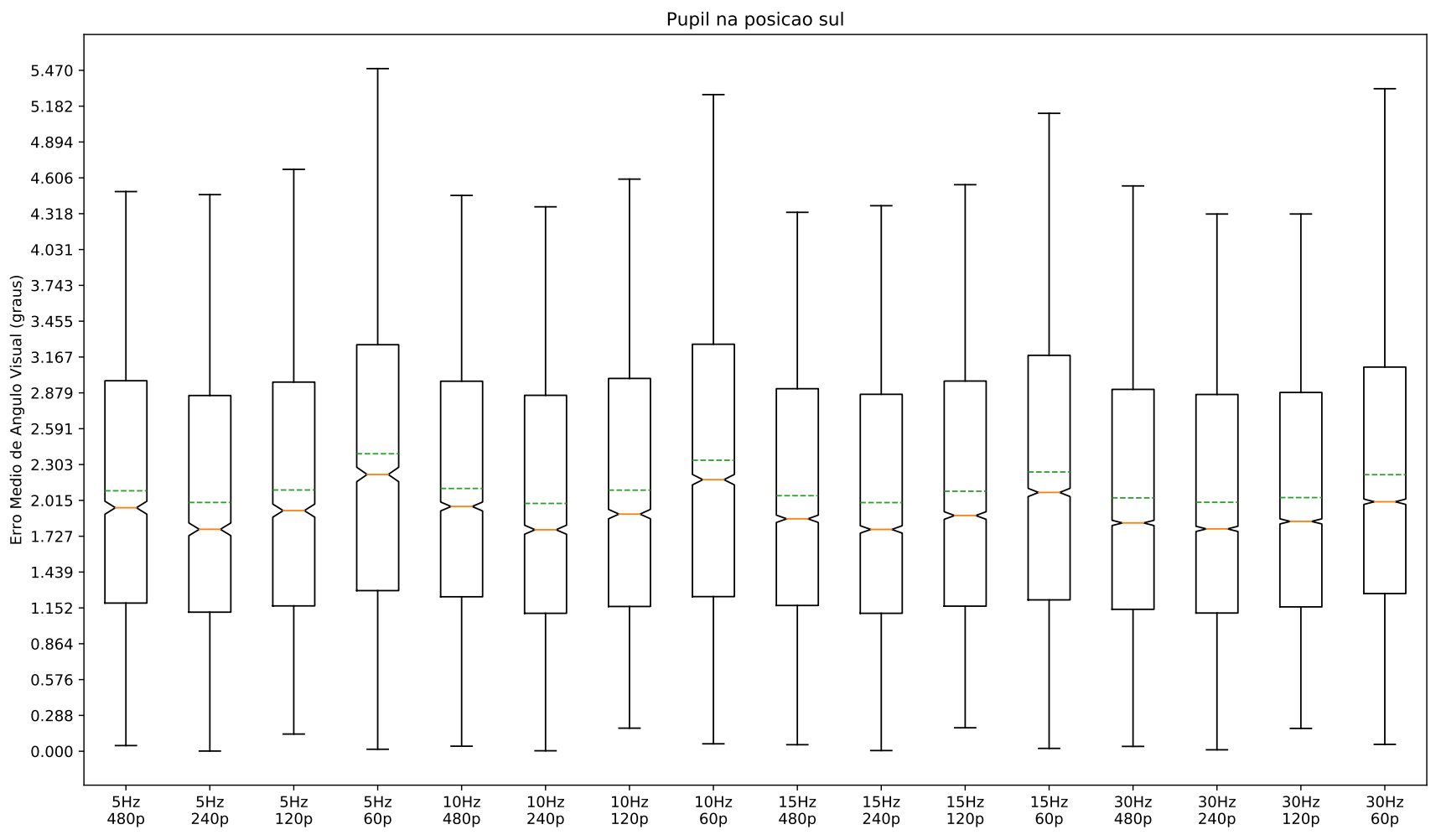

(a) Gráfico dos resultados da análise. A linha laranja é a mediana e seu intervalo de confiança, enquanto a linha pontilhada verde é a média dos dados.

\begin{tabular}{ccccc}
\hline Pupil / sul & \multicolumn{4}{c}{ Resolucao } \\
\cline { 2 - 5 } FPS & $\mathbf{4 8 0 p}$ & $\mathbf{2 4 0 p}$ & $\mathbf{1 2 0 p}$ & $\mathbf{6 0 p}$ \\
\hline 5 & $2.09( \pm 1.04)$ & $2.00( \pm 1.02)$ & $2.10( \pm 1.07)$ & $2.39( \pm 1.31)$ \\
\hline 10 & $2.11( \pm 1.05)$ & $1.99( \pm 1.02)$ & $2.10( \pm 1.07)$ & $2.34( \pm 1.28)$ \\
\hline 15 & $2.05( \pm 1.03)$ & $2.00( \pm 1.02)$ & $2.09( \pm 1.05)$ & $2.24( \pm 1.20)$ \\
\hline 30 & $2.04( \pm 1.04)$ & $2.00( \pm 1.02)$ & $2.04( \pm 1.01)$ & $2.22( \pm 1.18)$ \\
\hline
\end{tabular}

(b) Tabela de valores da análise. Cada célula indica a média ( \pm o desvio padrão $)$ dos resultados.

Figura 5.13: Análise de erro médio do Pupil para cada configuração de frequência $\times$ resolução na posição sul. 


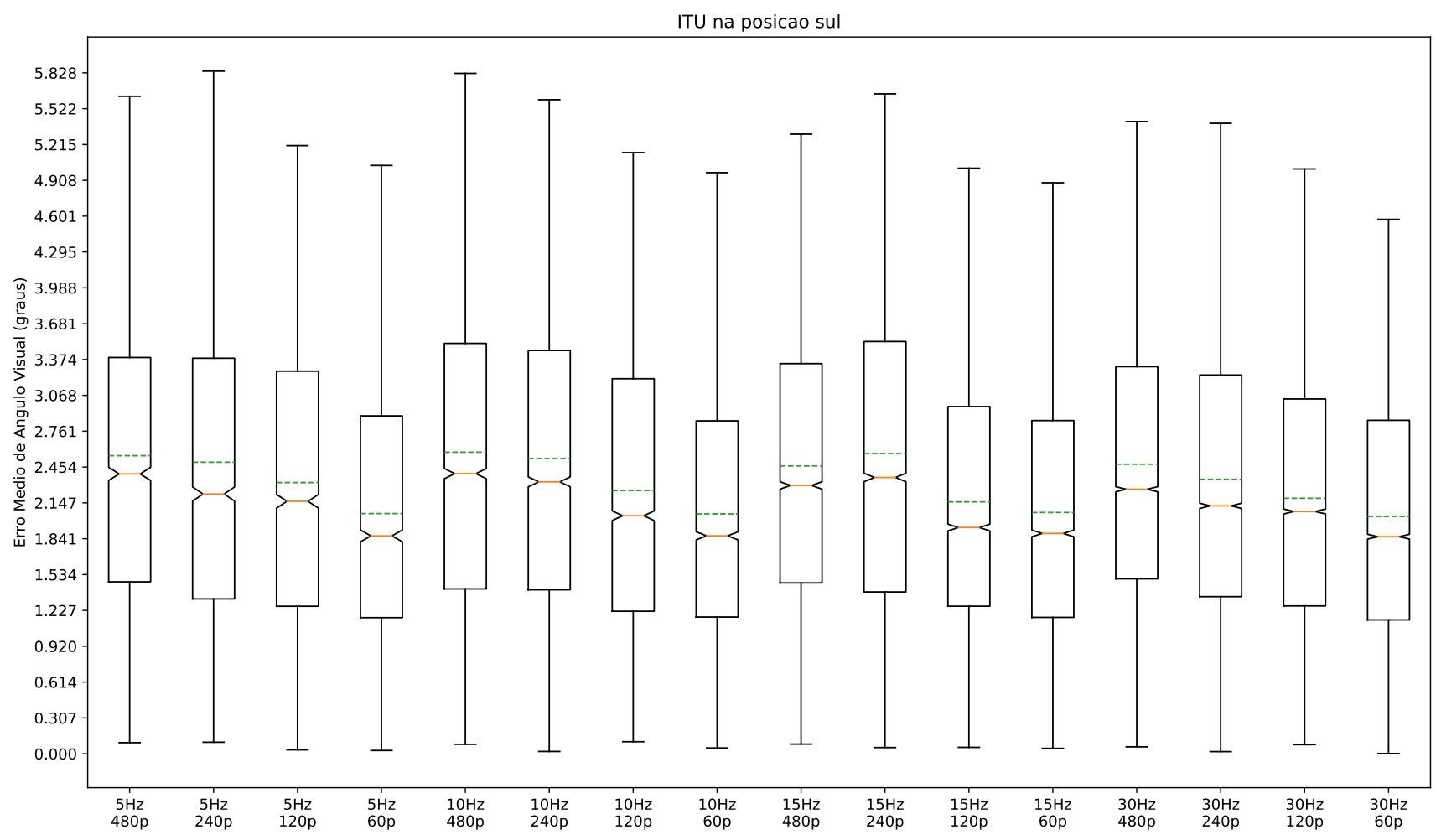

(a) Gráfico dos resultados da análise. A linha laranja é a mediana e seu intervalo de confiança, enquanto a linha pontilhada verde é a média dos dados.

\begin{tabular}{ccccc}
\hline ITU / sul & \multicolumn{4}{c}{ Resolucao } \\
\cline { 2 - 5 } FPS & $\mathbf{4 8 0 p}$ & $\mathbf{2 4 0 p}$ & $\mathbf{1 2 0 p}$ & $\mathbf{6 0 p}$ \\
\hline 5 & $2.55( \pm 1.32)$ & $2.50( \pm 1.38)$ & $2.32( \pm 1.22)$ & $2.06( \pm 1.08)$ \\
\hline 10 & $2.58( \pm 1.38)$ & $2.53( \pm 1.35)$ & $2.25( \pm 1.21)$ & $2.05( \pm 1.04)$ \\
\hline 15 & $2.46( \pm 1.23)$ & $2.57( \pm 1.39)$ & $2.16( \pm 1.08)$ & $2.06( \pm 1.06)$ \\
\hline 30 & $2.48( \pm 1.27)$ & $2.35( \pm 1.24)$ & $2.19( \pm 1.08)$ & $2.03( \pm 1.04)$ \\
\hline
\end{tabular}

(b) Tabela de valores da análise. Cada célula indica a média ( \pm o desvio padrão) dos resultados.

Figura 5.14: Análise de erro médio do ITU para cada configuração de frequência $\times$ resolução na posição sul. 


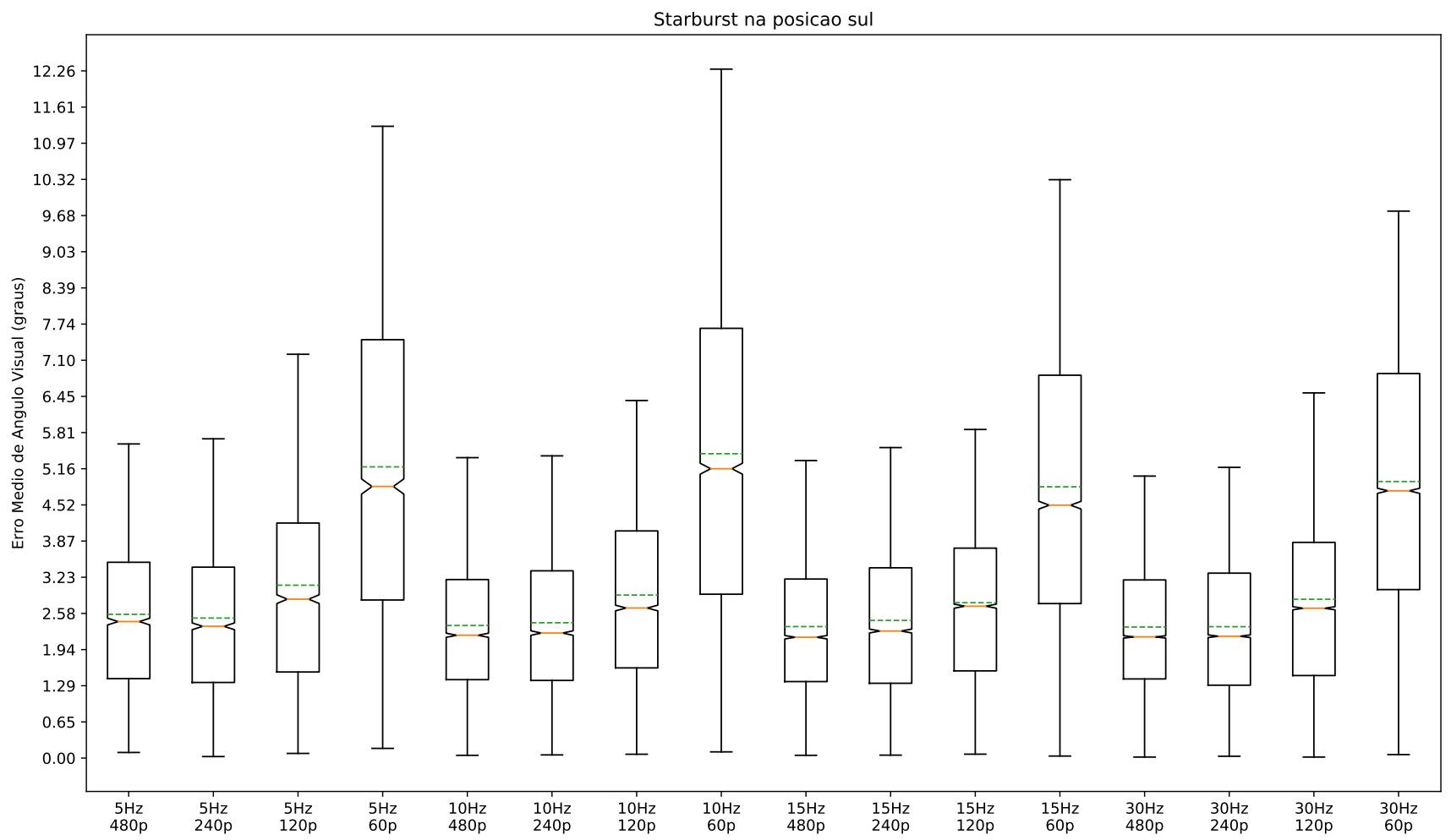

(a) Gráfico dos resultados da análise. A linha laranja é a mediana e seu intervalo de confiança, enquanto a linha pontilhada verde é a média dos dados.

\begin{tabular}{ccccc}
\hline \multirow{2}{*}{$\begin{array}{c}\text { Starburst } / \text { sul } \\
\text { FPS }\end{array}$} & \multicolumn{4}{c}{ Resolucao } \\
\cline { 2 - 5 } & $\mathbf{4 8 0}$ & $\mathbf{2 4 0} \mathbf{p}$ & $\mathbf{1 2 0 p}$ & $\mathbf{6 0 p}$ \\
\hline 5 & $2.56( \pm 1.36)$ & $2.50( \pm 1.37)$ & $3.08( \pm 1.77)$ & $5.20( \pm 2.85)$ \\
\hline 10 & $2.37( \pm 1.22)$ & $2.41( \pm 1.27)$ & $2.91( \pm 1.60)$ & $5.43( \pm 3.01)$ \\
\hline 15 & $2.35( \pm 1.21)$ & $2.46( \pm 1.33)$ & $2.77( \pm 1.42)$ & $4.84( \pm 2.59)$ \\
\hline 30 & $2.34( \pm 1.18)$ & $2.34( \pm 1.23)$ & $2.83( \pm 1.60)$ & $4.93( \pm 2.45)$ \\
\hline
\end{tabular}

(b) Tabela de valores da análise. Cada célula indica a média ( \pm o desvio padrão $)$ dos resultados.

Figura 5.15: Análise de erro médio do Starburst para cada configuração de frequência $\times$ resolução na posição sul. 


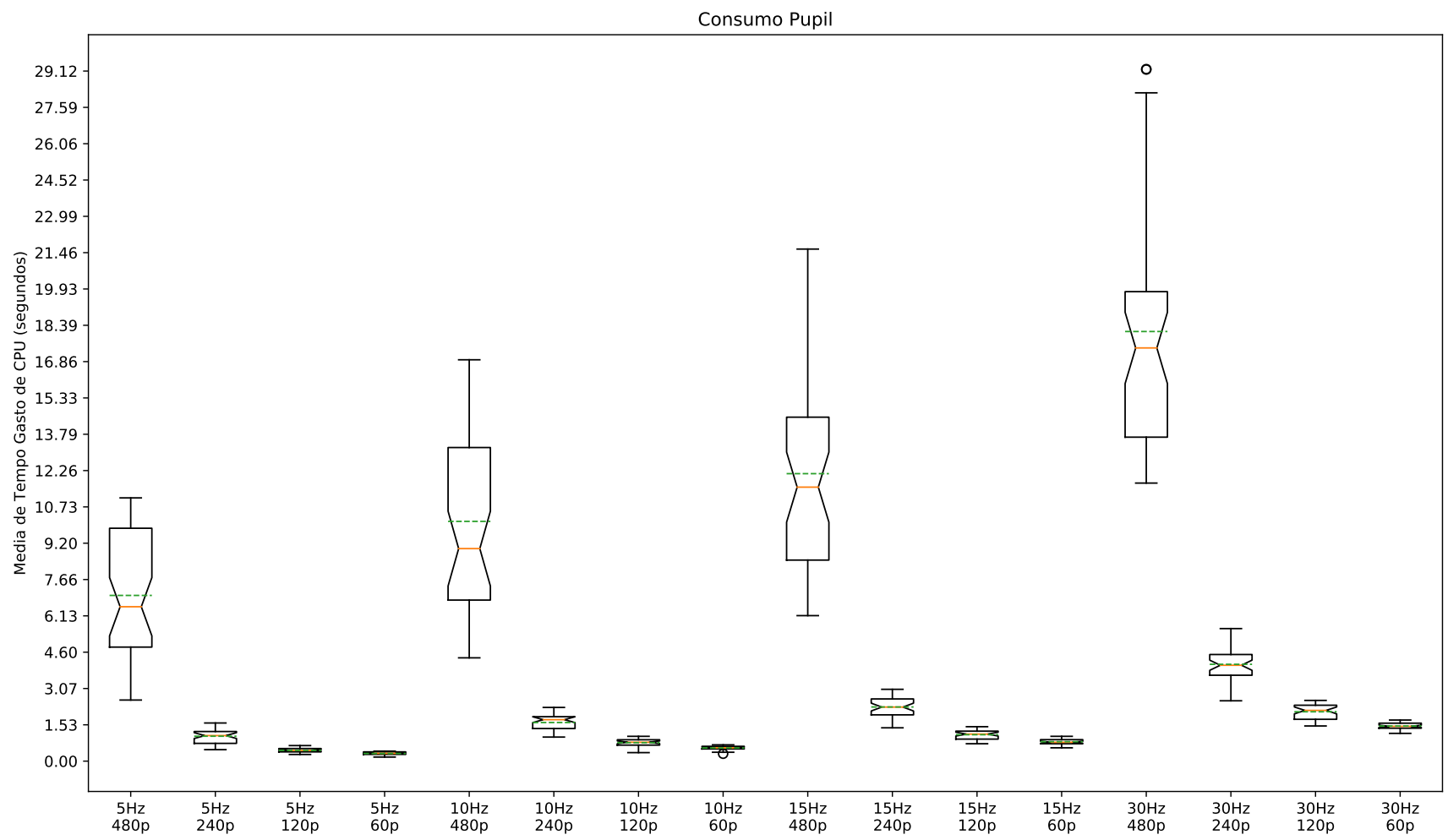

(a) Gráfico dos resultados da análise. A linha laranja é a mediana e seu intervalo de confiança, enquanto a linha pontilhada verde é a média dos dados.

\begin{tabular}{ccccc}
\hline Consumo Pupil & \multicolumn{4}{c}{ Resolucao } \\
\cline { 2 - 5 } FPS & $\mathbf{4 8 0 p}$ & $\mathbf{2 4 0 p}$ & $\mathbf{1 2 0 p}$ & $\mathbf{6 0 p}$ \\
\hline 5 & $6.99( \pm 2.64)$ & $1.05( \pm 0.29)$ & $0.46( \pm 0.10)$ & $0.32( \pm 0.07)$ \\
\hline 10 & $10.12( \pm 3.89)$ & $1.63( \pm 0.37)$ & $0.78( \pm 0.16)$ & $0.56( \pm 0.09)$ \\
\hline 15 & $12.13( \pm 4.47)$ & $2.29( \pm 0.41)$ & $1.11( \pm 0.21)$ & $0.82( \pm 0.12)$ \\
\hline 30 & $18.13( \pm 4.84)$ & $4.09( \pm 0.82)$ & $2.08( \pm 0.33)$ & $1.48( \pm 0.15)$ \\
\hline
\end{tabular}

(b) Tabela de valores da análise. Cada célula indica a média ( \pm o desvio padrão) dos resultados.

Figura 5.16: Análise de consumo médio da CPU (em segundos) em um caso de teste do Pupil para cada configuração de frequência $\times$ resolução. 


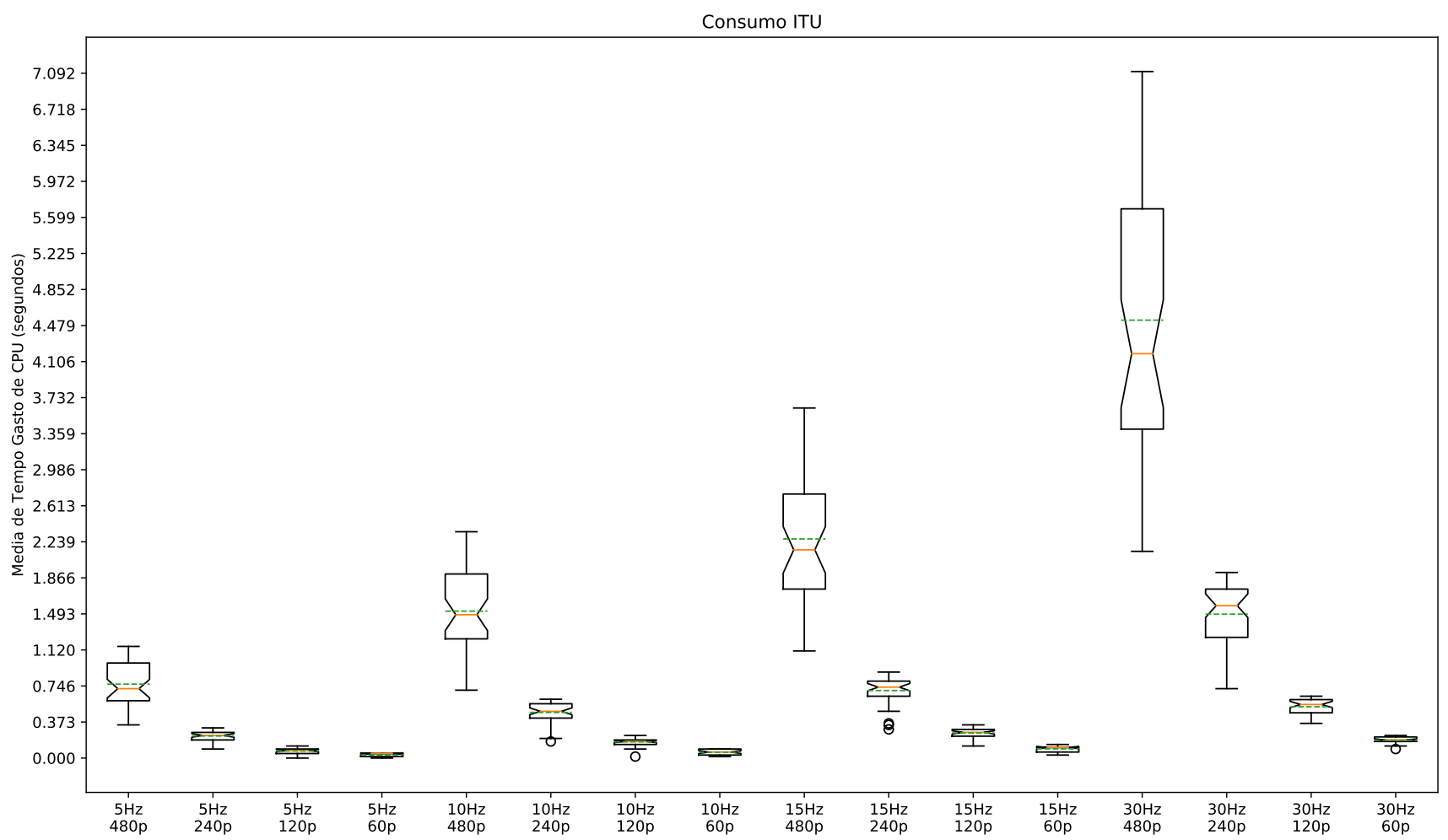

(a) Gráfico dos resultados da análise. A linha laranja é a mediana e seu intervalo de confiança, enquanto a linha pontilhada verde é a média dos dados.

\begin{tabular}{ccccc}
\hline \multirow{2}{*}{$\begin{array}{c}\text { Consumo ITU } \\
\text { FPS }\end{array}$} & $\mathbf{4 8 0 p}$ & $\mathbf{2 4 0 p}$ & $\mathbf{1 2 0 p}$ & $\mathbf{6 0 p}$ \\
\cline { 2 - 5 } & $0.77( \pm 0.23)$ & $0.23( \pm 0.05)$ & $0.07( \pm 0.03)$ & $0.03( \pm 0.02)$ \\
\hline 5 & $1.52( \pm 0.45)$ & $0.47( \pm 0.11)$ & $0.17( \pm 0.05)$ & $0.06( \pm 0.03)$ \\
\hline 10 & $2.27( \pm 0.72)$ & $0.70( \pm 0.15)$ & $0.26( \pm 0.06)$ & $0.10( \pm 0.03)$ \\
\hline 15 & $4.53( \pm 1.46)$ & $1.49( \pm 0.33)$ & $0.53( \pm 0.09)$ & $0.18( \pm 0.03)$ \\
\hline 30 &
\end{tabular}

(b) Tabela de valores da análise. Cada célula indica a média ( \pm o desvio padrão) dos resultados.

Figura 5.17: Análise de consumo médio da CPU (em segundos) em um caso de teste do ITU para cada configuração de frequência $\times$ resolução. 


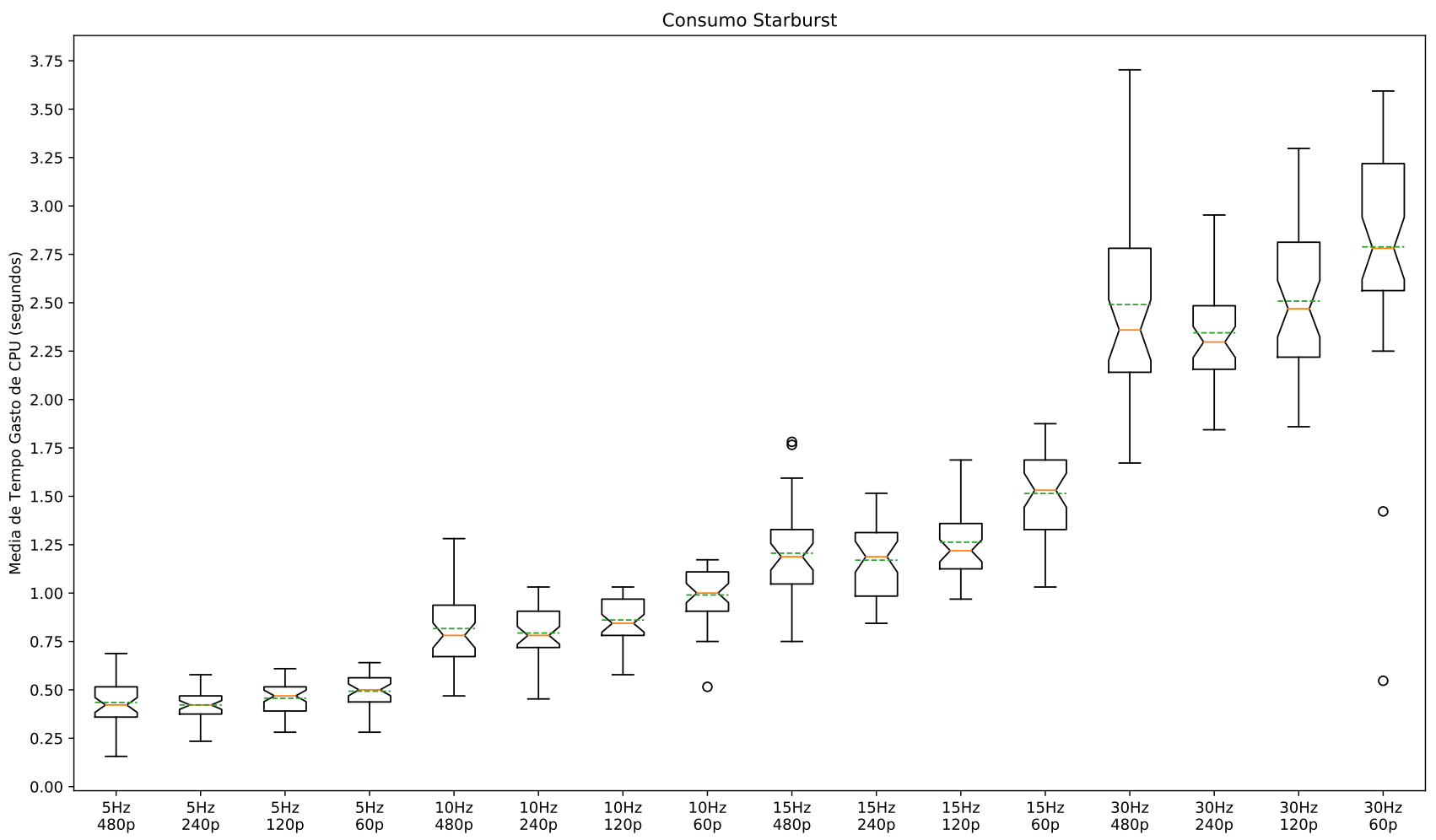

(a) Gráfico dos resultados da análise. A linha laranja é a mediana e seu intervalo de confiança, enquanto a linha pontilhada verde é a média dos dados.

\begin{tabular}{ccccc}
\hline \multirow{2}{*}{$\begin{array}{c}\text { Consumo Starburst } \\
\text { FPS }\end{array}$} & \multicolumn{4}{c}{ Resolucao } \\
\cline { 2 - 5 } & $\mathbf{4 8 0 p}$ & $\mathbf{2 4 0 p}$ & $\mathbf{1 2 0 p}$ & $\mathbf{6 0 p}$ \\
\hline 5 & $0.43( \pm 0.11)$ & $0.42( \pm 0.08)$ & $0.46( \pm 0.10)$ & $0.49( \pm 0.09)$ \\
\hline 10 & $0.82( \pm 0.19)$ & $0.79( \pm 0.13)$ & $0.86( \pm 0.12)$ & $0.99( \pm 0.15)$ \\
\hline 15 & $1.21( \pm 0.23)$ & $1.17( \pm 0.19)$ & $1.26( \pm 0.19)$ & $1.51( \pm 0.23)$ \\
\hline 30 & $2.49( \pm 0.48)$ & $2.34( \pm 0.28)$ & $2.51( \pm 0.39)$ & $2.79( \pm 0.56)$ \\
\hline
\end{tabular}

(b) Tabela de valores da análise. Cada célula indica a média ( \pm o desvio padrão) dos resultados.

Figura 5.18: Análise de consumo médio da CPU (em segundos) em um caso de teste do Starburst para cada configuração de frequência $\times$ resolução. 


\subsection{Análise de Variância}

Queremos investigar se a resolução da imagem da câmera pode afetar a acurácia dos algoritmos, mas o efeito da resolução pode ser diferente para cada frequência do vídeo. Conduzimos uma análise de variância (ANOVA) de 2 fatores com repetição para analisar os efeitos da resolução e da frequência sobre a acurácia dos algoritmos na posição de calibração.

Iniciaremos nossa análise considerando o erro de estimação dos algoritmos na posição de calibração (a posição central). Em seguida iremos analisar o efeito do movimento de cabeça sobre a acurácia considerando as outras posições de coleta do experimento. Apresentamos essas análises nas subseções a seguir para cada algoritmo, usando o mesmo valor de significância $\alpha=0.05$ para todos testes.

\subsubsection{Erro de estimação do Starburst:}

A análise do efeito individual da resolução do Starburst na posição central apresentou diferenças estatisticamente significativas de acurácia $\left(F(1.01,10.11)=84.65, p<.001, \eta^{2}=3.24\right.$ com correção de Greenhouse-Geisser $(\varepsilon=0.34))$. No entanto, a análise da frequência $(F(2.14,21.36)=0.75, p=0.49$, $\eta^{2}=0.01$ com correção de Greenhouse-Geisser $\left.(\varepsilon=0.71)\right)$ e da interação entre resolução e frequência $\left(F(2.42,24.17)=0.35, p=0.74, \eta^{2}=0.01\right.$ com correção de Greenhouse-Geisser $\left.(\varepsilon=0.27)\right)$ indicam que não há diferença significativa.

$\mathrm{Na}$ posição leste, ambos efeitos individuais de resolução $\left(F(1.07,10.66)=41.60, p<.001, \eta^{2}=0.73\right.$ com correção de Greenhouse-Geisser $(\varepsilon=0.36))$ e frequência $\left(F(2.29,22.95)=4.59, p=0.02, \eta^{2}=0.01\right.$ com correção de Huynh-Feldt $(\varepsilon=0.76))$ apresentam diferenças estatisticamente significativas enquanto a interação entre os fatores não $\left(F(2.56,25.57)=2.11, p=0.13, \eta^{2}=0.02\right.$ com correção de GreenhouseGeisser $(\varepsilon=0.28))$.

A posição oeste teve resultados semelhantes à central. O efeito individual da resolução apresenta diferenças significativas $\left(F(1.02,10.19)=68.18, p<.001, \eta^{2}=1.64\right.$ com correção de Greenhouse-Geisser $(\varepsilon=0.34))$. Enquanto o efeito individual da frequência $\left(F(1.99,19.94)=0.59, p=0.56, \eta^{2}=0.01\right.$ com correção de Greenhouse-Geisser $(\varepsilon=0.66))$ e da interação entre eles $(F(2.61,26.13)=0.84, p=0.47$, $\eta^{2}=0.02$ com correção de Greenhouse-Geisser $\left.(\varepsilon=0.29)\right)$ não mostram diferença.

A posição norte novamente se assemelha à posição central. A resolução mostra efeito significativo $\left(F(1.04,10.43)=22.99, p<.001, \eta^{2}=0.25\right.$ com correção de Greenhouse-Geisser $\left.(\varepsilon=0.35)\right)$, enquanto frequência $\left(F(1.99,19.92)=0.72, p=0.50, \eta^{2}=0.00\right.$ com correção de Greenhouse-Geisser $\left.(\varepsilon=0.66)\right) \mathrm{e}$ a interação entre fatores $\left(F(2.54,25.36)=0.72, p=0.53, \eta^{2}=0.00\right.$ com correção de Greenhouse-Geisser $(\varepsilon=0.28))$ não apresentam diferenças significativas.

$\mathrm{Na}$ posição sul, assim como nas anteriores, o efeito da resolução apresenta diferença significativa $\left(F(1.03,10.32)=43.01, p<.001, \eta^{2}=0.64\right.$ com correção de Greenhouse-Geisser $\left.(\varepsilon=0.34)\right)$. A frequência $\left(F(2.08,20.82)=2.94, p=0.07, \eta^{2}=0.01\right.$ com correção de Greenhouse-Geisser $\left.(\varepsilon=0.69)\right)$ e a interação entre fatores $\left(F(3.32,33.21)=1.22, p=0.32, \eta^{2}=0.01\right.$ com correção de Greenhouse-Geisser $\left.(\varepsilon=0.37)\right)$ não mostram diferenças significativas.

Esses resultados do efeito da resolução ser significativo em todas posições condiz com nossa observação anterior de que o Starburst na resolução 60p tem erros maiores que nas outras resoluções.

\subsubsection{Erro de estimação do ITU:}

O ITU na posição central apresentou diferença estatisticamente significativa no efeito individual da resolução $\left(F(1.22,12.19)=9.02, p=0.01, \eta^{2}=0.18\right.$ com correção de Greenhouse-Geisser $\left.(\varepsilon=0.41)\right)$. $\mathrm{O}$ efeito individual da frequência não mostrou efeito significativo $\left(F(2.28,22.83)=2.35, p=0.11, \eta^{2}=\right.$ 
0.01 com correção de Huynh-Feldt $(\varepsilon=0.76))$, assim como o efeito da interação entre os dois fatores $\left(F(3.88,38.80)=2.09, p=0.10, \eta^{2}=0.01\right.$ com correção de Greenhouse-Geisser $\left.(\varepsilon=0.43)\right)$.

Na posição leste, os resultados foram similares à posição central: a resolução apresentou efeito significativo $\left(F(1.41,14.14)=6.13, p=0.02, \eta^{2}=0.04\right.$ com correção de Greenhouse-Geisser $\left.(\varepsilon=0.47)\right)$, enquanto a frequência $\left(F(1.44,14.43)=0.75, p=0.45, \eta^{2}=0.00\right.$ com correção de Greenhouse-Geisser $(\varepsilon=0.48))$ e a interação $\left(F(1.60,16.01)=1.15, p=0.33, \eta^{2}=0.01\right.$ com correção de Greenhouse-Geisser $(\varepsilon=0.18))$ não mostraram diferenças estatisticamente significativas.

A posição oeste também teve resultados similares às posições leste e centro. Diferença significativa no efeito da resolução $\left(F(1.06,10.56)=7.43, p=0.02, \eta^{2}=0.12\right.$ com correção de Greenhouse-Geisser $(\varepsilon=0.35))$, e insignificantes nos efeitos da frequência $\left(F(1.26,12.55)=3.44, p=0.08, \eta^{2}=0.01\right.$ com correção de Greenhouse-Geisser $(\varepsilon=0.42))$ e interação $\left(F(1.62,16.18)=1.59, p=0.23, \eta^{2}=0.01\right.$ com correção de Greenhouse-Geisser $(\varepsilon=0.18)$ ).

$\mathrm{Na}$ posição norte, a análise tanto dos efeitos isolados (resolução: $F(1.45,14.50)=3.49, p=0.07$, $\eta^{2}=0.01$ com correção de Greenhouse-Geisser $(\varepsilon=0.48)$; frequência: $F(2.06,20.65)=0.44, p=0.65$, $\eta^{2}=0.00$ com correção de Greenhouse-Geisser $\left.(\varepsilon=0.69)\right)$ quanto da interação $(F(2.42,24.19)=1.60$, $p=0.22, \eta^{2}=0.00$ com correção de Greenhouse-Geisser $\left.(\varepsilon=0.27)\right)$ não apresentaram diferenças estatisticamente significantes.

Assim como a posição sul, na posição norte a análise tantn dos efeitos isolados quanto da interação não apresentou diferneças estatisticamente significantes:

- Resolução: $F(1.28,12.80)=4.27, p=0.05, \eta^{2}=0.03$ com correção de Greenhouse-Geisser $(\varepsilon=$ $0.43)$

- Frequência: $F(1.79,17.86)=0.31, p=0.71, \eta^{2}=0.00$ com correção de Greenhouse-Geisser $(\varepsilon=$ $0.60)$

- Interação: $F(2.63,26.30)=0.80, p=0.49, \eta^{2}=0.00$ com correção de Greenhouse-Geisser $(\varepsilon=0.29)$

\subsubsection{Erro de estimação do Pupil:}

Para o Pupil na posição central houve diferença estatisticamente significativa entre resoluções diferentes $\left(F(1.15,11.49)=31.87, p<.001, \eta^{2}=1.16\right.$ com correção de Greenhouse-Geisser $\left.(\varepsilon=0.38)\right)$, mas não há diferença significativa ao se variar a frequência $\left(F(1.88,18.81)=2.85, p=0.09, \eta^{2}=0.01\right.$ com correção de Greenhouse-Geisser $(\varepsilon=0.63))$ nem na interação entre os dois fatores $(F(2.78,27.77)=1.58$, $p=0.22, \eta^{2}=0.02$ com correção de Greenhouse-Geisser $\left.(\varepsilon=0.31)\right)$.

Na posição leste, variar individualmente a resolução $\left(F(1.10,11.04)=4.76, p=0.05, \eta^{2}=0.05\right.$ com correção de Greenhouse-Geisser $(\varepsilon=0.37))$ ou a frequência $\left(F(2.62,26.23)=1.07, p=0.37, \eta^{2}=0.00\right.$ com correção de Huynh-Feldt $(\varepsilon=0.87))$ não apresentaram diferenças significantes. A interação entre as duas variáveis também não mostrou diferença estatisticamente significante $(F(2.43,24.35)=0.65$, $p=0.56, \eta^{2}=0.00$ com correção de Greenhouse-Geisser $\left.(\varepsilon=0.27)\right)$.

A posição oeste apresentou diferença significante do efeito da resolução no erro da estimação $\left(F(1.10,10.95)=14.90, p<.001, \eta^{2}=0.29\right.$ com correção de Greenhouse-Geisser $\left.(\varepsilon=0.37)\right)$. Todavia variar a frequência $\left(F(2.44,24.38)=3.01, p=0.06, \eta^{2}=0.00\right.$ com correção de Huynh-Feldt $\left.(\varepsilon=0.81)\right)$ e a interação entre resolução e frequência $\left(F(3.90,39.00)=2.37, p=0.07, \eta^{2}=0.00\right.$ com correção de Greenhouse-Geisser $(\varepsilon=0.43))$ não apresentaram diferenças significantes.

A posição norte teve resultados semelhantes à posição oeste, com o efeito da resolução apresentando diferença significante no erro $\left(F(1.52,15.20)=7.48, p=0.01, \eta^{2}=0.10\right.$ com correção de GreenhouseGeisser $(\varepsilon=0.51))$, e a frequência não tendo diferença $\left(F(1.09,10.86)=0.95, p=0.36, \eta^{2}=0.00\right.$ com 
correção de Greenhouse-Geisser $(\varepsilon=0.36))$ assim como a interação $(F(1.48,14.76)=0.89, p=0.40$, $\eta^{2}=0.00$ com correção de Greenhouse-Geisser $\left.(\varepsilon=0.16)\right)$.

A posição sul também apresentou diferenças significativas na acurácia ao variar a resolução $\left(F(1.92,19.15)=6.40, p=0.01, \eta^{2}=0.01\right.$ com correção de Greenhouse-Geisser $\left.(\varepsilon=0.64)\right)$, e não mostrou diferenças ao variar a frequência $\left(F(1.93,19.28)=2.56, p=0.10, \eta^{2}=0.00\right.$ com correção de Greenhouse-Geisser $(\varepsilon=0.64))$ ou ambas variáveis em conjunto $(F(1.54,15.41)=1.64, p=0.23$, $\eta^{2}=0.00$ com correção de Greenhouse-Geisser $(\varepsilon=0.17)$ ).

\subsubsection{Discussão Geral}

No geral o ANOVA mostra que em muitos casos há um efeito estatisticamente significativo da resolução no erro de estimação dos algoritmos, enquanto a frequência ou a interação entre os dois fatores não faz diferença significante na acurácia. Há poucas casos que fogem desse padrão, e neles, não podemos determinar um ponto em comum (como um algoritmo ou posição) então atribuímos isso a variações pontuais dos dados nesses casos.

Todavia, enquanto casos como o Pupil na posição central tiveram a hipótese nula do efeito da resolução rejeitada, e portanto não podemos afirmar que as médias dos erros para as resoluções diferentes desse caso são iguais estatisticamente, podemos discutir sobre sua significância prática. Nesse mesmo caso do Pupil na posição central, a média dos erros para as resoluções 480, 240, 120 e 60p são respectivamente $0.33,0.31,0.31$ e 0.54 graus de erro. 


\section{Capítulo 6}

\section{Conclusões}

Neste trabalho buscamos entender a relação entre desempenho, consumo de energia e parâmetros da câmera usada pelo rastreador do olhar. A motivação por trás disso foi mostrar que é possível alterar os parâmetros da câmera para reduzir o consumo de energia enquanto se mantém o mesmo desempenho do rastreador. Por meio de um experimento com usuários, exploramos essa relação em três algoritmos de rastreamento que usam iluminação ativa com luzes PIV: Starburst, ITU e Pupil.

Nossas análises mostraram que no geral é possível diminuir resolução e frequência e manter o desempenho dos algoritmos. Mostramos que na prática o desempenho se mantém igual (dentro de uma pequena tolerância) variando a resolução. Em alguns casos, uma redução de até $95 \%$ de consumo de energia foi atingida reduzindo a resolução, enquanto o desempenho se manteve similar ( $.2^{o}$ de diferença).

Concluímos que a movimentação do usuário em relação à posição na qual ele calibrou o rastreador afeta de forma mais significativa o desempenho do que alterando os parâmetros da câmera. Além disso, determinamos que a configuração correta do rastreador para funcionar adequadamente na resolução e frequência desejada é imperativo.

Note-se também que nossos resultados são independentes em relação ao contexto de uso de um rastreador (como uma aplicação usa um rastreador) - medimos o erro da estimação do olhar independente do que está sendo mostrado ao usuário ou como a aplicação usa a posição do olhar. Logo os resultados alcançados aqui, sobre consumo e desempenho em resoluções e frequências diferentes, devem ser aplicáveis em quaisquer atividade com um rastreador que o usuário faça, tomando cuidado, é claro, com possíveis requerimentos de frequência da aplicação.

Para a realização dessas análises foi criado uma plataforma genérica para experimentos com rastreadores do olhar que poderá ser aproveitada no futuro para outras pesquisas e testes.

\subsection{Sugestões para Pesquisas Futuras}

A primeira e mais óbvia sugestão é que pesquisas futuras levem em consideração os resultados alcançados aqui. Que determinem como parâmetros dos seus algoritmos, movimentos do usuário, resolução e taxa de quadros usadas afetam precisão, acurácia e consumo de energia de seus algoritmos de rastreamento e dispositivos vestíveis. Que exerçam cuidado no desenvolvimento deles para tentar maximizar precisão e acurácia e minimizar consumo de energia em vez de cegamente aumentar resolução e frequência na vaga esperança que isso melhore a qualidade de seus resultados enquanto o consumo de energia é ignorado.

Além desse ponto, análises mais detalhadas do movimento do usuário e como isso afeta a precisão e acurácia dos rastreadores, assim como possíveis meios de mitigar erro de estimação com o movimento, ou formas de calibração e estimação do olhar que não sejam significativamente afetadas pelo movimento 
seriam benéficas a trabalhos futuros envolvendo rastreadores vestíveis, dado que pela natureza dos mesmos o movimento do usuário é praticamente garantido.

Uma continuação direta deste trabalho seria repetir a análise feita aqui para outros algoritmos, particularmente algoritmos rastreadores e não detectores como os que usamos, para comprovar nossa hipótese para todos tipos de rastreadores de olhar baseados em vídeo. Outro ponto importante de analisar algoritmos rastreadores seria determinar o comportamento em casos como rastreamento em alta frequência, e como isso se compara com algoritmos detectores. Caso seja mostrado que algoritmos rastreadores conseguem manter o mesmo consumo de energia e desempenho de algoritmos detectores, porém em frequência maior, seria um incentivo interessante para futuras pesquisas em algoritmos rastreadores.

Desenvolver uma ferramenta que, baseado em algumas coletas, determina os parâmetros "ideais" dos algoritmos de rastreamento do olhar seria um trabalho interessante que poderia ser uma extensão deste. Usando de alguma heurística para determinar quais parâmetros de um algoritmo, possivelmente dentro de um intervalo possível de valores, minimiza uma função objetivo que poderia, por exemplo, ser o erro da estimação ou consumo de energia. Uma ferramenta como esta ajudaria pesquisadores a determinar os parâmetros dos algoritmos a ser usado nos seus experimentos (algo que usualmente não é feito de forma ideal ou se é feita, toma muito tempo do pesquisador) ou até usuários a determinar a configuração de seu rastreador.

Outra sugestão é uma análise como a nossa, mas considerando o gasto real de energia da câmera e da CPU para o processamento, em vez da aproximação do consumo de tempo da CPU como usamos. Tal análise mostraria com mais detalhes a economia de energia real ao alterar resolução e frequência dos rastreadores. Tal experimento também poderia mostrar como tais mudanças afetam na prática o tempo de bateria de um dispositivo móvel ou vestível. 


\section{Referências Bibliográficas}

[BG10] Andreas Bulling e Hans Gellersen. Toward mobile eye-based human-computer interaction. IEEE Pervasive Computing, 9:8-12, 2010. 2

[HJ10] Dan Witzner Hansen e Qiang Ji. In the eye of the beholder: a survey of models for eyes and gaze. IEEE transactions on pattern analysis and machine intelligence, 32(3):478-500, 2010. $2,5,6$

$\left[\mathrm{HNA}^{+}{ }^{11}\right]$ Kenneth Holmqvist, Marcus Nyström, Richard Andersson, Richard Dewhurst, Halszka Jarodzka e Joost de Weijer. Eye tracking: A comprehensive guide to methods and measures. Oxford University Press, 2011. 2

$\left[\mathrm{KBW}^{+} 12\right]$ Simon J Knopp, Philip J Bones, Stephen J Weddell, Carrie R H Innes e Richard D Jones. A miniature head-mounted camera for measuring eye closure. Proceedings of the 27th Conference on Image and Vision Computing New Zealand - IVCNZ '12, páginas 313-318, 2012. $\mathrm{v}, 9$

[KPB14] Moritz Kassner, William Patera e Andreas Bulling. Pupil. Proceedings of the 2014 ACM International Joint Conference on Pervasive and Ubiquitous Computing Adjunct Publication - UbiComp '14 Adjunct, páginas 1151-1160, 2014. v, 22, 23, 34

[LP06] Dongheng Li e Derrick Parkhurst. Open-source software for real-time visible-spectrum eye tracking. Proceedings of the COGAIN Conference, (c):1-3, 2006. 20

$\left[\mathrm{MHM}^{+}{ }^{14}\right]$ Addison Mayberry, Pan Hu, Benjamin Marlin, Christopher Salthouse e Deepak Ganesan. iShadow. MobiSys '14, páginas 82-94, 2014. v, 10, 11

[MM05] Carlos H. Morimoto e Marcio R.M. Mimica. Eye gaze tracking techniques for interactive applications. Computer Vision and Image Understanding, 98(1):4-24, apr 2005. 1, 2, 6, 16

$\left[\mathrm{MTH}^{+} 15\right]$ Addison Mayberry, Yamin Tun, Pan Hu, Duncan Smith-freedman, Deepak Ganesan, Benjamin M Marlin e Christopher Salthouse. CIDER : Enabling Robustness-Power Tradeoffs on a Computational Eyeglass Categories and Subject Descriptors. Proceedings of the 21st Annual International Conference on Mobile Computing and Networking, páginas 400-412, 2015. v, 11,12

$\left[\mathrm{NBM}^{+} 15\right]$ Jetmir Nehani, Davide Brunelli, Michele Magno, Lukas Sigrist e Luca Benini. An Energy Neutral Wearable Camera with EPD Display. Proceedings of the 2015 workshop on Wearable Systems and Applications - WearSys '15, páginas 1-6, 2015. 10

[NKB11] Basilio Noris, Jean Baptiste Keller e Aude Billard. A wearable gaze tracking system for children in unconstrained environments. Computer Vision and Image Understanding, 115(4):476486, 2011. v, 8,9

[PDTK13] Bernardo Rodrigues Pires, Michael Devyver, Akihiro Tsukada e Takeo Kanade. Unwrapping the eye for visible-spectrum gaze tracking on wearable devices. Proceedings of IEEE Workshop on Applications of Computer Vision, páginas 369-376, 2013. v, 7, 8

[RWDB08] Wayne J. Ryan, Damon L. Woodard, Andrew T. Duchowski e Stan T. Birchneld. Adapting starburst for elliptical iris segmentation. BTAS 2008 - IEEE 2nd International Conference on Biometrics: Theory, Applications and Systems, 00, 2008. 20 
[SBD12] Lech Swirski, Andreas Bulling e Neil Dodgson. Robust real-time pupil tracking in highly off-axis images. Eye Tracking Research \& Applications 2012, páginas 1-4, 2012. v, 5, 6, 7, 22,23

[SSM $\left.{ }^{+} 10\right]$ Javier San Agustin, Henrik Skovsgaard, Emilie Mollenbach, Maria Barret, Martin Tall, Dan Witzner Hansen e John Paulin Hansen. Evaluation of a low-cost open-source gaze tracker. Em Proceedings of the 2010 Symposium on Eye-Tracking Research 8 Applications ETRA '10, página 77, New York, New York, USA, mar 2010. ACM Press. 21, 22

[STCZ13] Fengyi Song, Xiaoyang Tan, Songcan Chen e Zhi Hua Zhou. A literature survey on robust and efficient eye localization in real-life scenarios. Pattern Recognition, 46(12):3157-3173, 2013. 6

[TK12] Akihiro Tsukada e Takeo Kanade. Automatic acquisition of a 3D eye model for a wearable first-person vision device. ... the Symposium on Eye Tracking Research and . ., 1(212):1013, 2012. 7

[TSDK11] A Tsukada, M Shino, Michael Devyver e Takeo Kanade. Illumination-free gaze estimation method for first-person vision wearable device. IEEE International Conference on Computer Vision Workshops, 2011. 7

[WPL05] D. Winfield, D.J. Parkhurst e D. Li. Starburst: A hybrid algorithm for video-based eye tracking combining feature-based and model-based approaches. Em 2005 IEEE Computer Society Conference on Computer Vision and Pattern Recognition (CVPR'05) - Workshops, volume 3, páginas 79-79. IEEE, 2005. v, 16, 18 